\title{
Formulation and Evaluation of a Novel Irrigant for the Disinfection of Root Canals Using a Candida albicans Biofilm Model
}

Dustin S. Reynolds

West Virginia University

Follow this and additional works at: https://researchrepository.wvu.edu/etd

\section{Recommended Citation}

Reynolds, Dustin S., "Formulation and Evaluation of a Novel Irrigant for the Disinfection of Root Canals Using a Candida albicans Biofilm Model" (2013). Graduate Theses, Dissertations, and Problem Reports. 3622.

https://researchrepository.wvu.edu/etd/3622

This Thesis is protected by copyright and/or related rights. It has been brought to you by the The Research Repository @ WVU with permission from the rights-holder(s). You are free to use this Thesis in any way that is permitted by the copyright and related rights legislation that applies to your use. For other uses you must obtain permission from the rights-holder(s) directly, unless additional rights are indicated by a Creative Commons license in the record and/ or on the work itself. This Thesis has been accepted for inclusion in WVU Graduate Theses, Dissertations, and Problem Reports collection by an authorized administrator of The Research Repository @ WVU. For more information, please contact researchrepository@mail.wvu.edu. 


\title{
Formulation and Evaluation of a Novel Irrigant for the Disinfection of Root Canals Using a Candida albicans Biofilm Model
}

\author{
Dustin S. Reynolds, DDS \\ Thesis submitted to the \\ School of Dentistry \\ at West Virginia University \\ in partial fulfillment of the requirements \\ for the degree of \\ Master of Science \\ In \\ Endodontics \\ John G. Thomas, $\mathrm{PhD}$, Chair \\ Anthony T. Borgia, DDS, MHA \\ Michael Bagby, DDS, PhD \\ Department of Endodontics \\ Morgantown, West Virginia \\ 2013
}

Keywords:

Irrigation, Penetration, Biofilm, Candida albicans, Clindamycin, Nystatin, Dimethyl sulfoxide 


\title{
$\underline{\text { Abstract }}$ \\ Formulation and Evaluation of a Novel Irrigant for the Disinfection of Root Canals Using a Candida albicans Biofilm Model
}

\author{
Dustin S. Reynolds, DDS
}

An important goal of root canal therapy is elimination of microorganisms which are usually organized into a biofilm phenotype. Irrigants play an indispensable role in areas inaccessible to mechanical instrumentation. In this study, a novel endodontic irrigant was formulated composed of a penetrating solvent, 70\% Dimethyl sulfoxide (DMSO), with a 1:1 molar ratio of an antibiotic (Clindamycin $\mathrm{HCl}$ ) and antifungal agent (Nystatin). Nuclear Magnetic Resonance Spectroscopy (NMR) stability tests were conducted to prove the mixture was chemically stable. This study compared different concentrations of the novel irrigant to $6 \%$ sodium hypochlorite $(\mathrm{NaOCl})$ using a $C$. albicans biofilm model. Furthermore, it is proposed that the novel irrigant has the ability to penetrate into dentin tubules and therefore be able to achieve better root canal disinfection.

Solutions of the irrigant were prepared and used at $100 \%, 50 \%$, and $25 \%$ concentration then compared to $6 \% \mathrm{NaOCl}$ in the following tests: $\mathrm{ZOI}, \mathrm{CFU}$, absorbance, coverage area, and penetration. Standard zones of inhibition (ZOI) trials were conducted to verify that the novel irrigant was, in fact, effective against microorganisms. C. albicans, a common oral fungi, and possible co-aggregate in biofilm formation, was then grown on hydroxyapatite-coated pegs (Calgary Biofilm Model) for 48 hours at $37^{\circ} \mathrm{C}$ and immersed in treatment solutions for one minute. Biofilm was removed from the pegs via sonication and colony forming units per $\mathrm{ml}$ were assayed. On additional pegs, biofilm was stained with crystal violet, washed, placed in glacial acetic acid and read at $562 \mathrm{~nm}$; the absorbance values reflected the amount of remaining biofilm. On other pegs the remaining biofilm was stained and analyzed with computer software to determine the coverage area. Lastly, ten extracted human teeth were prepared, sterilized, and irrigated using $6 \% \mathrm{NaOCl}$, Ethylenediaminetetraacetic acid (EDTA), and the novel irrigant at $100 \%, 50 \%$, and $25 \%$ concentration. The teeth were then stained with Rhodamine B and viewed at $10 \mathrm{X}$ with a laser confocal microscope to evaluate penetration.

The ZOI studies showed that the novel irrigant possessed effective anti-microbial properties. The CFU assay positive control showed $2.9 \times 10^{6} \mathrm{CFUs}$, the irrigant concentrations from greatest to least had the following CFUs respectively: $8.7 \times 10^{3}, 2.7 \times 10^{4}$, and $6.7 \times 10^{3}$. No CFUs were observed with $\mathrm{NaOCl}$; corresponding absorbance data revealed the following: 0.786 , $0.830,0.818$ compared to a control value of 0.765 . $\mathrm{NaOCl}$ had an absorbance of 0.843 . These numbers suggest similar activity against a recalcitrant $C$. albicans biofilm. The biofilm coverage assay showed that the novel irrigant was more effective than $6 \% \mathrm{NaOCl}$. By utilizing the laser confocal microscope the ability of the novel irrigant to penetrate into dentin tubules was visualized.

Preliminary results using a $C$. albicans biofilm model show that all concentrations of the novel irrigant are anti-biofilm and demonstrate similar efficacy to that of $6 \% \mathrm{NaOCl}$. Furthermore, the novel irrigant is able to penetrate further into dentinal tubules than that of $6 \%$ $\mathrm{NaOCl}$ and EDTA or some combination of the two. 


\section{Dedication}

To Cary: I thank you and your family for accepting me as one of your own. I could not have made this journey without you. Thank you for leaving your job, moving six hours from home, and putting up with me so that I could pursue my dreams. You are a beautiful person, an amazing woman and exceptional mother.

For Laurel: I thank God every day for bringing you into my life. You are the most beautiful, intelligent, amazing child a father could ever ask for. I pray God will be your Sheppard through life's ups and downs; that you will always look to Him for answers and guidance. You make Mommy and Daddy so very proud. No matter what, you will always be Daddy's little snuggle bug.

To my family: Dad thank you for always providing me with every possible opportunity and for teaching me to be a friend, having never met a stranger, and always looking to help others in need. Mom, thank you for supporting me in all that I have set out to accomplish, you are my rock. Thanks for always listening and understanding, no matter what the circumstances. P.G., I hope that I have been a positive example for you. Thank you for being an amazing brother, listener, friend, and uncle. I pray that life blesses you to the fullest. Always strive for your best. I love you all and appreciate everything that you have done for me. 


\section{Acknowledgements}

Dr. Anthony "Tom" Borgia: Thank you for the opportunity to pursue my dream of becoming an Endodontist. Your leadership, guidance, and friendship over the past years are irreplaceable. Without your knowledge and support this project would not have been possible. Thank you for being the mentor that you are and pushing me to become a better scientist/clinician and not just another "tooth carpenter". I look forward to many years of continued friendship.

Dr. C. Russell Jackson: Thank you for taking a chance on a poor country boy from Virginia. You recognized qualities in me that many overlook. Thank you for the opportunity to join the esteemed ranks of our profession. Thank you most for your afternoons of talking trains, planes, and automobiles while listening to SRV. Enjoy retirement, you deserve it!

Dr. John G. Thomas: "Hello, Hello" Thank you for mentoring me on this project. Without your expertise, laboratory space, and staff this project would not have been possible. Thank you for always making time for me, even if we weren't talking science.

Dr. Michael Bagby: Thank you for guiding me on this project and keeping me on track not only in residency but through dental school. You really do wear every hat here at the SOD. Thank you for your service and dedication.

Dr. Amanda Ammer: Thank you for your willingness to help me with all of my images captured in the WVU Microscope Imaging Facility.

Drs. Peter Gannett and Paula Stout: Thank you for your expertise in the Basic Pharmaceutical Sciences and for your help in completing the NMR stability study.

Dr. Gerry Hobbs: Thank you for your help with my statistical analysis.

Jeremy Hardinger: Thank you for your assistance with the SEM images.

Sarah LaRue and Laura Bradel: Thank you for your assistance in the laboratory with the Calgary Biofilm Device and accompanying assays.

Dr. Gabriel Holley: I could not have imagined completing this program with anyone other than you. We are a package deal, Bert and Ernie. It will take more than a few fly over states to keep us from being able to chill on a dirt road in the very near future.

Drs. Nathaniel Nicholson and Khaled Seifelnasr: Though the two of you will never share a relationship (or King bed) like Gabe and I do, you are both amazing people and it has been a pleasure to share the last year of residency with you. I wish you many successes in your future. Mahalo!

Drs. Tuyen Pham and Patrick Petley: Thank you for a diverse first year of residency. Thank you for allowing Gabe and I to pick your brains and for the late night sporting events. 
Renee Cooper: Thank you for your hard work as part of the Endodontics team. Thank you most of all for your friendship over the years and your assistance while moonlighting. Thanks for always listening. I wish you all the best for your future; I'll be there with bells on.

Tammy Ord: Thank you for making sure all of our charges were always entered and that we were back from lunch promptly at 1:00pm. In all seriousness, thank you for having a sense of humor and for all the laughs over the last two years.

Gina White: They really broke the mold when they made you, in fact, they lost it. Thank you for putting up with Gabe and me over the last two years. We will always cherish the "Gina Stories" at many AAE Annual Sessions to come. Continue being the hardest working woman at the SOD.

Charalene Haynes: I enjoyed getting to know you during the first year of residency. Thank you for your hard work and always keeping me on my toes. I wish you the best in your future.

Donna Butler and Ashley Bennett: Though our time together has been short, it has been memorable. You are both amazing additions to our Endodontic family. I wish you all the best in your futures.

Charlie Groff: Thank you for all of the technical computer support you have given me, not only on this project, but on a daily basis here at the dental school. More importantly, thanks for listening and being a friend.

Thank you to all the faculty, staff, students, and residents who have made a lasting impression on me and for making my time at West Virginia University so special. I will be forever a Mountaineer! 


\section{TABLE OF CONTENTS}

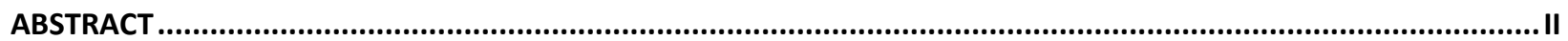

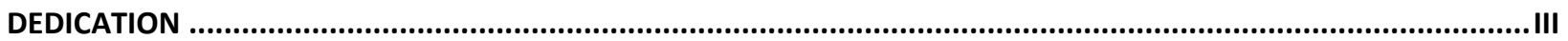

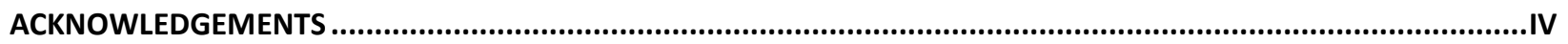

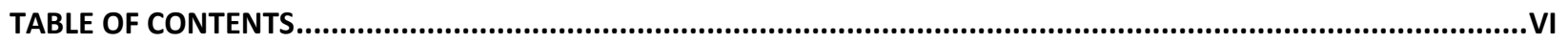

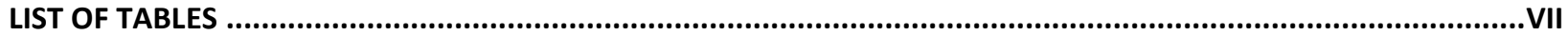

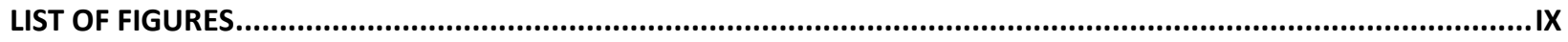

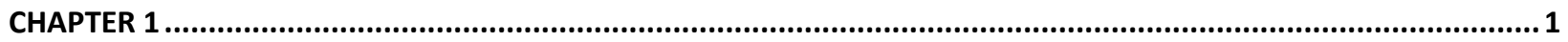

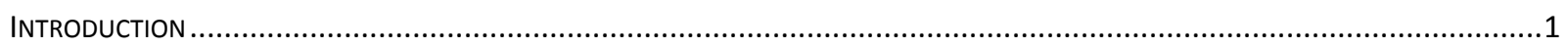

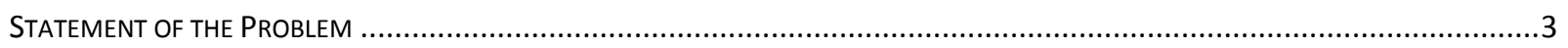

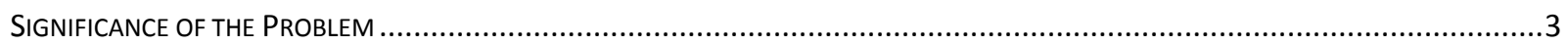

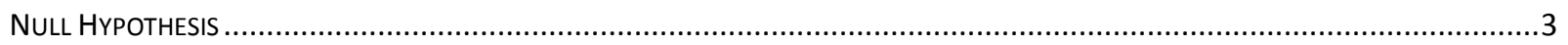

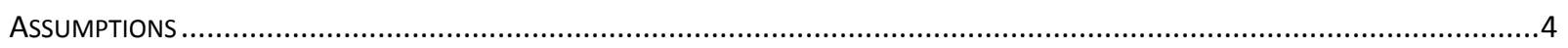

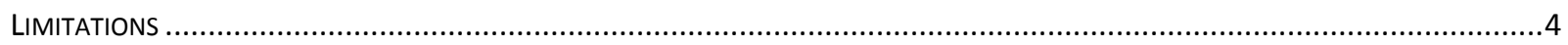

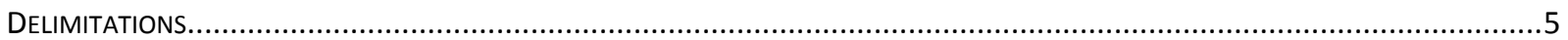

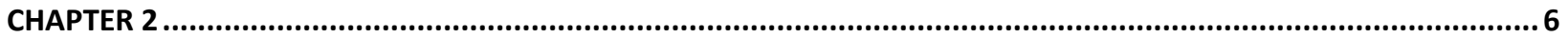

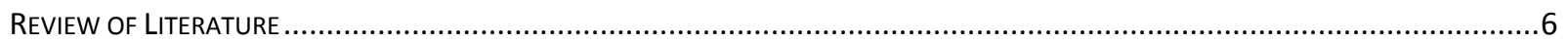

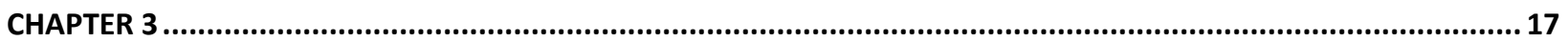

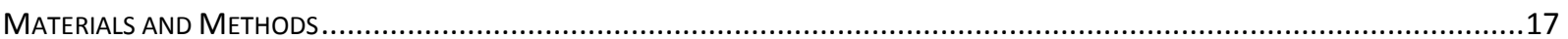

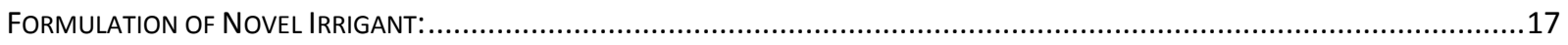

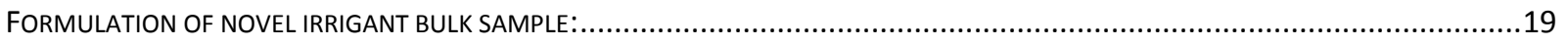

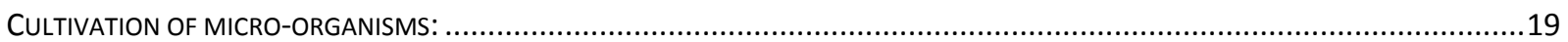

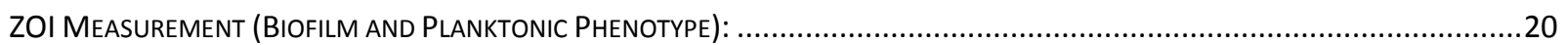

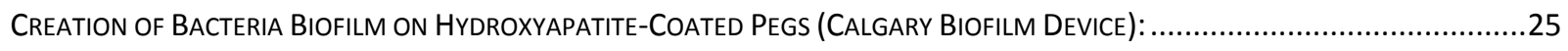

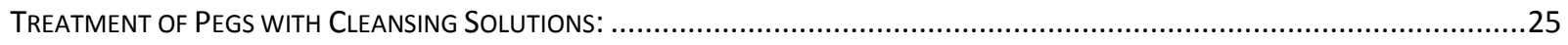

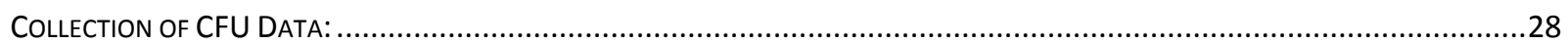

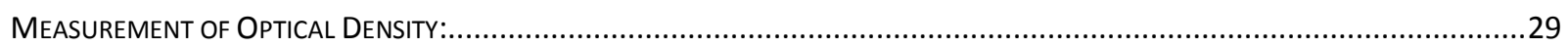

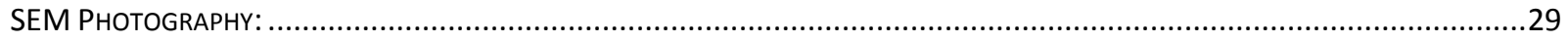

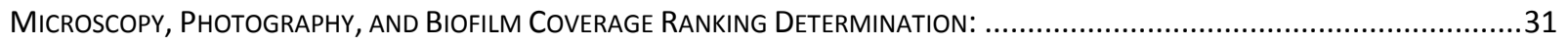

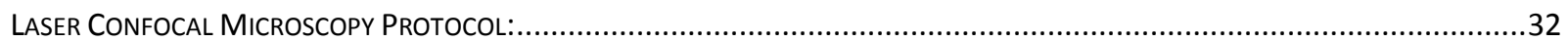

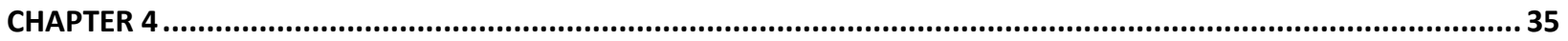

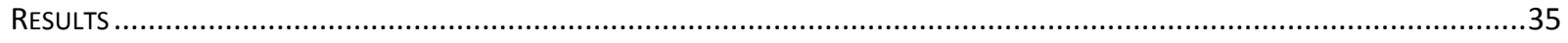

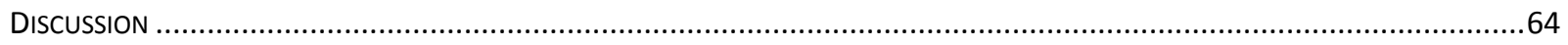

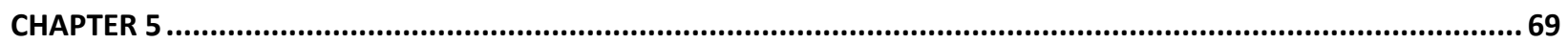

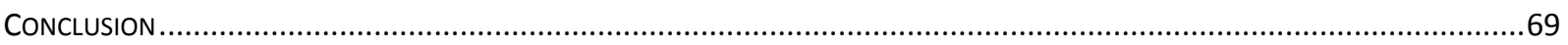

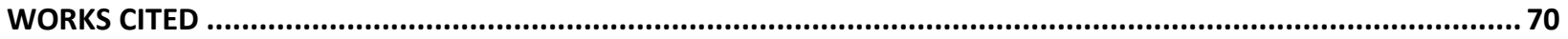

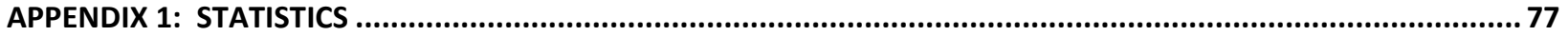




\section{List of Tables}

Table 1: Zones of Inhibition Study, C. albicans, 24-hr incubation period ................................. 39

Table 2: ZOI results of C. albicans trials (AVG and STD DEV) ............................................ 39

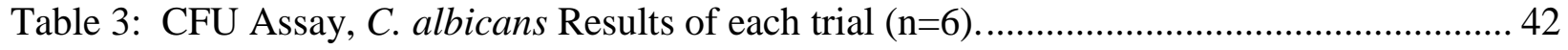

Table 4: Average of CFU Assay Results, C. albicans ......................................................... 43

Table 5: Results of Absorbance Assay, C. albicans .............................................................. 45

Table 6: One-way Analysis, (Summary of Fit) ZOI Study, C. albicans (Planktonic)................ 77

Table 7: ANOVA, ZOI Study, C. albicans (Planktonic)....................................................... 77

Table 8: Means of One-way ANOVA, ZOI Study, C. albicans (Planktonic) ............................ 77

Table 9: Means Comparisons using Tukey-Kramer HSD, ZOI, C. albicans (Planktonic) ......... 77

Table 10: LSD Threshold Matrix, ZOI Study, C. albicans (Planktonic).................................... 77

Table 11: Connecting Letters Report, ZOI C. albicans (Planktonic) ......................................... 78

Table 12: Ordered Differences Report, ZOI C. albicans (Planktonic) ...................................... 78

Table 13: One-way Analysis (Summary of Fit) ZOI, C. albicans (Biofilm)............................ 78

Table 14: Analysis of Variance, ZOI, C. albicans (Biofilm)................................................ 78

Table 15: Means of One-way ANOVA, ZOI, C. albicans (Biofilm) ...................................... 78

Table 16: Means Comparisons using Tukey-Kramer HSD, ZOI, C. albicans (Biofilm) ............ 79

Table 17: LSD Threshold Matrix, ZOI, C. albicans (Biofilm) ............................................... 79

Table 18: Connecting Letters Report, ZOI, C. albicans (Biofilm)............................................ 79

Table 19: Ordered Differences Report, ZOI, C. albicans (Biofilm)....................................... 79

Table 20: One-way Analysis of CFU (Summary of Fit) C. albicans, Dilution $=10^{-6} \ldots \ldots \ldots \ldots \ldots . . . . . . . .79$

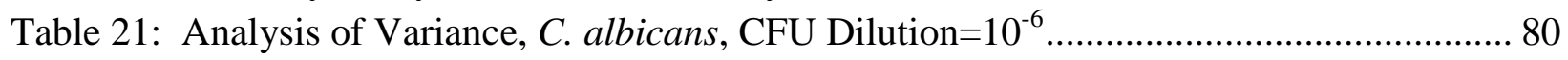

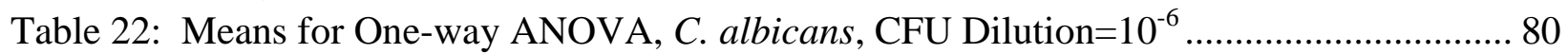

Table 23: Wilcoxon / Kruskal-Wallis Tests (Rank Sums), C. albicans, CFU Dilution $=10^{-6} \ldots . . .80$

Table 24: 1-way Test, ChiSquare Approximation, C. albicans, CFU Dilution $=10^{-6} \ldots \ldots \ldots \ldots \ldots . . . . . .80$

Table 25: Means Comparisons using Tukey-Kramer HSD, C. albicans, CFU Dilution=10 ${ }^{-6}$.... 80

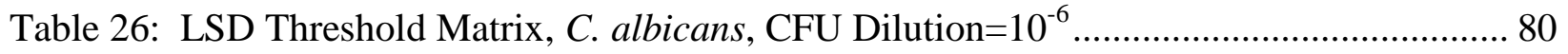

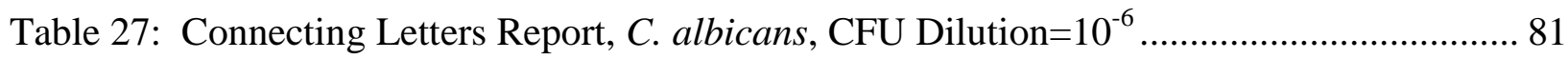

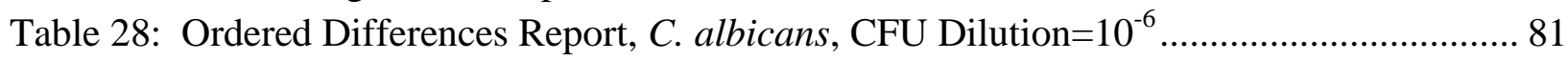

Table 29: One-way Analysis of CFU (Summary of Fit) C. albicans, Dilution $=10^{-4} \ldots \ldots \ldots \ldots \ldots . . . . .81$

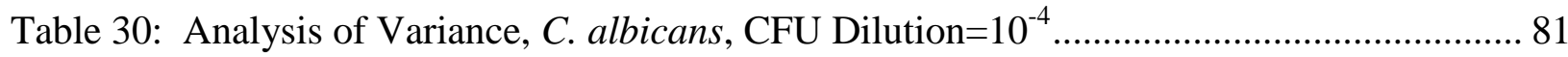

Table 31: Means for One-way ANOVA, C. albicans, CFU Dilution $=10^{-4} \ldots \ldots \ldots \ldots \ldots \ldots \ldots \ldots \ldots . . . . . . . . . . . . . . .81$

Table 32: Wilcoxon / Kruskal-Wallis Tests (Rank Sums), C. albicans, CFU Dilution $=10^{-4}$...... 82

Table 33: 1-way Test, ChiSquare Approximation, C. albicans, CFU Dilution $=10^{-4}$................. 82

Table 34: Connecting Letters Report, C. albicans, CFU Dilution $=10^{-4}$................................... 82

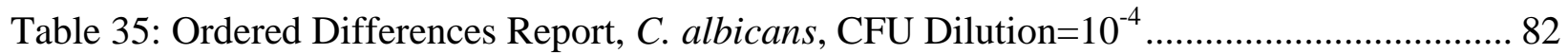

Table 36: One-way Analysis of CFU (Summary of Fit) C. albicans, Dilution $=10^{-2} \ldots \ldots \ldots \ldots \ldots . . . . . . . . .82$

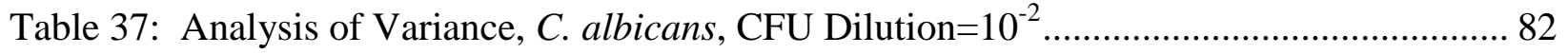

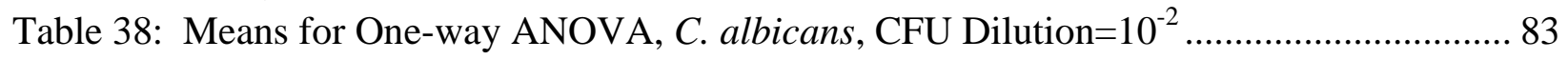

Table 39: Wilcoxon / Kruskal-Wallis Tests (Rank Sums), C. albicans, CFU Dilution=10 ${ }^{-2} \ldots . . .83$ 
Table 40: 1 -way Test, ChiSquare Approximation, C. albicans, CFU Dilution $=10^{-2}$. 83

Table 41: Means Comparisons using Tukey-Kramer HSD, C. albicans, CFU Dilution $=10^{-2} \ldots . .83$

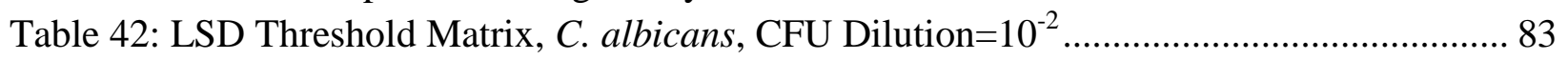

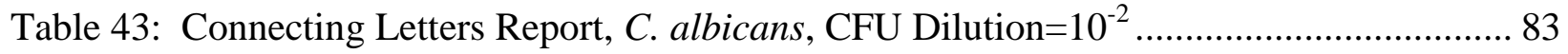

Table 44: Ordered Differences Report, $C$. albicans, CFU Dilution $=10^{-2}$.................................... 84

Table 45: One-way Analysis of Variance of Area of Biofilm Coverage on Pegs of Calgary

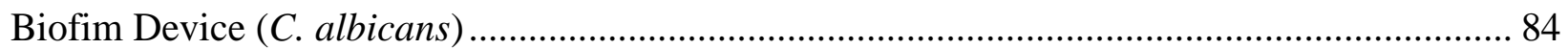

Table 46: Means for One-way ANOVA, Area of Biofilm Coverage ........................................... 84

Table 47: Means Comparisons using Tukey-Kramer HSD, Area of Biofilm Coverage ............... 84

Table 48: Connecting Letters Report, Area of Biofilm Coverage ………………….................. 84

Table 49: Ordered Differences Report, Area of Biofilm Coverage .............................................. 85

Table 50: One-way Analysis of Variance of Penetration into Dentin Tubules of prepared root

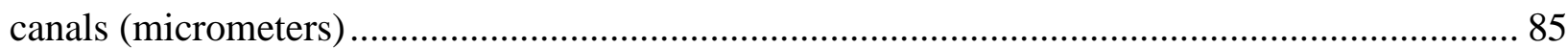

Table 51: Means for One-way ANOVA, Penetration Study ………………………………..... 85

Table 52: Means Comparisons for all pairs using Tukey-Kramer HSD, Penetration Study ........ 85

Table 53: Connecting Letters Report, Penetration Study …………………………………...... 85

Table 54: Ordered Differences Report, Penetration Study ...................................................... 86 


\section{List of Figures}

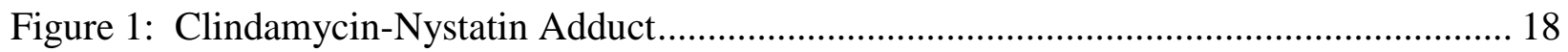

Figure 2: Blood Agar Plate inoculated with C. albicans .......................................................... 21

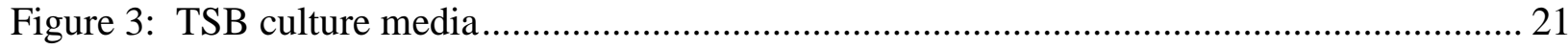

Figure 4: Digital Micrometer ........................................................................................... 21

Figure 5: ZOI Diagram (Biofilm and Planktonic) 30\% Poloxamer and Mueller-Hinton............. 24

Figure 6: Photo of Calgary Biofilm Device ………………................................................. 26

Figure 7: Diagram of Eukaryotic Yeast Cell Membrane (Courtesy of Dr. John G. Thomas) ..... 26

Figure 8: Diagram of Calgary Biofilm Device and assay template ………………………….... 27

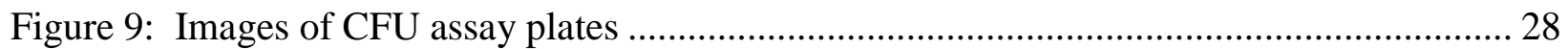

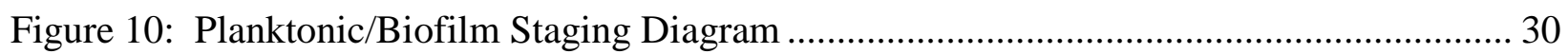

Figure 11: Biofilm formation (Courtesy of Dr. John G. Thomas) …………………………........ 31

Figure 12: Radiograph and cross-section of sample, slow speed diamond disc saw................... 33

Figure 13: Irrigation armamentarium, putty jig, EDTA, DMSO ………………………........... 34

Figure 14: Prepared samples ready for sectioning, blue acrylic material used to mount teeth.... 34

Figure 15: Partial NMR spectrum of Clindamycin HCl, Nystatin, and a 1:1 mixture................. 35

Figure 16: ZOI Results of all 5 microorganisms tested, Mueller-Hinton Media (Planktonic) .... 37

Figure 17: ZOI Results of all 5 microorganisms tested, Poloxamer Media (Biofilm) ................ 38

Figure 18: ZOI Results C. albicans (Average of trials n=12), M-Hinton Media (Planktonic) ... 40

Figure 19: ZOI Results C. albicans (Average of trials n=12) Poloxamer Media (Biofilm)........ 41

Figure 20: Graph of CFU Assay C. albicans Results ................................................................ 44

Figure 21: Graph showing results of Optical Density Absorbance Assay, C. albicans ............... 45

Figure 22: Bi-phasic budding yeast (Stage III), hyphae and pseudo-hyphae (Stage I) ................ 46

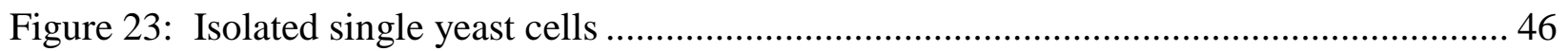

Figure 24: Pseudo hyphae, penetrating hyphae, example of bi-phasic eukaryote ....................... 47

Figure 25: Graph of Biofilm Coverage Area Assay, C. albicans .............................................. 48

Figure 26: 100\% Concentration of Novel Irrigant: Original image, 8-bit, threshold value, and

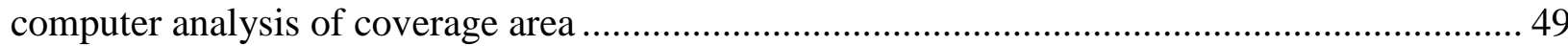

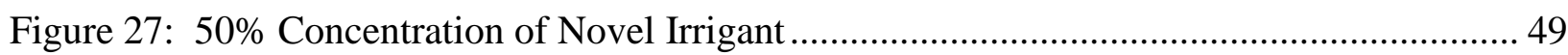

Figure 28: 25\% Concentration of Novel Irrigant ............................................................... 50

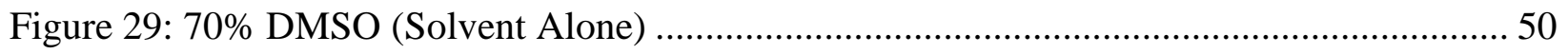

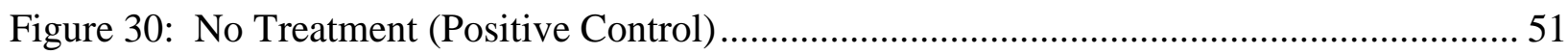

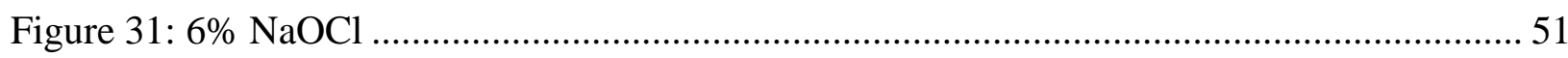

Figure 32: Graph of Penetration into Dentin Tubules (micrometers) ........................................ 52

Figure 33: Comparison of Control and all concentrations of Novel Irrigant Tested ..................... 54

Figure 34: Confocal Laser Microscopy 10X No treatment ……………………….................... 55

Figure 35: Confocal Laser Microscopy 10X 6\% NaOCl Treatment ............................................ 56

Figure 36: Confocal Laser Microscopy 17\% EDTA Treatment ................................................... 57

Figure 37: Confocal Laser Microscopy 10X 70\% DMSO Treatment ............................................ 58

Figure 38: Confocal Laser Microscopy 10X 100\% Concentration of Novel Irrigant ................... 59 
Figure 39: Confocal Laser Microscopy 10X 50\% Concentration of Novel Irrigant .................. 60

Figure 40: Confocal Laser Microscopy 25\% Concentration of Novel Irrigant ......................... 61

Figure 41: Confocal Laser Microscopy 10X Treatment with 17\% EDTA and 6\% $\mathrm{NaOCl}$........ 62

Figure 42: Confocal Laser Microscopy 20X 100\% Concentration Novel Irrigant.................... 63 


\section{Chapter 1}

\section{$\underline{\text { Introduction }}$}

Even with the evolution of modern rotary instrumentation, various new sealers, and multiple obturation techniques there is no substitute for proper chemical disinfection and physical debridement of the root canal system. Every health care professional has a disease to address, with endodontists treating pulpitis (inflammation of the pulp tissues) and apical periodontitis (inflammation and pathology associated with the apical tissues). It has long been known that microorganisms are the main cause of periapical disease (Kakehashi 1965). Therefore, what is placed into the prepared root canal system for the purpose of obturation may not be as important as what is removed prior to placing a final seal. One of the goals of effective root canal therapy (RCT) is the elimination of bacteria from the root canal system and the prevention of recontamination (Bystrom \& Sundqvist 1981). Endodontic therapy remains an effective means of stabilizing and preserving the natural dentition. The rate of success versus failure of endodontic therapy completed at West Virginia University from 1959 to 1979 was evaluated and determined that success had been achieved in $89.66 \%$ of 1,770 canals (Swartz 1983). Other studies report success rates of up to $96 \%$ (Sjogren 1990). Success rates of endodontic therapy are known to be better when teeth are free of bacteria after chemomechanical instrumentation (Bystrom 1987, Sjogren 1997). Under most clinical circumstances, endodontists are unable to create a sterile root canal environment, and the aim of treatment should be to effectively reduce the bio load in the root canal system and apical tissues by proper disinfection to a level where the body's defenses and healing mechanisms are able to prevail. Proper instrumentation is undoubtedly an important component of effective RCT and provides for the removal of a significant amount of intra-radicular infected dentin. Irrigants play an 
indispensable role in areas inaccessible to instrumentation such as lateral and accessory canals, fins, and webs (Hasselgren 1988).

The properties of an ideal endodontic irrigant include possessing an anti-bacterial effect, ability to dissolve organic and inorganic tissue, have a lubricating and flushing effect, not be toxic to surrounding tissue, and not weaken tooth structure (Haapasalo 2010). Though there are currently numerous endodontic irrigants on the market, none of the presently available agents meet such requirements. In this study, a new endodontic irrigant containing $70 \%$ Dimethyl sulfoxide and an approximate 1:1 molar ratio of Clindamycin $\mathrm{HCl}$ and Nystatin is evaluated. This new irrigant is compared to full strength $(6 \%) \mathrm{NaOCl}$ on the ability to eliminate known endodontic pathogens, including Candida albicans, from a cultured biofilm grown on hydroxyapatite coated plastic pegs (Calgary Biofilm Device). The new irrigant is also compared to $6 \% \mathrm{NaOCl}$ and $17 \%$ Ethylenediaminetetraacetic acid (EDTA) for its ability to penetrate into dentin tubules. Laser confocal microscopy was used to visualize penetration into dentin tubules of extracted human teeth. 


\section{Statement of the Problem}

Will a novel endodontic irrigant composed of Clindamycin, Nystatin, and DMSO have the ability to penetrate into the dentin tubules and be anti-microbial against a Candida albicans biofilm phenotype as compared to full strength $\mathrm{NaOCl}$ ?

\section{Significance of the Problem}

Although the success rate of non-surgical endodontic therapy is relatively high $(92 \%$ success in cases without apical periodontitis and $74 \%$ in cases with apical periodontitis according to Phase One of the Toronto Study), it remains that if 24 million root canals are performed in the United States each year, there are 2 million failures of cases without apical periodontitis and 6 million failures of cases with apical periodontitis (Friedman 2003). With the advent of modern rotary instrumentation we are able to better clean and shape the canal space; however, it is well known that the canal anatomy and dentin tubule structure may still harbor pathogens that can contribute to endodontic failure. In a case study by Vieira et al., it was shown that a persistent intraradicular infection caused by bacteria located within dentinal tubules was the most reasonable explanation for resurgence of an apical periodontitis lesion (Vieira 2012). These areas are only accessible by chemical debridement; therefore, if the success rate of non-surgical endodontic therapy is to be increased, an endodontic irrigant capable of addressing these areas inaccessible to mechanical debridement must be developed.

\section{Null Hypothesis}

There is no significant difference in the ability of the test solution to penetrate into dentin tubules and effectively eliminate a Candida albicans biofilm phenotype as compared to full strength $\mathrm{NaOCl}$. 


\section{Assumptions}

1) $\mathrm{NaOCl}$ is the most commonly used irrigation material and thus chosen for comparison in this experiment.

2) Passive irrigation with a 30 ga ProRinse ${ }^{\circledR}$ (DENTSPLY) needle results in a clinically acceptable method of irrigation.

3) No current irrigation materials meet the characteristics of an ideal irrigant.

4) Incomplete or ineffective irrigation contributes to endodontic failure and apical periodontitis.

5) A Calgary Biofilm Device study model is an appropriate method of evaluating irrigant effectiveness against a biofilm phenotype.

6) Laser Confocal Microscopy is an effective way to visualize penetration into dentin tubules.

\section{$\underline{\text { Limitations }}$}

1) An in vitro experiment is simulating an in vivo situation.

2) There is a human element in performing all techniques.

3) The plastic hydroxyapatite coated pegs may not accurately simulate biofilm formation in vivo.

4) The root canals used will be similar, but will not have identical morphology.

5) Individual root canal system variability could affect the instrumentation and irrigation of any given tooth. 


\section{$\underline{\text { Delimitations }}$}

1) The extracted teeth were selected carefully in an attempt to minimize variability.

2) Only single rooted anterior teeth were selected

3) Teeth selected had completely formed apices

4) Teeth were sectioned at the mid-root level to allow uniform sampling of penetration into the canal.

5) All experimentation, instrumentation, and irrigation were performed by the principal investigator. 


\section{Chapter 2}

\section{$\underline{\text { Review of Literature }}$}

Sodium hypochlorite $(\mathrm{NaOCl})$ in varying concentrations from $0.5 \%$ to $6 \%$ has long remained as the most commonly recommended irrigating solution utilized in RCT. It was first recommended as an antiseptic solution by Dr. Henry Dakin (Dakin 1915). In a recent survey by Dutner to members of the American Association of Endodontists (AAE), it was found that $>90 \%$ of respondents used $\mathrm{NaOCl}$ as an irrigant (Dutner 2012). $\mathrm{NaOCl}$ has strong antibacterial (Bystrom 1983) and tissue dissolving effects (Rosenfeld 1978), but is toxic to periapical tissue (Gernhardt 2004) and has been suggested to degrade micromechanical characteristics of dentin (Ari 2004). In addition, $\mathrm{NaOCl}$ has no effect on the inorganic part of the smear layer (Baumgartner 1987). Therefore 17\% EDTA is used as part of some irrigation protocols after the use of $\mathrm{NaOCl}$ to remove the smear layer by chelation. In 2011, Qian et al. showed that if $\mathrm{NaOCl}$ is used again after EDTA or citric acid as the final antibacterial rinse, it causes marked erosion of the root canal wall dentin (Qian 2011). While NaOCl remains a part of the endodontic armamentarium, there continues to be some areas of debate and concern over its use.

The subject of much discussion over the years has been which dilution of $\mathrm{NaOCl}$ is appropriate to use during endodontic irrigation. In a case study by Cymbler and Ardakani, it was shown that the accidental injection of sodium hypochlorite into the periapical soft tissues can elicit a severe reaction including severe pain and a burning sensation (Cymbler 1994). 5.25\% $\mathrm{NaOCl}$ has been used as an irrigant for at least seven decades (Walker 1936). Shih's tube dilution studies showed that $\mathrm{NaOCl}$ had germicidal activity against Str. faecalis and S. aureus, even at a dilution of 1:1,000; however, only full strength $\mathrm{NaOCl}$ had an apparent immediate sterilizing effect in root canals of extracted human teeth inoculated with Str. faecalis or S. aureus (Shih 1970). A study performed by Hand et al. found that $5.25 \% \mathrm{NaOCl}$ was significantly more 
effective as a necrotic tissue solvent than $2.5 \% \mathrm{NaOCl}, 1 \% \mathrm{NaOCl}, 0.5 \% \mathrm{NaOCl}$, distilled water, normal saline solution, or 3\% Hydrogen Peroxide (Hand 1978). For many years the bulk of literature had turned its attention on NaOCl's ability to dissolve necrotic tissue with no mention of its effect on vital tissue.

Rosenfeld et al. performed a study to evaluate the solvent action of $5.25 \% \mathrm{NaOCl}$ on vital human pulp tissue that had not been disturbed by instrumentation. They found that in nonconfined areas, it is apparent that $\mathrm{NaOCl}$ has a strong, nonspecific, surface-acting solvent action on vital, intact, young, pulp tissue (Rosenfeld 1978). Major problems have also been reported when $5.25 \% \mathrm{NaOCl}$ is injected into human periapical tissue (Sabala 1989). Because of these types of safety concerns, Spangberg et al. recommended $0.5 \% \mathrm{NaOCl}$ for acceptably noncytotoxic levels (Spangberg 1973). Baumgartner and Cuenin could not detect any difference in the removal of pulpal remnants and predentin in the middle third of root canals with 5.25\%, $2.5 \%$, or $1 \% \mathrm{NaOCl}$ delivered with either a needle or an ultrasonic device. $0.5 \% \mathrm{NaOCl}$ left what appeared to be a few fibrils from predentin on the surface (Baumgartner 1992).

Hand et al. stated that "the surface area of tissue exposed to the test solution is important because dissolution is a function of surface contact" (Hand 1978). Koskinen et al. stressed the importance of good contact between tissue and irrigant (Koskinen 1980). Palazzi et al. concluded that the new 5.25\% NaOCl solutions modified with surfactants, Hypoclean A and Hypoclean B, had surface tension values that were significantly lower than Chlor-Xtra ${ }^{\mathrm{TM}}$ and $5.25 \% \mathrm{NaOCl}$. It was also reported that these new irrigants have the potential to both penetrate more readily into un-instrumented areas of the root canal system and also allow a more rapid exchange with fresh solution enabling greater antimicrobial effectiveness and enhanced pulp tissue dissolution ability (Palazzi 2012). Baker et al. concluded that "the removal of micro- 
organisms and debris seemed to be a function of the quantity rather than the type of irrigant" (Baker 1975). Moorer et al. found that an excess of organic matter rapidly depletes the activity of $\mathrm{NaOCl}$ and also lowers the $\mathrm{pH}$ drastically during the first moments of the reaction (Moorer 1982). Moorer concluded that "the amount of available chlorine in a hypochlorite system is important, not the mere initial strength of the hypochlorite solution. The recommended strength of antibacterial $\mathrm{NaOCl}$ is dependent on the amount of organic substances that are present. It can be safely stated that any hypochlorite solution that is able to dissolve tissue is, at the same time, a powerful disinfectant" (Moorer 1982). Baumgartner also concluded that "the effectiveness of low concentrations of $\mathrm{NaOCl}$ may be improved by using larger volumes of irrigant, by frequent exchange of irrigant, or by the presence of replenished irrigant in the canals for longer periods of time" (Baumgartner 1992). Senia et al. found that full strength $\mathrm{NaOCl}$ did not appear to be very effective in removing pulp tissue which remained after instrumentation. Furthermore, without direct contact with $\mathrm{NaOCl}$, the deeper protected tissues were dissolved more slowly and less completely (Senia 1971). Any tissue that remains after instrumentation and in deeper areas may harbor additional bacteria that could lead to endodontic failure.

$\operatorname{MTAD}^{\circledR}$ (DENTSPLY) is a mixture of $3 \%$ doxycycline, $4.25 \%$ citric acid, and a detergent (Tween 80). It was introduced in 2003 by Torabinejad and Johnson at the Loma Linda University as an endodontic irrigant to address some of the short comings of $\mathrm{NaOCl}$ and other endodontic irrigants. It is considered to be a clinically effective, biocompatible endodontic irrigant (Zhang 2003). Ring et al. concluded that the cytotoxicity of $\mathrm{NaOCl} / \mathrm{MTAD}^{\circledR}$ was found to be slightly less than $\mathrm{NaOCl}$ and $\mathrm{NaOCl} / \mathrm{EDTA}$, indicating that $\mathrm{MTAD}^{\circledR}$ is more biocompatible than $\mathrm{NaOCl}$ (Ring 2008). This finding may prove beneficial as we move toward more pulp regenerative techniques in endodontics. Doxycycline, being MTAD $^{\circledR}$ s antibacterial agent, is a 
bacteriostatic antibiotic and does not kill bacteria; it prevents the multiplication of susceptible bacteria. It can be assumed that residual bacteria may resume growth when appropriate conditions are restored and may cause reinfection (Singla 2011). Early in-vitro studies by Torabinejad showed that $\mathrm{MTAD}^{\circledR}$ demonstrated superior ability in killing E. faecalis and exerted better anti-bacterial properties at high dilutions than did $\mathrm{NaOCl}$ (Torabinejad 2003). Later research however, has shown that $\mathrm{MTAD}^{\circledR}$ may not exhibit optimal antimicrobial properties. In a study by Kho and Baumgartner, it was shown that there was no difference in the antimicrobial efficacy for irrigation with $5.25 \% \mathrm{NaOCl}$ and $15 \%$ EDTA versus irrigation with $1.3 \% \mathrm{NaOCl}$ and $\mathrm{MTAD}^{\circledR}$ in the apical $5 \mathrm{~mm}$ of roots infected with E. faecalis (Kho 2006). Dunavant found that $\mathrm{NaOCl}$ was significantly more efficient in elimination E. faecalis biofilms than $\mathrm{MTAD}^{\circledR}$ (Dunavant 2006). In a study performed by Johal et al., no growth of E. faecalis was found in root canals irrigated with $5.25 \% \mathrm{NaOCl}$ and $15 \%$ EDTA, while $50 \%$ of canals irrigated with $1.3 \% \mathrm{NaOCl}$ and $\mathrm{MTAD}^{\circledR}$ demonstrated growth of E. faecalis (Johal 2007). Giardino et al. showed that only $5.25 \% \mathrm{NaOCl}$ could disaggregate and remove the E. faecalis biofilm each time when compared to $\mathrm{MTAD}^{\circledR}$ and other endodontic irrigants (Giardino 2007). In regard to antifungal activity, Ruff et al. showed that $6 \% \mathrm{NaOCl}$ and $2 \%$ chlorhexidine independently were equally effective and superior to MTAD ${ }^{\circledR}$ and $17 \%$ EDTA independently (Ruff 2006). De-Deus et al. reported significantly faster dissolution of inorganic material by both $5 \%$ citric acid and MTAD $^{\circledR}$ as compared with $17 \%$ EDTA (De-Deus 2007). Also, MTAD ${ }^{\circledR}$ has been shown to solubilize pulpal tissue (Beltz 2003). MTAD $^{\circledR}$ has made its mark on endodontics as an adjunct to the current irrigation protocol, but some of its antibacterial efficacy has come into question, leading to the pursuit of several possibilities of alternative irrigants. In addition, as is the case 
with many endodontic products, MTAD $^{\circledR}$, s use has been hindered by its relatively high cost and difficult handling and storage characteristics.

$\mathrm{QMiX}^{\mathrm{TM}}$ (DENTSPLY) is an endodontic irrigant that possesses antimicrobial effects with the added ability to remove the smear layer in one ready to use solution. QMiX ${ }^{\mathrm{TM}}$ contains EDTA, chlorhexidine (CHX) and a detergent. Mixing EDTA and CHX is known to produce a white precipitate (Rasimick 2008). There has also been concern that mixing $\mathrm{NaOCl}$ and $\mathrm{CHX}$ produces a brown/orange precipitate that could potentially be carcinogenic. Despite the CHX content, mixing $\mathrm{QMiX}^{\mathrm{TM}}$ with $\mathrm{NaOCl}$ does not produce any precipitate and the solution does not change color (Stojicic 2012). The antimicrobial agent in $\mathrm{QMiX}^{\mathrm{TM}}, \mathrm{CHX}$, is a chemical antiseptic with activity against both gram positive and gram negative organisms. It exerts both bacteriostatic and bactericidal effects. $\mathrm{CHX}$ is found in many dental applications as well as some topical preparations. $\mathrm{CHX}$ is deactivated by anionic compounds commonly used as surfactants in detergents (Denton 2001). In a study by Stojicic et al. it was concluded that QMiX ${ }^{\mathrm{TM}}$ and $\mathrm{NaOCl}$ were superior to $\mathrm{CHX}$ and $\mathrm{MTAD}^{\circledR}$ under laboratory conditions in killing E. faecalis and plaque bacteria in planktonic and biofilm culture (Stojicic 2012). Ma et al. concluded that $\mathrm{QMiX}^{\mathrm{TM}}$ was equally effective in killing bacteria in dentin as 6\% $\mathrm{NaOCl}$ (Ma 2011). In a study by Ordinola-Zapata et al. comparing $1 \% \mathrm{NaOCl}, 2 \% \mathrm{CHX}, 10 \%$ citric acid, 17\% EDTA, and distilled water, only $1 \% \mathrm{NaOCl}$ had a significant effect on biofilm viability and architecture (Ordinola-Zapata 2012). Mohammadi and Abbott conclude that CHX is an effective antifungal agent, but its efficacy is significantly less than $\mathrm{NaOCl}$ (Mohammadi 2009). The ability of $\mathrm{QMiX}^{\mathrm{TM}}$ to remove the smear layer is comparable to EDTA (Stojicic 2012). Because CHX does not have the ability to dissolve tissue, $\mathrm{QMiX}^{\mathrm{TM}}$ is recommended as a final rinse after $\mathrm{NaOCl}$. Dai et al. concluded that the two experimental versions of $\mathrm{QMiX}^{\mathrm{TM}}$ used in the open canal 
designed experiment were as effective as 17\% EDTA in removing canal wall smear layers after the use of $5.25 \% \mathrm{NaOCl}$ as the initial rinse (Dai 2011). While $\mathrm{QMiX}^{\mathrm{TM}}$ is another addition to the endodontic irrigation protocol there are still some shortcomings of its use as a lone irrigant and inability to dissolve tissue.

Dimethyl sulfoxide (DMSO) was first synthesized by Alexander Saytzeff in 1867 by the oxidation of dimethyl sulfide (Saytzeff 1867). DMSO is basically a by-product of a process known as kraft pulping, in which wood is turned into wood pulp for many paper making applications. Lignin is the source of DMSO and wood contains approximately $25-30 \%$ lignin. In 1962, Crown Zellerbach obtained a patent for the processing of this by-product, which utilized the methyl groups of kraft lignin by adding molten sulfur to form dimethyl sulfide. Nitrogen tetroxide was then used to oxidize the dimethyl sulfide to dimethyl sulfoxide (Herschler 1965). Several peculiar chemical and therapeutic properties of DMSO were soon discovered when Dr. Stanley Jacob began seeking a relatively pure solution of DMSO for use as a cryostatic agent to protect organ transplants against freezing damage while in storage (David 1972). Perhaps the most fascinating characteristic of DMSO is its ability to penetrate living tissues without causing significant damage. This is related to its relatively compact structure and polar nature as well as its capacity to accept hydrogen bonds. Dr. Stanley Jacob at the University of Oregon Medical School then began a series of experiments to show that DMSO was an active penetrant and carrier of other substances through the skin or tissue membranes. Initial studies showed that DMSO enhanced the absorption of heparin, insulin, sodium salicylate, Evans Blue dye, sulfadiazine, aminophylline, and thio TEPA through the intact urinary bladder of the dog (Jacob 1964). DMSO is classified as a dipolar, aprotic hydroscopic solvent that appears pyramidal in shape or like a tetrahedron with the sulfur atom in the center and the two methyl groups, the 
oxygen atom, and a nonbonding electron pair located at the apices (David 1972). The ability of DMSO to penetrate skin and mucous membranes may be the result of its dynamic interaction with tissue water (Szmant 1971). "The alteration in the configuration of immobile protein structures brought about by DMSO exchanging sites with bound water molecules may explain the penetration of DMSO through the skin. The transfer of DMSO across the dermal barrier is accomplished rapidly and completely without irreversible tissue damage and the alterations in protein structure are reversible" (David 1972). There have been numerous animal studies to confirm the membrane penetrability of DMSO. McDermot, Murray \& Heggie investigated the percutaneous penetrability and drug carrier potentials of DMSO in guinea pigs and rabbits. They detected longer plasma duration of 1-methyl-2-hydroximinomethylpyridium methane sulfonate (P2S) when it was added to DMSO and applied topically versus intramuscular injection. This was attributed to the slow continuous passage of the compound through the skin or by DMSO interfering in some way with the metabolism or excretion of P2S (McDermot 1965). Hucker et al. found maximum serum levels of DMSO 4 to 8 hours after dermal administration; these levels then declined and 36-48 hours after application no DMSO was detected (Hucker 1967). Kligman obtained the fastest and greatest penetrability of dyes, corticosteroids, and other pharmacological agents through skin with 70-90\% DMSO (Kligman 1965 Part I). Chronic toxicity studies have been made for a number of routes of administration using various concentrations of DMSO. Dermal application of 100\% DMSO to backs of guinea pigs in 28 daily applications and to hairless mice given two applications a week for 30 weeks caused no skin irritation and no toxicity (Smith 1967). Kumar et al. showed that DMSO and Ethanol acted as a penetration enhancer for the transdermal delivery of Acyclovir and skin flux of the drug could be enhanced up to 107 fold compared to its aqueous solution (Kumar 2011). In addition to 
being able to penetrate human membranes and potentially carry other compounds with it, some have found that DMSO exerts anti-inflammatory and pain relief ability on its own. "Pain relief from dermal administration of DMSO to affected areas seems to involve more than local analgesia, anti-inflammatory action, or vasodilation. Cutaneous application of DMSO at some distance from the affected site usually relieves pain and inflammation in the latter location, suggesting that DMSO either has been carried by the circulation to the affected area to act locally or has depressed the central nervous system pain centers or both" (David 1972). Ramirez \& Luza gave intramuscular injections of $5 \mathrm{ml}$ of $80 \%$ DMSO two or three times a day to 42 severely disturbed psychiatric patients. They felt that DMSO had antipsychotic and antianxiety properties and that its action differed from tranquilizers in that little sedation or central depression was produced (Ramirez 1967). It was shown in a study by Formanek \& Kovac that DMSO increased the infiltration of leukocytes into the traumatized area of cotton pellet implantation and suggested that the decreased formation of granulation tissue is due to an anti-inflammatory action (Formanek 1966). Kligman observed that DMSO possesses potent histamine-like properties at the site of cutaneous application, resulting in an increased blood flow to the skin (Kligman 1965 Part I). DMSO has even been shown to have antibacterial properties of its own. Jacob et al. found 20\% DMSO bacteriostatic against E. coli, Staph. aureus, Pseudomonas, and in 5\% concentration, against the tubercle bacillus (Jacob 1964). Kligman found DMSO a weak antifungal agent, which might be more effective when topical fungicides are incorporated in it (Kligman 1965 Part II). Jacob reported on studies that indicated pretreatment of tubercle bacilli resistant to 2000 micro grams of streptomycin or isoniazid with $0.5-5 \%$ DMSO rendered this organism sensitive to 10 micro grams of either drug (Jacob \& Wood 1967, Jacob 1971). Kamiya et al added 5\% DMSO to culture media, which restored the sensitivity of antibiotic-resistant 
strains of bacteria to antibiotics and increased the sensitivity of those strains already sensitive to these agents. For example, DMSO restored the sensitivity of Pseudomonas to colistin. In addition, growth of $E$. coli, which is not affected by penicillin, showed growth-inhibitory effects when 5\% DMSO was added to the culture (Kamiya 1966). Significant amounts of methylmethanthiosulfinate was identified in DMSO treated bacterial cultures by Tsuchiya, Iriyama, \& Umezawa, which they believe contributed to the antibacterial effect of DMSO (Tsuchiya 1964). Gillchriest \& Nelson believe DMSO may interfere with bacterial growth by altering the RNA conformational structure required for protein synthesis (Gillchriest 1969). In an article by Rosenbaum, continued dermal application of DMSO in patients with postoperative or posttraumatic intractable pain, post-amputation phantom pain, and tic douloureux resulted in marked pain relief in 32 of 37 patients (Rosenbaum 1965). Jacob found that over $75 \%$ of patients in a 60 patient study obtained relief of headache secondary to trigeminal neuralgia, sinusitis, cervical osteoarthritis, and temporal arteritis, when about $10-15 \mathrm{ml}$ of $50 \%$ DMSO were applied twice daily to the skin of the face and neck (Jacob 1965).

Clindamycin has long been used to treat odontogenic infections of endodontic origin. Clindamycin reversibly binds to $50 \mathrm{~S}$ ribosomal subunits preventing peptide bond formation thus inhibiting bacterial protein synthesis. It is bacteriostatic or bactericidal depending on the drug concentration, infection site, and organism. Clindamycin is metabolized in the liver where clindamycin phosphate is converted to clindamycin $\mathrm{HCl}$ (active). Clindamycin is excreted in the urine (10\%) and feces (4\%) as active drug and metabolites. Clindamycin is a pregnancy risk factor category B meaning adverse events were not observed in animal reproduction studies. Clindamycin crosses the placenta throughout pregnancy and at term, but use during pregnancy has not been shown to cause adverse fetal effects. Clindamycin pharmacokinetics are not 
affected by pregnancy. Small amounts of clindamycin transfer to human milk. The manufacturer does not recommend the use of clindamycin during breast-feeding. Clindamycin has not been shown to interfere with oral contraceptive activity; however, it reduces GI micro-flora, thus, oral contraceptive users should be advised to use additional methods of birth control. About $1 \%$ of clindamycin users develop pseudomembranous colitis. Prolonged use may result in fungal or bacterial super-infection, including $C$. difficile-associated diarrhea (CDAD) and pseudomembranous colitis; CDAD has been observed >2 months post-antibiotic treatment.

Nystatin binds to sterols in fungal cell membrane, changing the cell wall permeability allowing for leakage of cellular contents. Nystatin is excreted in the feces. It is a pregnancy category risk factor C. Animal reproduction studies have not been conducted. Adverse events in the fetus or newborn have not been reported following maternal use of vaginal nystatin during pregnancy. Absorption following oral use is poor. Excretion into breast milk is not known. The biological activity of polyene antibiotics (PA's), like Nystatin, sharply increases after their dissolution in DMSO and they are tenfold more efficient than their water-solved forms. DMSO is the main solvent of membranoactive polyene antibiotics such as nystatin (Ibrajimova 2004).

The polymorphic fungus Candida albicans is a member of the normal human micro biome. In most individuals, $C$. albicans resides as a lifelong, harmless commensal. Under certain circumstances, however, C. albicans can cause infections that range from superficial infections of the skin to life-threatening systemic infections. Candida now ranks as the fourth most frequently encountered microbe among nosocomial bloodstream pathogens (Pfaller 1998). Several factors and activities have been identified which contribute to the pathogenic potential of this fungus. Among them are molecules which mediate adhesion to and invasion into host cells, the secretion of hydrolases, the yeast-to-hypha transition, contact sensing and thigmotropism, 
biofilm formation, phenotypic switching and a range of fitness attributes (Mayer 2013). C. albicans may be the universal co-aggregate of endodontic biofilm formation. In a study by Baumgartner et al. the presence of C. albicans was detected in $21 \%$ of samples taken from root canals (Baumgartner 2000). C. albicans, a normal commensal of human mucosal surfaces and opportunistic pathogen in immunocompromised patients, is most frequently associated with biofilm formation. Colonization of C. albicans allows the development of adherent biofilm structures from which cells can then detach and cause an acute fungemia and/or disseminated infection (Ramage 2012). Microbiologists have historically studied planktonic organisms (free floating and homogeneous cells) in pure culture. However, there has been a paradigm shift as the link between sessile (surface attached and heterogeneous cells) and microbial pathogenesis and human infection is now widely accepted (Costerton 1995). Estimates suggest that up to 80\% of all microorganisms in the environment exist in biofilm communities (Donlan 2002). A growing body of knowledge suggests that organisms in biofilms assume a stronger pathogenic potential than those in a planktonic state (Svensater 2004). "Biofilms are defined as highly structured communities of microorganisms that are either surface associated or attached to one another and are enclosed within a self-produced protective extracellular matrix (ECM). Biofilm formation includes protection from the environment, resistance of physical and chemical stress, metabolic cooperation, and a community-based regulation of gene expression. There has been an increased appreciation of the role that fungal biofilms play in human disease as microbes growing within biofilms exhibit unique phenotypic characteristics compared to their planktonic counterpart cells, particularly increased resistance to antimicrobial agents" (Ramage 2009). Glycoproteins and proteins supplied by saliva or gingival crevicular fluid act as the primary source of nutrients for the microbial communities of dental biofilms (Beighton 1986). 


\section{Chapter 3}

\section{Materials and Methods}

\section{Formulation of Novel Irrigant:}

Chemically pure samples of Clindamycin $\mathrm{HCl}$ (Lot \# 021M1533V) and Nystatin (Lot \# 110M8715V) were purchased through Sigma Aldrich (Milwaukee, WI). DMSO was obtained through Jacob Laboratories (Portland, OR) in 70\% concentration. An approximate 1:1 molar ratio of the two substances was dissolved in the DMSO (1 mg Nystatin, $0.425 \mathrm{mg}$ Clindamycin HCL, $0.75 \mathrm{~mL}$ of $70 \%$ aqueous DMSO [1.08mM or $0.1 \% \mathrm{wt}$.$] ). NMR spectroscopy was$ performed to ensure stability of the new mixture.

There was a concern that Clindamycin $\mathrm{HCl}$ may not be stable in the presence of Nystatin. Clindamycin is an alkyl chloride and Nystatin contains a primary amine. Thus, alkylation of the amine portion of Nystatin to form the Clindamycin-Nystatin adduct (Figure 1) is possible. While alkyl chlorides are often of low reactivity, alkylation reactions of the type shown in figure $1 \mathrm{can}$ occur in DMSO and solvents containing a preponderance of DMSO. This possibility was examined using NMR.

The experiment required proton NMR data be acquired on samples of Clindamycin $\mathrm{HCl}$, Nystatin, and a 1:1 mixture of the two. If no reaction occurred, the spectrum of the 1:1 mixture should be comprised of the sum of the two spectra. However, if a reaction occurred, significant changes in chemical shift of some of the protons are expected. Chemical shift is dependent upon the attached functional groups. Upon going from Clindamycin to the Clindamycin-Nystatin adduct, the chlorine is replaced by a nitrogen. Protons adjacent to a chlorine appear at below $3.44 \mathrm{ppm}$ (below 3.44 means at numeric values greater than $3.44 \mathrm{ppm}$ or protons adjacent to a chlorine are expected to appear downfield of $3.44 \mathrm{ppm}$ and there is a shift expected due to the beta amino group to move it further downfield). If the chlorine were replaced by an amino 
group, an up-field shift is expected and the same proton would be expect to appear above $3 \mathrm{ppm}$ (i.e., numerically, less than $3 \mathrm{ppm}$ ).

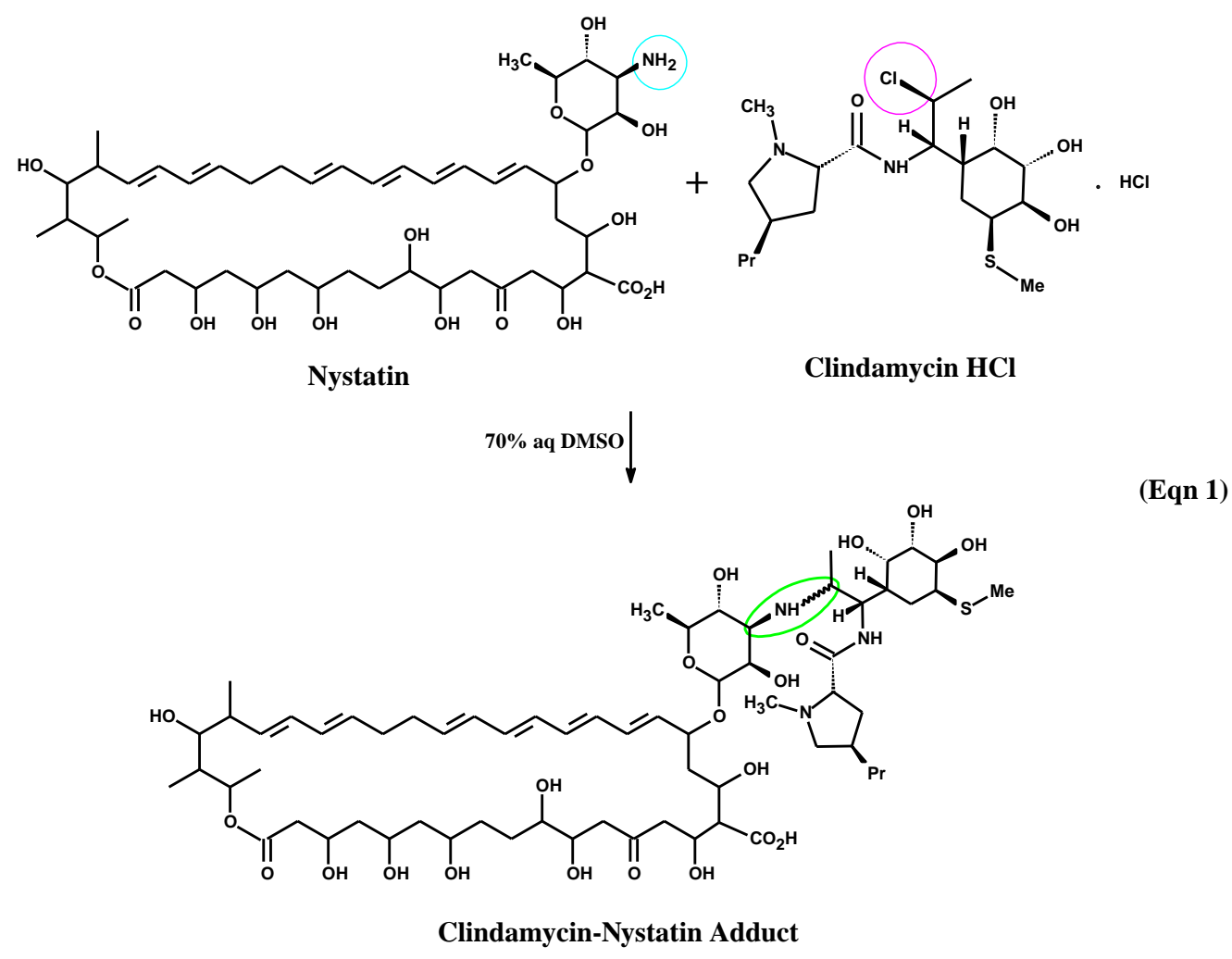

Figure 1: Clindamycin-Nystatin Adduct

Clindamycin $\mathrm{HCl}$, Nystatin, $\mathrm{D}_{2} \mathrm{O}$, and dmso- $\mathrm{d}_{6}$ were obtained from Aldrich (Milwaukee,

WI). All materials were used as received. Samples containing Nystatin were protected from light. Nuclear Magnetic Resonance (NMR) spectra were recorded on a Varian Inova spectrometer operating at $600 \mathrm{MHz}$. NMR tubes were obtained from Wilmad Glass (Vineland, NJ). NMR assignments were made using a combination of TOCSY spectra, selective decoupling experiments, chemical shift and coupling information obtained from the NMR spectra. The assignments were in general agreement with literature values for clindamycin (Verdier 2000) and nystatin (Bruheim 2004) though the literature values were obtained in solvents other than $\mathrm{D}_{2} \mathrm{O} /$ dmso- $_{6}$. 
Stock solutions for NMR studies of Clindamycin $\mathrm{HCl}$ and Nystatin were prepared in a mixture of $\mathrm{D}_{2} \mathrm{O}$ and dmso- $\mathrm{d}_{6}(3: 7)$ at a concentration of $1 \mathrm{mM}$. Samples that only contained Clindamycin $\mathrm{HCl}$ or Nystatin were prepared by mixing the stock solution $(0.5 \mathrm{~mL})$ and then diluting with $\mathrm{D}_{2} \mathrm{O}$ and dmso- $\mathrm{d}_{6}(3: 7)(0.5 \mathrm{~mL})$. The Clindamycin $\mathrm{HCl} / \mathrm{Nystatin}$ sample was prepared by mixing equal amounts of the Clindamycin $\mathrm{HCl}$ and Nystatin stock solutions. Once prepared, the NMR samples were maintained at $25^{\circ} \mathrm{C}$.

\section{Formulation of novel irrigant bulk sample:}

A sterile spatula was used to remove Clindamycin and Nystatin from their original containers which had been stored out of sunlight at 0 degrees Fahrenheit in a commercial freezer. Sterile pipets were used to remove the $70 \%$ DMSO from its stock container. In a weight boat on a digital scale, the following was measured $.0212 \mathrm{~g}$ Nystatin, .0108g Clindamycin, $15 \mathrm{~mL} 70 \%$ aqueous DMSO. The powder contents were carefully emptied into a $20 \mathrm{~mL}$ screw top vial carefully using the $70 \%$ DMSO to wash the powder residue from the weigh boat into the vial. The remaining necessary 70\% DMSO was added and the mixture was vortexed until all particles were dissolved. The sample was stored in a commercial refrigerator at two degrees Celsius and the vial containing the novel irrigant was covered with aluminum foil to protect from sunlight.

\section{Cultivation of micro-organisms:}

Blood agar plates were streaked with stock samples of the following bacteria:

Escherichia coli

Pseudomonas aeruginosa

Staphylococcus aureus

Candida albicans

Lactobacillus 
These five organisms were chosen to be used in preliminary screening trials. Based on the ease of growth, bi-phasic nature, and response to initial trials, C. albicans, was targeted for further study. The plates were placed in an incubator at 37 degrees Celsius for 24 hours.

\section{ZOI Measurement (Biofilm and Planktonic Phenotype):}

A $1 \mathrm{uL}$ loop of bacteria was taken from the blood agar plates and then placed into $5 \mathrm{~mL}$ of Tryptic Soy Broth (TSB) in a test tube. The test tube was vortexed to ensure mixture of contents. $250 \mathrm{uL}$ of bacteria-containing TSB was plated onto a $30 \%$ poloxamer (nonionic tri-block of copolymers composed of a central hydrophobic chain of polyoxpropylene flanked by two hydrophilic chains of polyoxyethylene) plate (from stock poloxamer that had been poured and allowed to reach room temperature in order to firm). An additional bacterial sample was also placed on stock Mueller-Hinton (Planktonic) agar plates. The liquid was spread with an Lspreader. Blank discs (designed to hold a specific amount of treatment solution) were allowed to soak in each solution for 10 seconds and then they were wicked on a paper towel and placed onto the inoculum of bacteria. See figure 10. The plates were placed into an incubator (at $37^{\circ} \mathrm{C}$ ) for 24 hours. After 24 hours, the plates were removed and ZOIs were recorded for each treatment

type. ZOIs were measured in $\mathrm{mm}$ with a digital micrometer. Plates were then placed back into the incubator and ZOIs were again recorded at $48 \mathrm{hrs}$. 


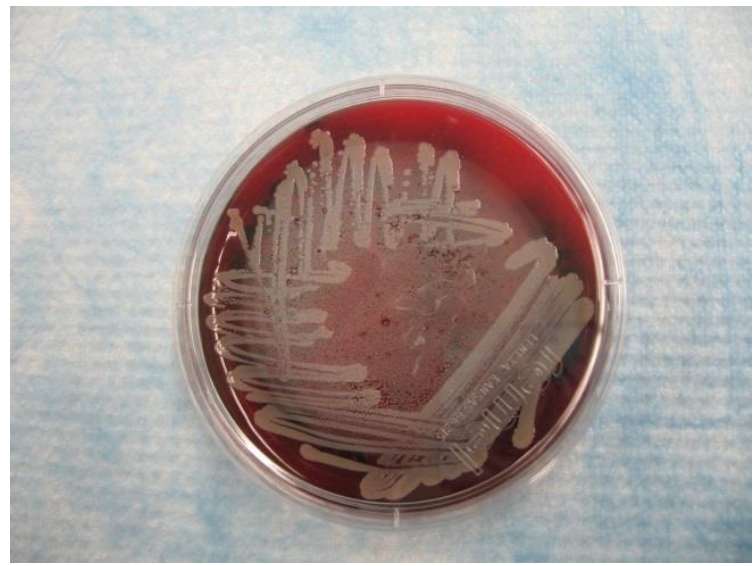

Figure 2: Blood Agar Plate inoculated with C. albicans

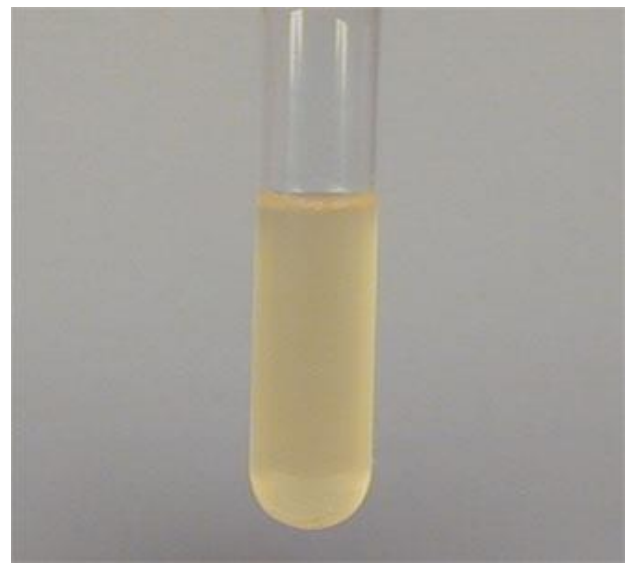

Figure 3: TSB culture media

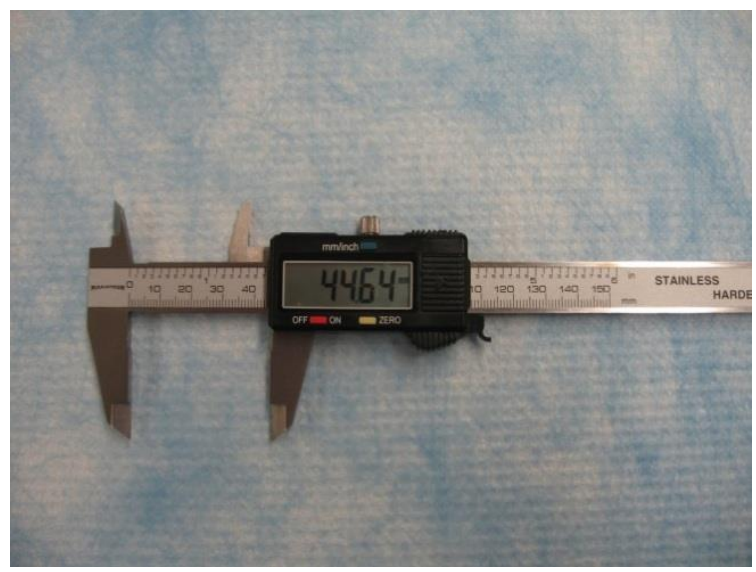

Figure 4: Digital Micrometer 


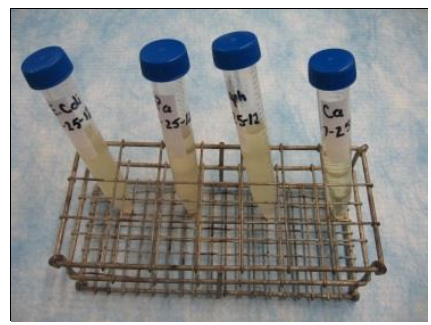

Figure 5: Inoculated TSB

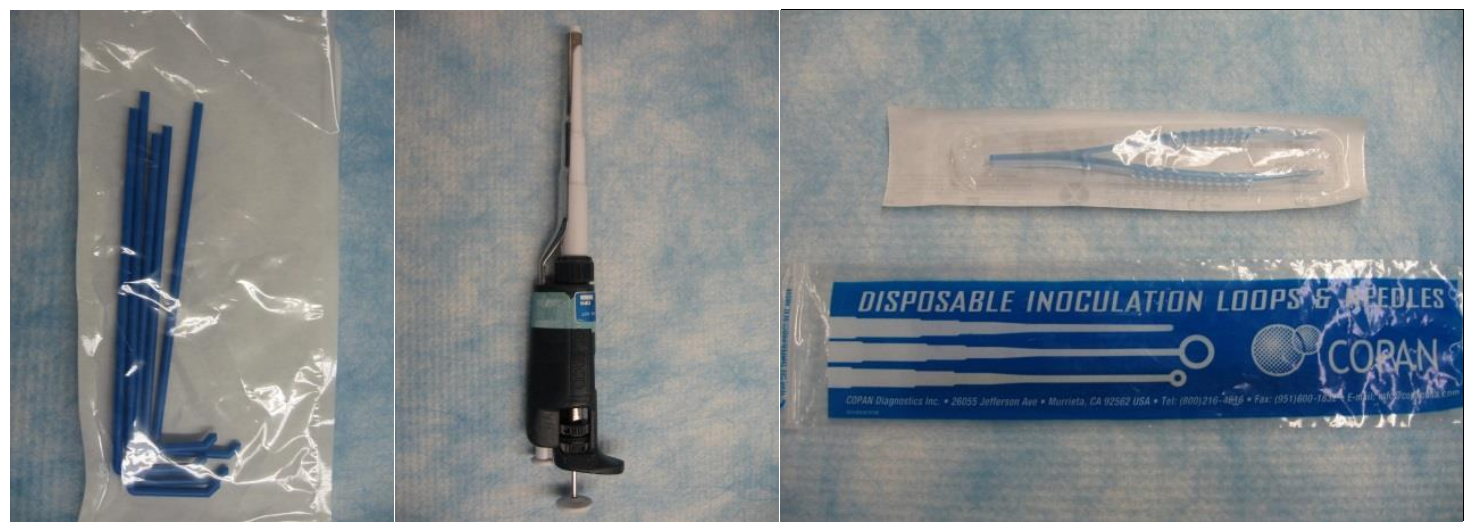

Figure 6: L-spreaders, micropipette, disposable inoculation loops and forceps

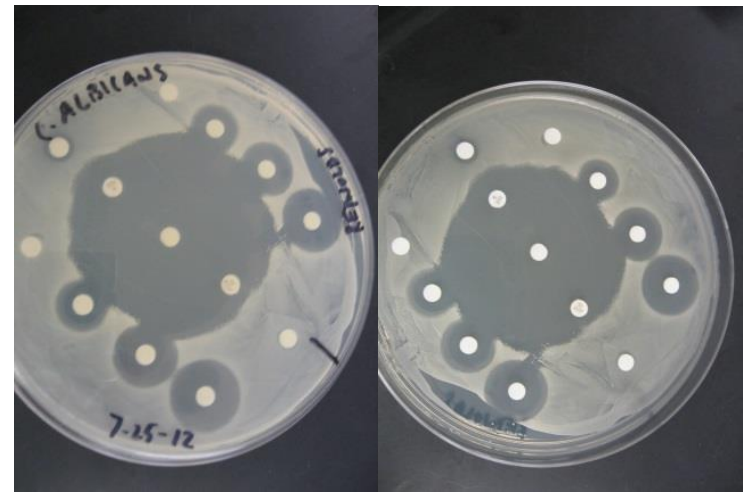

Figure 7: C. albicans ZOI plates Poloxamer (Biofilm)* 


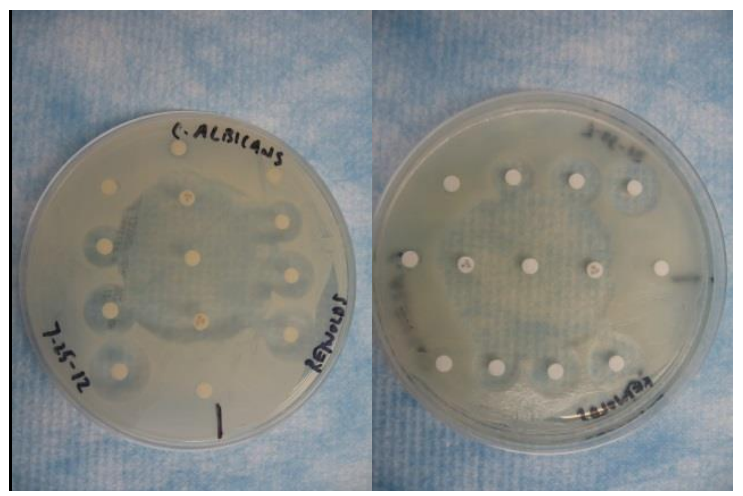

Figure 8: C. albicans ZOI Mueller-Hinton Plates (Planktonic)*

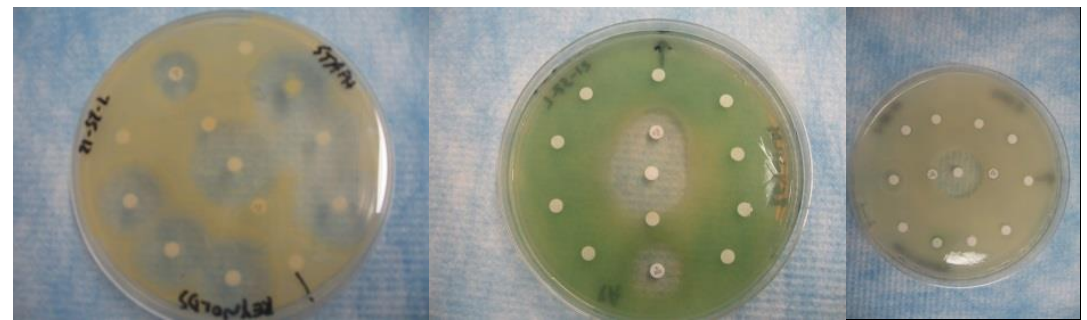

Figure 9: S. aureus, P. aeruginosa, E. coli ZOI plates*

*Note that these photos differ slightly from the template that appears on the next page because two anti-biotic discs were used (ATM- Aztreonam \& LVX- Levofloxacin) on either side of the $\mathrm{NaOCl}$; these results were not included because the ZOIs were overtaken by $\mathrm{NaOCl}$ and unreliable. A blank disc was also soaked in PerioSheild ${ }^{\mathrm{TM}}$ (located between the two blank control discs); these results were also not included. 


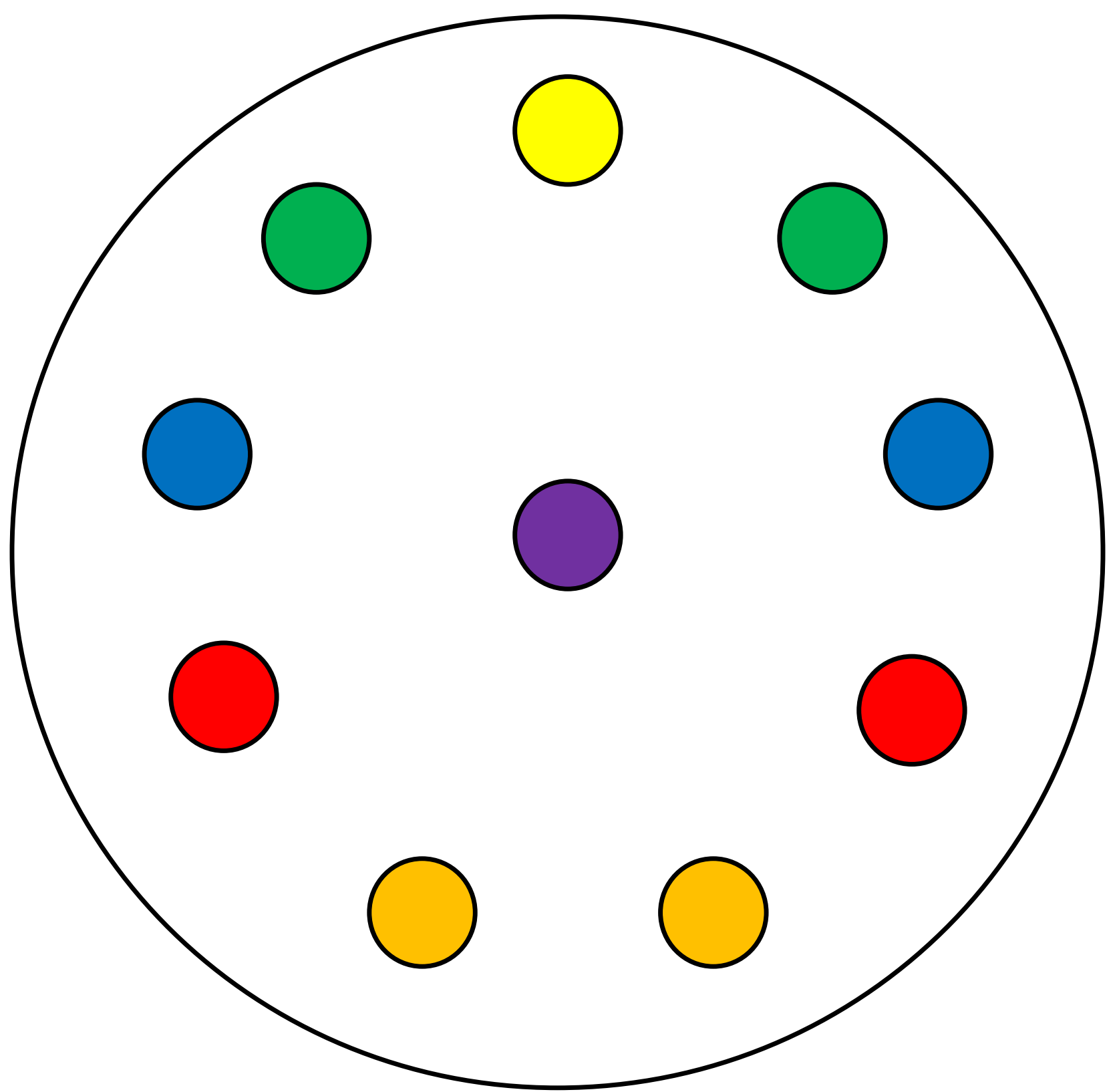

Figure 5: ZOI Diagram (Biofilm and Planktonic) 30\% Poloxamer and Mueller-Hinton

\begin{tabular}{|c|c|}
\hline $100 \%$ Concentration of Novel Irrigant & $50 \%$ Concentration of Novel Irrigant \\
\hline $25 \%$ Concentration of Novel Irrigant & $70 \%$ DMSO (Solvent Alone) \\
\hline $6 \% \mathrm{NaOCl}$ & Blank (No Treatment) \\
\hline
\end{tabular}




\section{Creation of Bacteria Biofilm on Hydroxyapatite-Coated Pegs (Calgary Biofilm Device):}

Candida albicans was chosen as the test organism. A $10 \mathrm{uL}$ loop was filled with the sample of C. albicans and placed into $40 \mathrm{~mL}$ TSB in a test tube. The loop was swirled to ensure all contents had been released from the loop into the solution. The test tube was vortexed to ensure even mixing. An Innovotech microtider tray was filled with $200 \mathrm{~mL}$ of C. albicans-containing TSB into each well (perimeter wells were excluded to eliminate the chance of evaporation during incubation period). The hydroxyapatite-coated pegs were placed into the microtider tray of $C$. albicans-containing TSB and allowed to incubate $\left(37^{\circ} \mathrm{C}\right.$ ) for 48 hours (on a rocker set to 3.5 rpm). Rocking helped to ensure even biofilm formation on each of the hydroxyapatite- coated pegs.

\section{Treatment of Pegs with Cleansing Solutions:}

Once the incubation period was complete, two more microtider trays were filled. The first tray was filled with treatment solutions $(100 \%, 50 \%, 25 \%$ concentration of Novel Irrigant as well as 70\% DMSO and Full strength 6\% NaOCl). See figure 13. The dilutions were made with sterile physiologic saline solution. The second tray was filled with saline solution (for a wash). The biofilm coated pegs were placed into the treatment solutions for 1 minute. The biofilm coated pegs were then placed into the saline solution to wash for 1 minute. The one minute in saline reflects the rinsing and drying of a root canal space and deactivation of the treatment solution. 


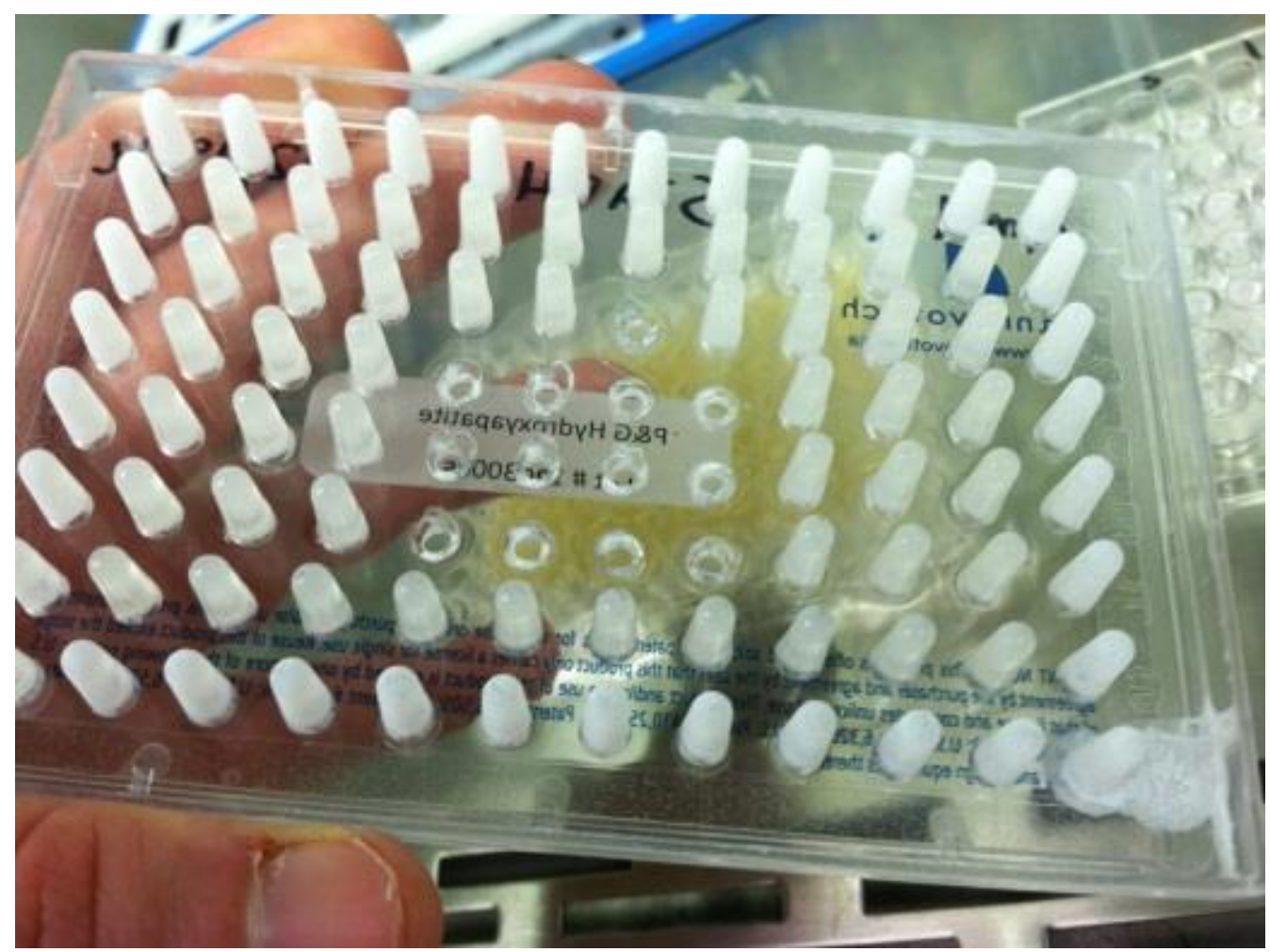

Figure 6: Photo of Calgary Biofilm Device

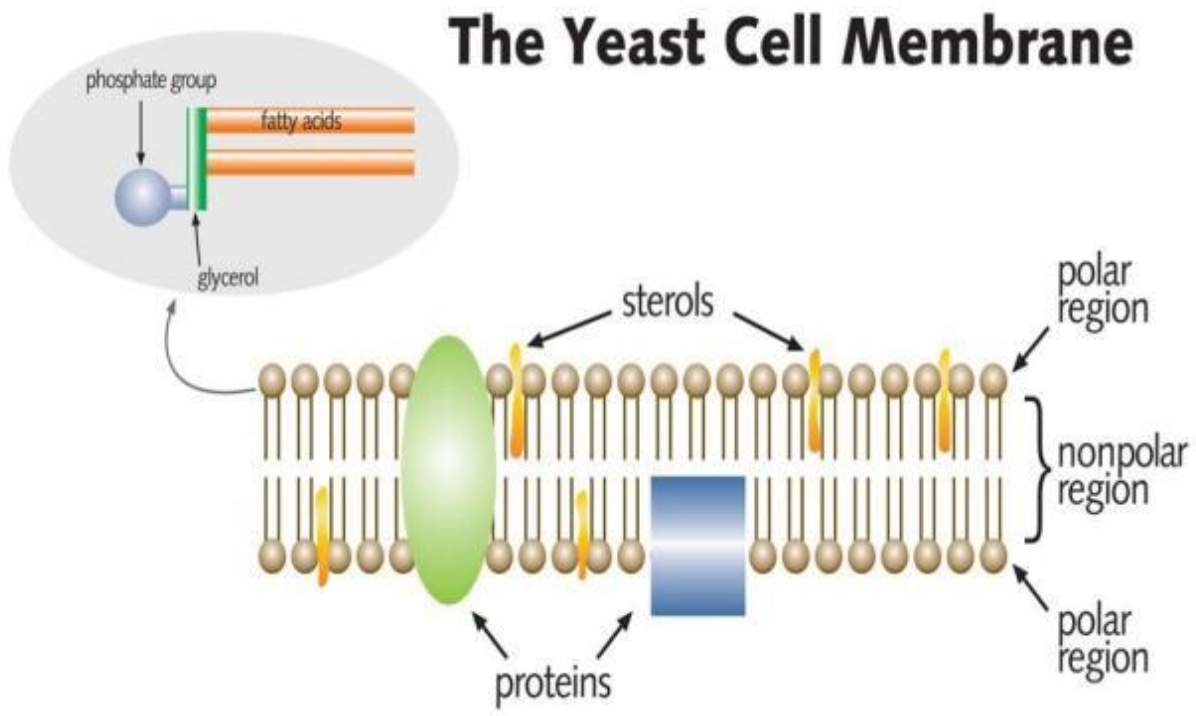

Figure 7: Diagram of Eukaryotic Yeast Cell Membrane (Courtesy of Dr. John G. Thomas) 


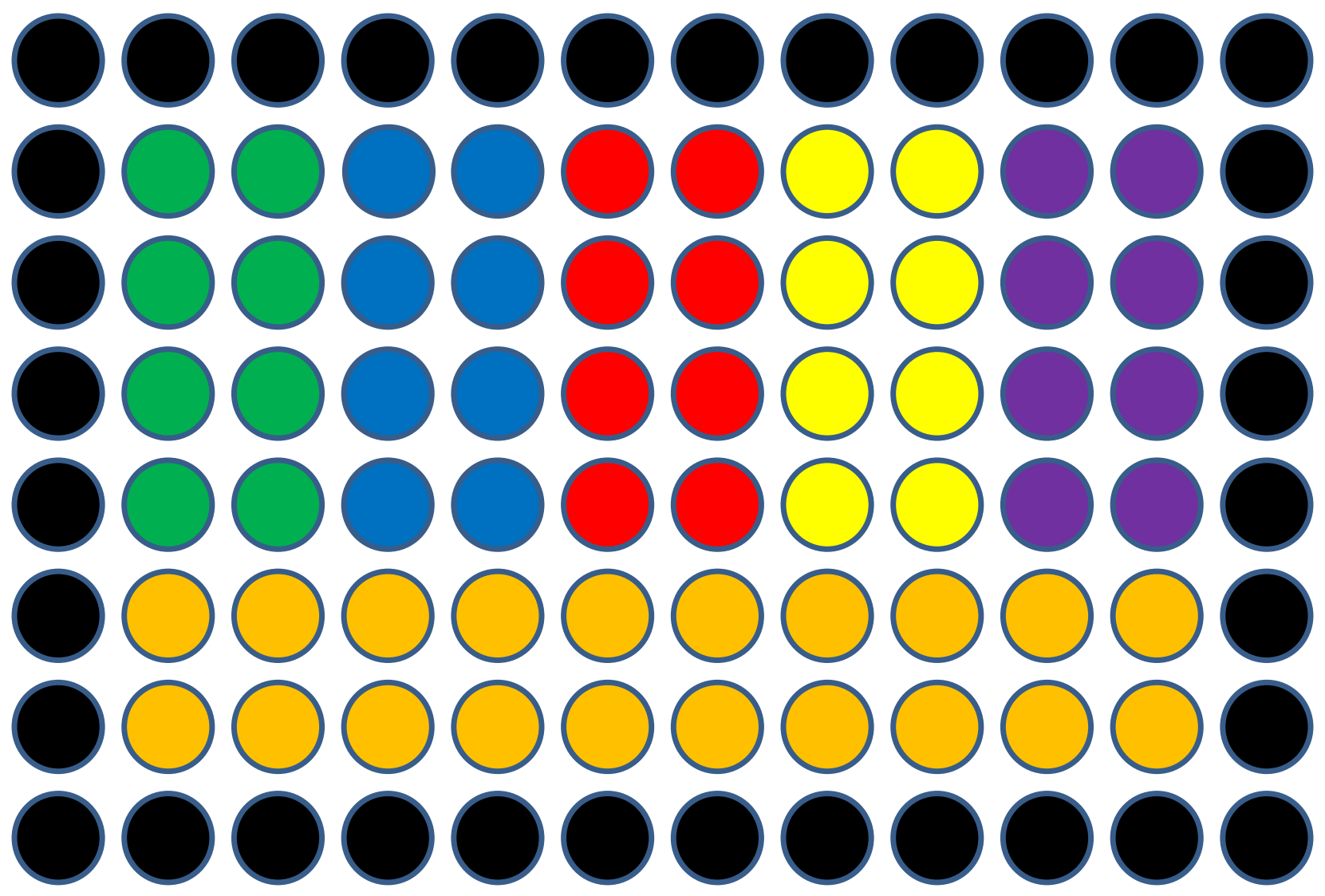

Figure 8: Diagram of Calgary Biofilm Device and assay template

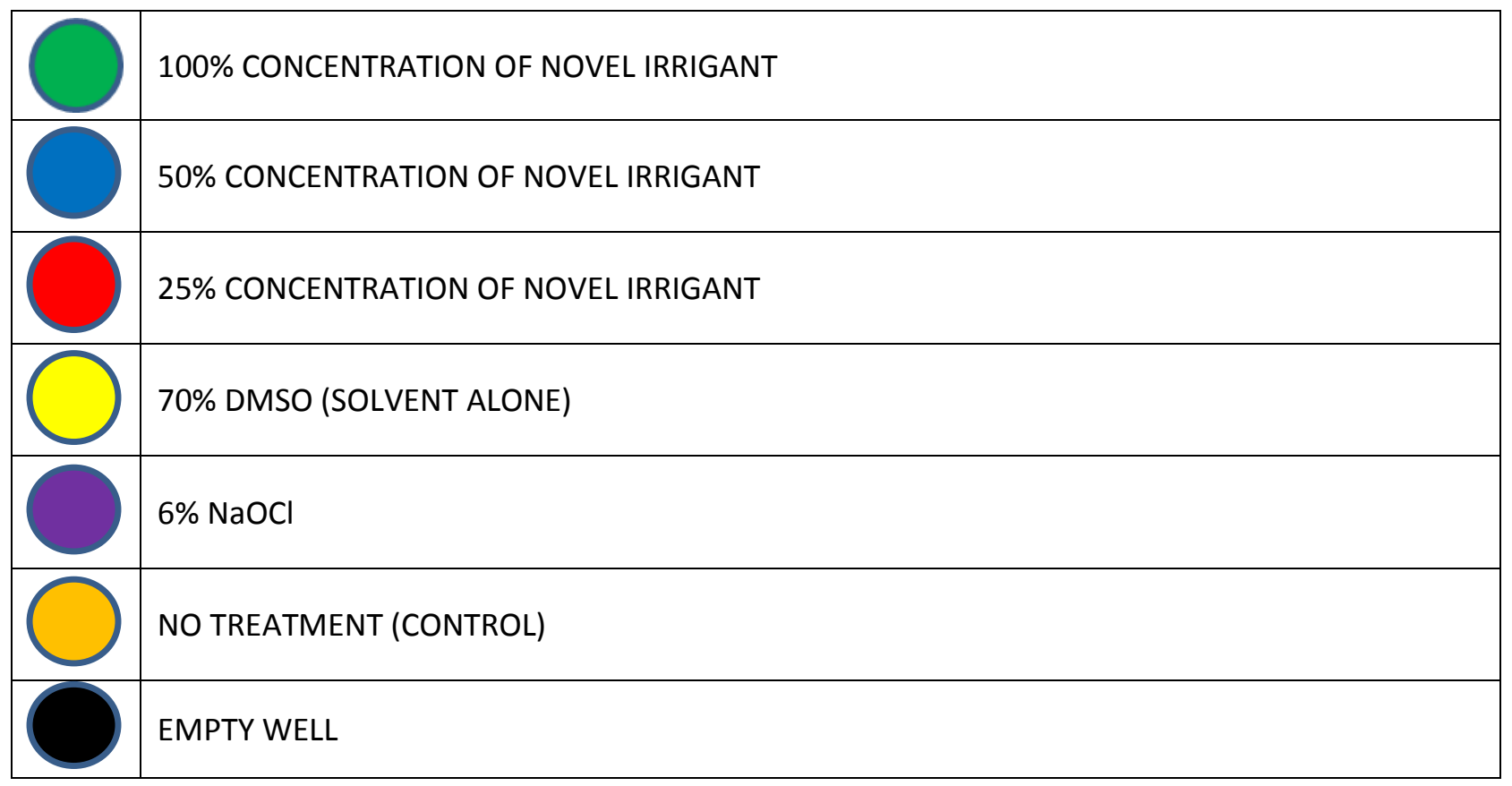




\section{Collection of CFU Data:}

A pair of sterile needle-nose pliers was used to break off pegs and place them into test tubes containing $4 \mathrm{~mL}$ saline. Care was used to ensure that pegs treated with each treatment solution were collected separately and the needle-nose pliers were disinfected with a $70 \%$ ethyl alcohol rinse followed by de-ionized water and allowed to dry between samples. Positive control pegs (no treatment) were also collected. The test tubes were sonicated in a water bath set at $37^{\circ} \mathrm{C}$ for 30 seconds. Sonicating the tooth in saline ensures that all of the biofilm bacteria are extracted from the tooth surface and come off in solution. A series of three 1 in 10 dilutions were made from each of the sonicated test tubes (sterile saline was used for dilution) and $250 \mathrm{uL}$ of solution from each individual dilution was plated onto a Mueller-Hinton agar plate. Mueller-Hinton plates were placed into the incubator (at $37^{\circ} \mathrm{C}$ ) for 24 hours. A colony-count of each plate was performed using aCOLyte software. CFU (colony forming units) were calculated based upon the dilutions that were performed in order to reflect the actual number of bacteria that were present on the peg surface after it was treated with each solution.

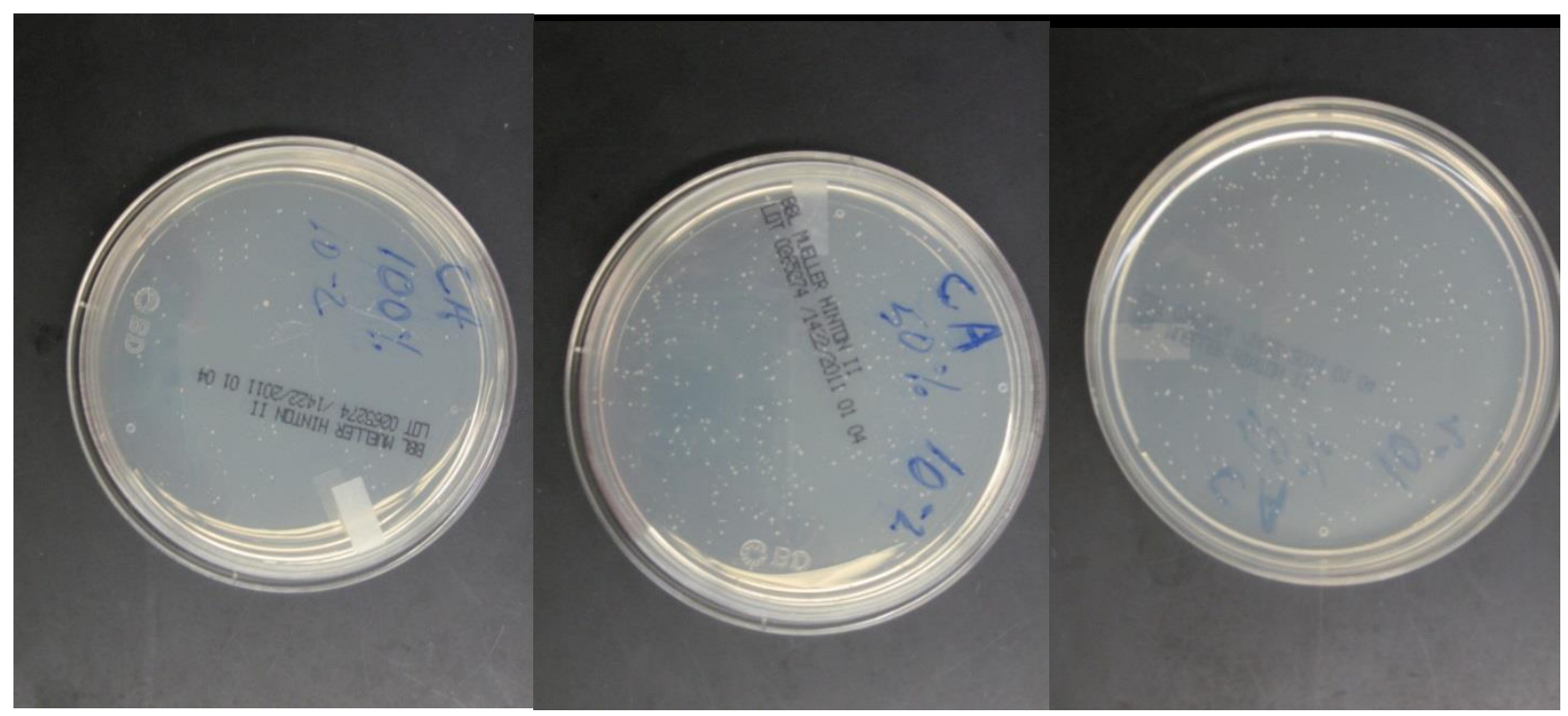

Figure 9: Images of CFU assay plates 


\section{Measurement of Optical Density:}

Needle-nose pliers were again utilized to break off tooth pegs (cleaning the pliers with alcohol wipes in between usages, but they were allowed to dry completely in between as well to avoid removal of the biofilm). The pegs were placed into $2 \mathrm{~mL}$ of Crystal Violet for $15 \mathrm{~min}$ (tooth was completely coated in Crystal Violet to be used as a stain). Pegs were removed from Crystal Violet and placed into $2 \mathrm{~mL}$ of de-ionized $\mathrm{H}_{2} \mathrm{O}$ to wash for 1 min. Pegs were placed into $2 \mathrm{~mL}$ glacial acetic acid (at 100\% strength) to remove biofilm for 15 minutes. Absorbance of solution was recorded at $562 \mathrm{~nm}$.

\section{SEM Photography:}

Pegs were placed into vials of $10 \%$ neutral buffered formalin to preserve the biofilm formation. Pegs were photographed by SEM to ensure the presence of biofilm. Consistent orientation was attempted by capturing the apical $1 / 3$ of the pegs. The samples were held down with carbon tape and a strip of copper tape was put over top of them. They were then coated with a gold palladium alloy. The thickness of the coating was between 5-10 nm. The samples were tall and round, so the copper tape makes a circuit with the gold palladium coating. The instrument used was a Hitachi S-4700 FE-SEM with an EDAX brand EDS detector in the WVU Department of Chemical Engineering, Benjamin M. Statler College of Engineering and Mineral Resources. All samples were run at $5.0 \mathrm{kV}$ and a working distance of $10.5 \mathrm{~mm}$. These numbers are included in the images. $\mathrm{SE}(\mathrm{M})$ means both upper and lower detectors were used (mixed), $\mathrm{SE}(\mathrm{L})$ means just the lower, and $\operatorname{SE}(\mathrm{U})$ means the upper detector was used. The lower detector is better for samples that charge or samples that have a lot of topography. The upper detector provides a clearer image in general, but doesn't show as much of the three dimensional features of the sample. Think of it as lighting a sample from above and looking down on it (upper detector) and 
lighting a sample from the side and looking at it (lower detector). The mixed detector averages the two images together. Biofilm Images were identified and staged according to the following table.

\begin{tabular}{|c|c|c|}
\hline \multicolumn{3}{|c|}{ Planktonic / Biofilm Staging } \\
\hline Staging & Description & Characteristics \\
\hline 0 & Free Floating & Individual Cells \\
\hline I A,B & Early & Loose, open \\
\hline II & Immature/Moderate & Increased biomass \\
\hline III & Mature/Highly Complex & Increased biodiversity \\
\hline IV A,B & Late/Apoptosis or Necrosis & Free-floating \\
\hline
\end{tabular}

Figure 10: Planktonic/Biofilm Staging Diagram 


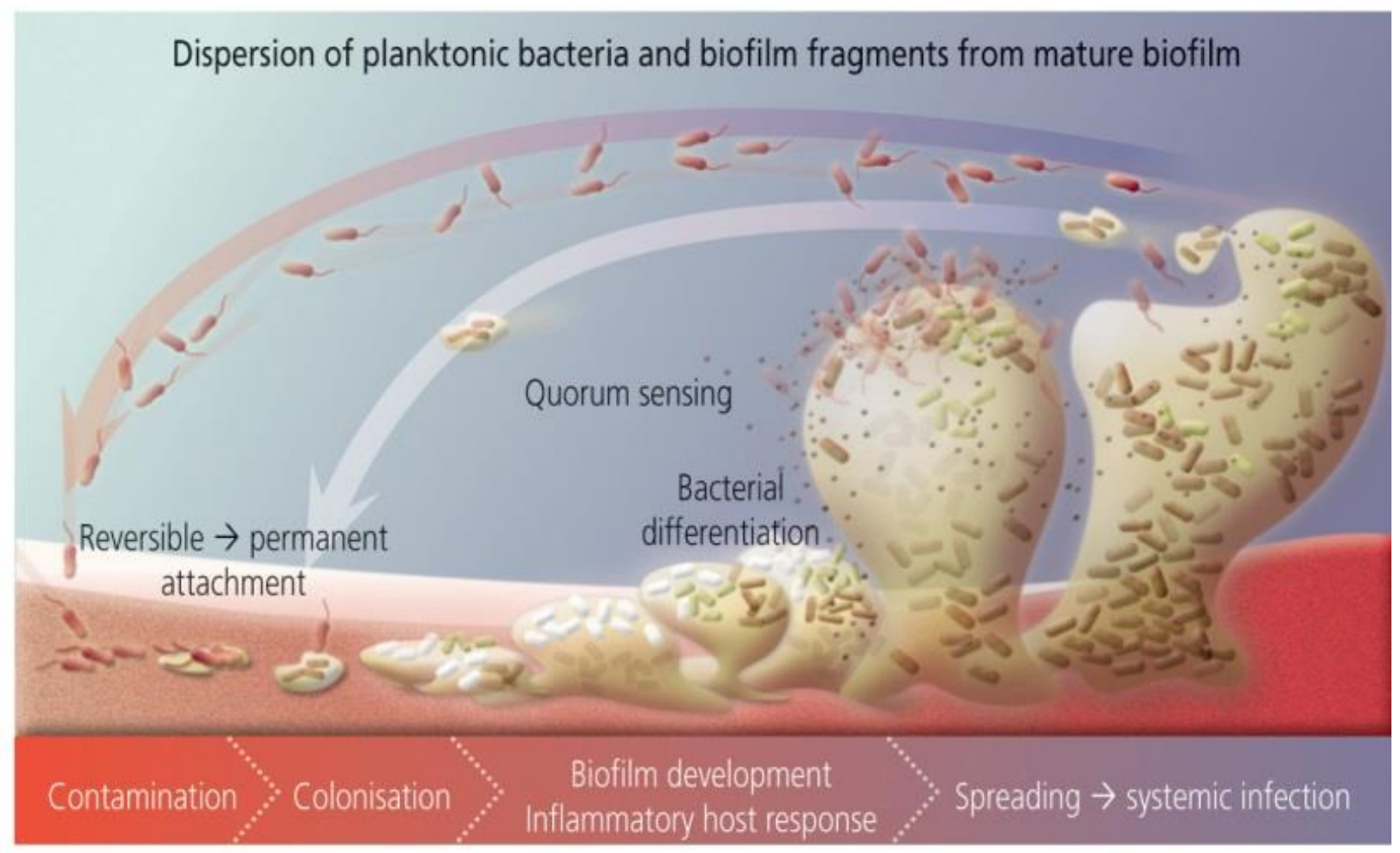

Figure 11: Biofilm formation (Courtesy of Dr. John G. Thomas)

\section{Microscopy, Photography, and Biofilm Coverage Ranking Determination:}

Additional pegs were stained in crystal violet for 30 seconds. Pegs were placed on microscope slides in emersion oil and viewed at 5X magnification via Zeiss microscope. Representative photographs were taken. Determination of biofilm coverage was performed by computer analysis using Image $\mathrm{J}$ software. Appropriate information was obtained to set the scale of measurement. An 8-bit reproduction of the original image was created. The threshold value of pixels was adjusted to gain representation of the area of biofilm coverage. The computer software then generated an outline image of the area covered including any holes in the selected area and measurement was made. An average area was obtained and statistically analyzed. 


\section{Laser Confocal Microscopy Protocol:}

Extracted human single rooted anterior teeth were obtained from a local private dental practice which had been extracted as part of a normal dental treatment plan within the last 12 months. The teeth had been stored in full strength $\mathrm{NaOCl}$, glycerin, and distilled $\mathrm{H}_{2} \mathrm{O}$. The teeth were accessed with sterile 330 and Endo-Z burs in a high speed air-driven handpiece under high speed evacuation and water spray. The teeth were then instrumented to length with EndoSequence ${ }^{\circledR}$ (Brassler) \#40/06 rotary files at 550rpm. Sterile $\mathrm{H}_{2} 0$ was used for lubrication and the procedure was performed on a bench top in the operator's hand. The prepared teeth were radiographed, placed in a plastic container of sterile water (provided by WVU SOD central dispensing and sterilization department), and were then autoclaved. A jig was created with PVS heavy body putty (3M ESPE) to be used as a mold so that blue acrylic custom tray material could be poured around the sterile instrumented teeth approximately $6 \mathrm{~mm}$ up the root surface. See figures 18 and 19. The following irrigation protocols were conducted with a new $3 \mathrm{~mL}$ Monoject ${ }^{\circledR}$ syringe equipped with a 30 gauge ProRinse ${ }^{\circledR}$ side-venting needle. $3 \mathrm{~mL}$ of each solution were utilized for the time indicated. A new irrigation syringe and needle were used with each trial.

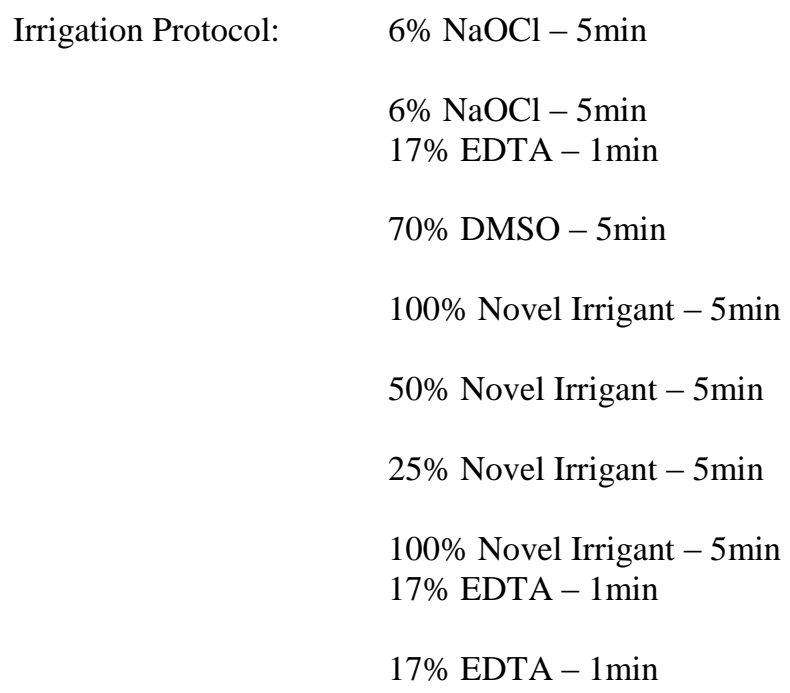


The teeth were then stained with an appropriate laser fluorescent confocal microscopy stain (Rhodamine B). $0.1 \mathrm{mM}$ of Rhodamine B solution was prepared by adding $23.95 \mathrm{mg}$ of Rhodamine B dye (Aldrich Chemicals, Milwaukee, WI) to 500ml of deionized water. The dye was injected into the specimens with an additional new $3 \mathrm{~mL}$ Monoject ${ }^{\circledR}$ syringe with 30 gauge ProRinse $^{\circledR}$ side-venting needle. The teeth were stained with the $0.1 \mathrm{mM}$ Rhodamine B and stored in glass screw top vials for 24 hours, with no subsequent rinsing. See figure 19. Rhodamine B from the solution incorporates into demineralized tooth structure, but does not penetrate intact tooth structure. After 24 hours, the teeth were sectioned mid-root with a slow speed circular saw equipped with a diamond disc blade. A second cut was then made adjacent to the initial cut to obtain a $0.75 \mathrm{~mm}$ circular cross section. The sections were then placed on a T-4 heated coverslip and viewed with a Zeiss laser confocal microscope using helium and neon gas at $543 \mathrm{~nm}$ to excite the Rhodamine B. Images were obtained at 10X and keeping each specimen oriented in a similar manner.
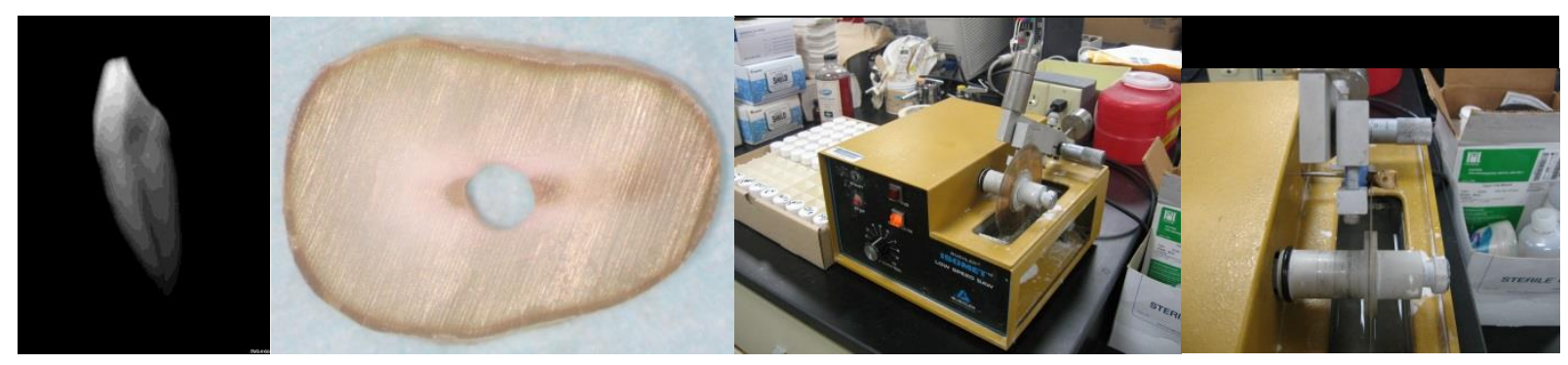

Figure 12: Radiograph of prepared sample, cross-section of sample, slow speed diamond disc saw 


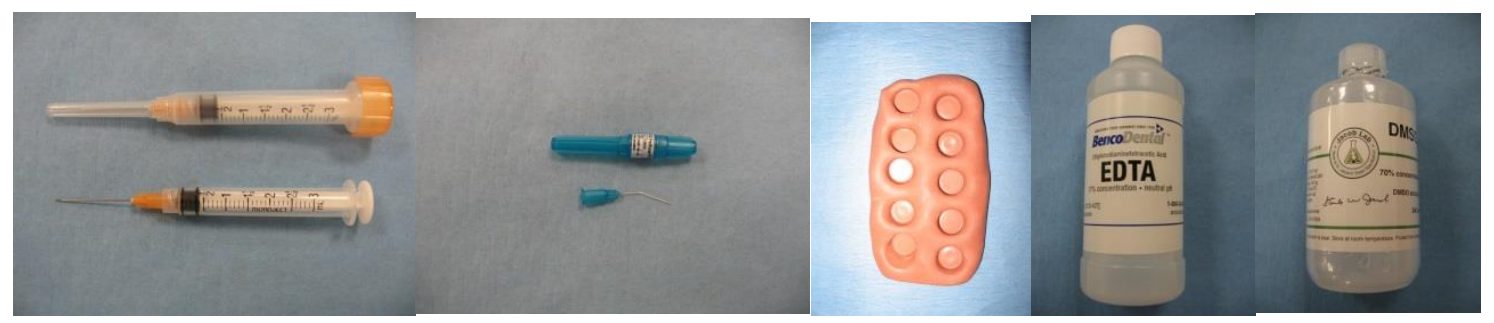

Figure 13: Irrigation armamentarium, putty jig, EDTA, DMSO

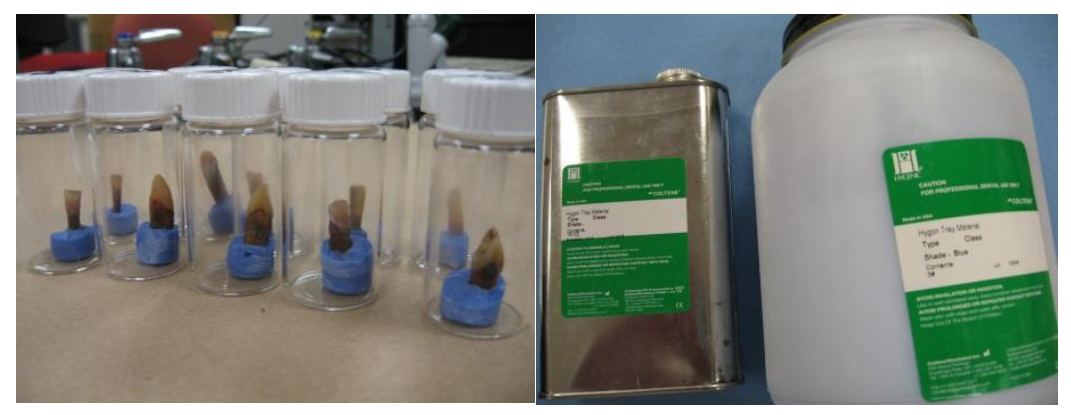

Figure 14: Prepared samples ready for sectioning, blue acrylic material used to mount teeth 


\section{Chapter 4}

\section{$\underline{\text { Results }}$}

NMR: Samples of Clindamycin $\mathrm{HCl}$, Nystatin, in a 1:1 mixture were examined immediately after preparation, after standing at $25^{\circ} \mathrm{C}$ for $24 \mathrm{~h}$, after 1 week, and after 1 week plus heating to $50^{\circ} \mathrm{C}$. All three samples were stable and remained unchanged by NMR. Figure 20 displays the partial proton NMR spectra of the three samples taken after 1 week. The region displayed corresponds to the proton adjacent to the chlorine of clindamycin, which is subject to replacement by the amino group in Nystatin. The set of four peaks (ratio 1:3:3:1, the quartet) is due to this proton. The single peak in the Nystatin sample that is observed in this region is due to proton on the carbon that bears the sugar residue. The spectrum obtained on the combined sample is simply the sum of the two spectra (Clindamycin $\mathrm{HCl}$ and Nystatin) indicating that no reaction occurred. Examination of the full spectrum of the individual and combined samples indicated that no alternative reactions occurred (i.e., the spectrum obtained for Clindamycin $\mathrm{HCl} / \mathrm{Nystatin}$ was merely the sum of those for Clindamycin $\mathrm{HCl}$ and Nystatin, Data not shown.

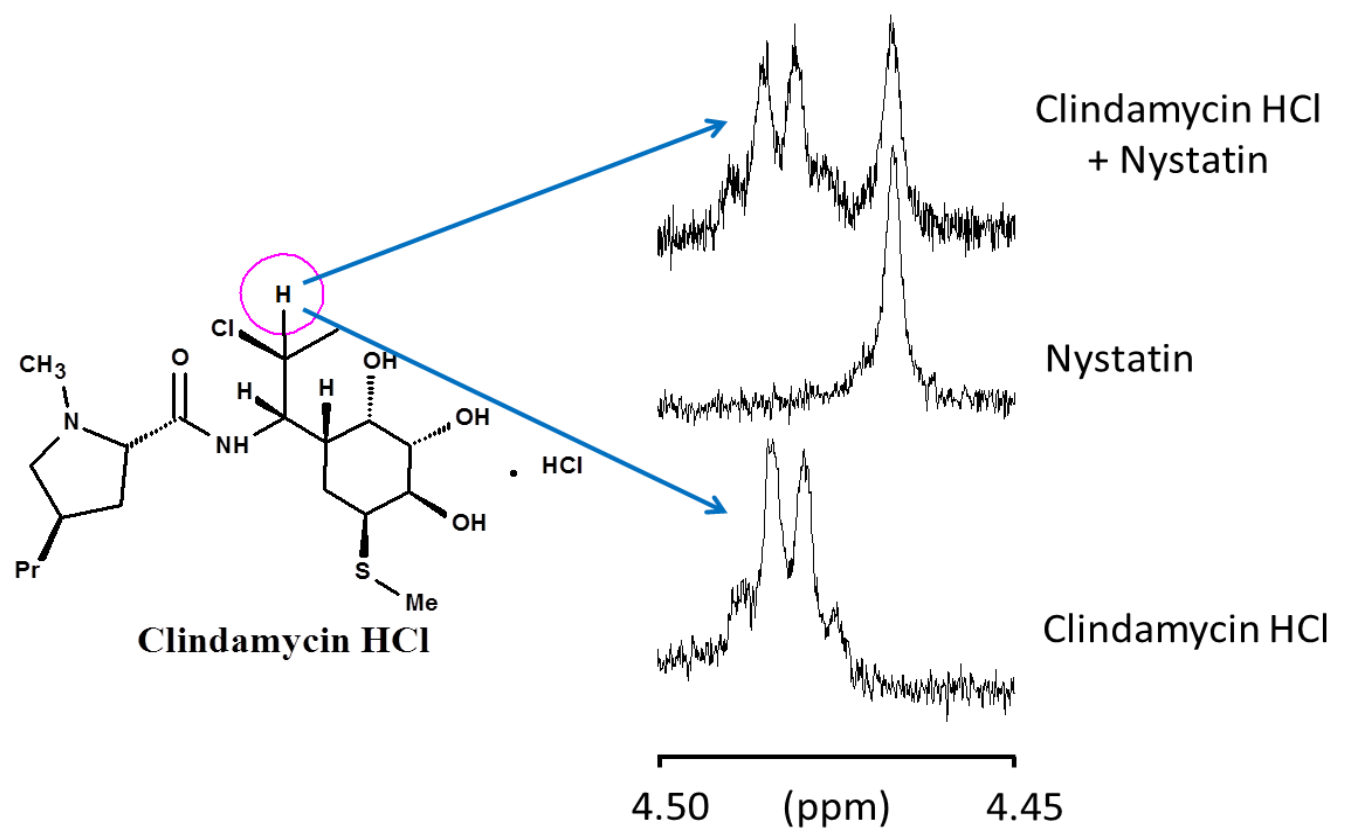

Figure 15: Partial NMR spectrum of Clindamycin HCl, Nystatin, and a 1:1 mixture in the range of $4.45-4.50 \mathrm{ppm}$. The quartet in spectra of samples with clindamycin is due to the circled proton. 
ZOI: The ZOI studies indicated that the novel irrigant was effective against E. coli, S. aureus, and $C$. albicans both in the planktonic form (Mueller-Hinton) and biofilm phenotype (poloxamer) in all concentrations $(25,50$, and $100 \%) .6 \% \mathrm{NaOCl}$ was also effective against these organisms. The novel irrigant did not appear to exhibit antimicrobial activity against the $P$. aeruginosa and Lactobacillus. The $\mathrm{NaOCl}$ did exhibit antimicrobial activity against $P$. aeruginosa and Lactobacillus; however, after the 48 hour reading there appeared to be colonies forming back inside the ZOI. Interesting to note was the fact that the solvent alone $(70 \%$ DMSO) exhibited antibacterial activity against $E$. coli in both the planktonic and biofilm phenotype and exhibited activity against the biofilm phenotype of the C. albicans trial. All concentrations of the Novel Irrigant produced a "double zone" of inhibition after 48 hours in both Mueller-Hinton and poloxamer trials of S. aureus. 


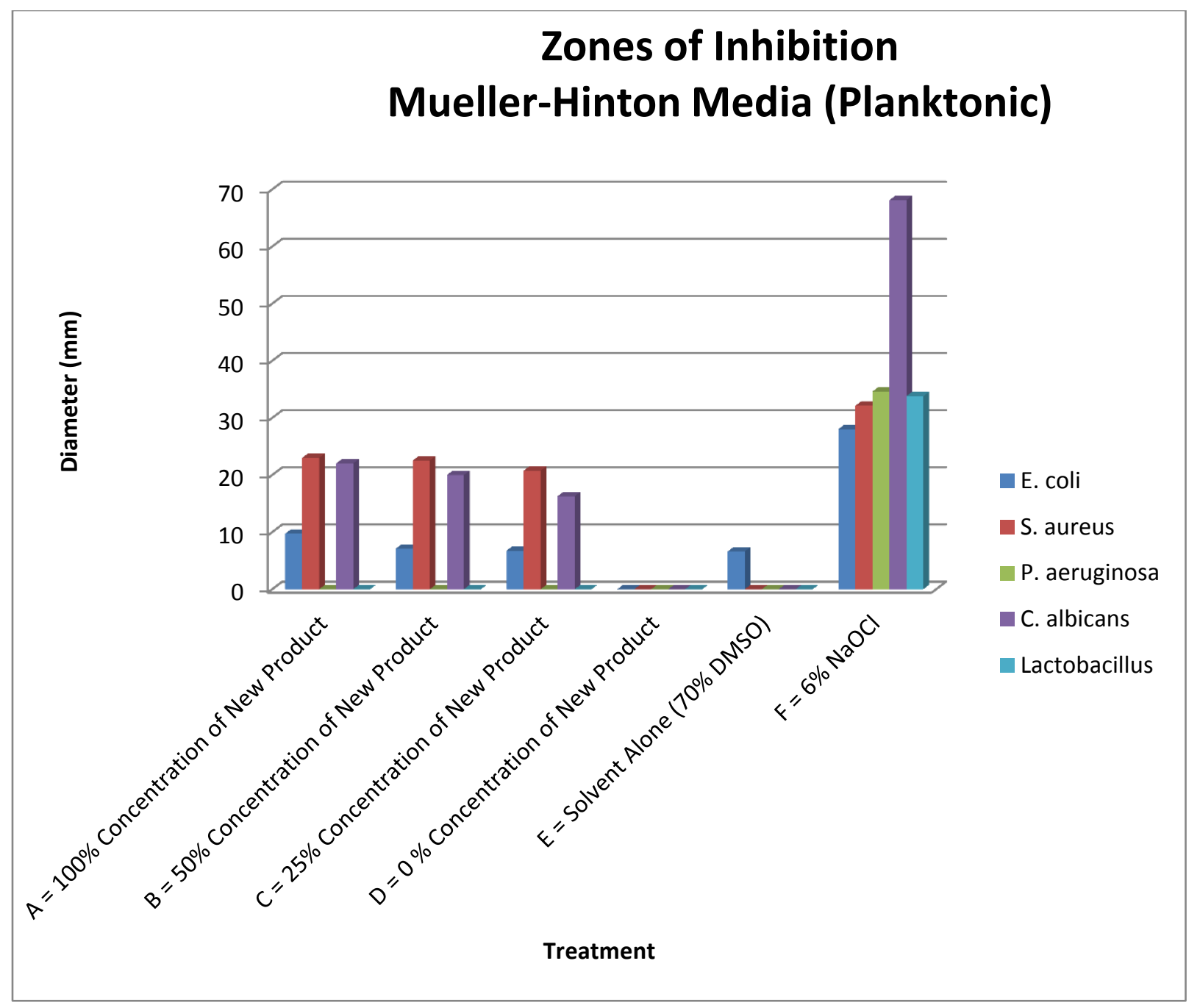

Figure 16: ZOI Results of all 5 microorganisms tested, Mueller-Hinton Media (Planktonic) 


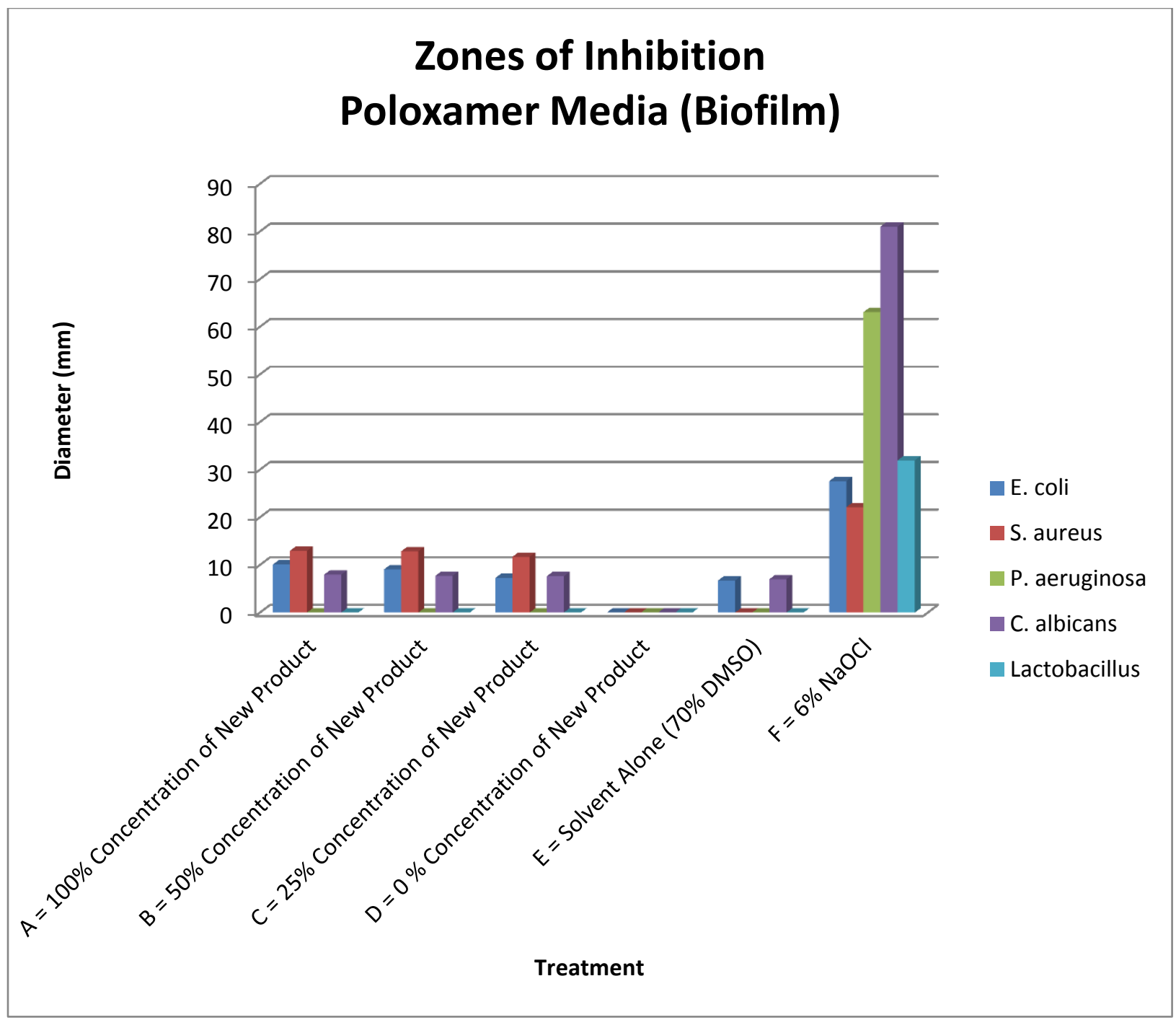

Figure 17: ZOI Results of all 5 microorganisms tested, Poloxamer Media (Biofilm)

Five additional ZOI trials were performed with $C$. albicans as the test organism and the results were averaged. 


\begin{tabular}{|l|r|r|r|r|r|r|r|r|r|r|r|r|}
\hline & M-H & POLX & M-H & POLX & M-H & POLX & M-H & POLX & M-H & POLX & M-H & POLX \\
\hline A1 & 20.15 & 11.54 & 23.18 & 11.41 & 23.04 & 10.79 & 23.57 & 10.15 & 22.83 & 8.49 & 22.53 & 7.47 \\
\hline A2 & 22.08 & 11.07 & 23.01 & 10.77 & 24.4 & 11.75 & 25.04 & 11.46 & 22.52 & 9.57 & 21.52 & 8.46 \\
\hline B1 & 15.67 & 9.9 & 18.03 & 10.63 & 20.18 & 9.98 & 19.82 & 10.61 & 18.43 & 9.28 & 20.41 & 7.24 \\
\hline B2 & 17.03 & 9.74 & 18.51 & 10.66 & 21.58 & 12.03 & 20.79 & 11.08 & 19.39 & 10.27 & 19.59 & 8.23 \\
\hline C1 & 14.97 & 8.23 & 15.9 & 8.78 & 16.75 & 10.42 & 15.85 & 8.47 & 16.27 & 7.78 & 16.39 & 7.13 \\
\hline C2 & 15.42 & 9.32 & 15.26 & 9.23 & 17.88 & 9.86 & 17.55 & 9.49 & 16.03 & 8.63 & 16.17 & 8.15 \\
\hline D1 & 0 & 0 & 0 & 0 & 0 & 0 & 0 & 0 & 0 & 0 & 0 & 0 \\
\hline D2 & 0 & 0 & 0 & 0 & 0 & 0 & 0 & 0 & 0 & 0 & 0 & 0 \\
\hline E & 0 & 7.76 & 0 & 7.6 & 0 & 8.43 & 0 & 8.41 & 0 & 7.53 & 0 & 7 \\
\hline F & 76.68 & 63.49 & 73.4 & 75.33 & 61.45 & 78.53 & 62.24 & 82.24 & 66.17 & 77.06 & 68.11 & 81.06 \\
\hline
\end{tabular}

Table 1: Zones of Inhibition Study, C. albicans, 24-hr incubation period (all measurements in $\mathbf{~ m m ) ~}$

$A=100 \%$ Concentration of New Product

$B=50 \%$ Concentration of New Product

$C=25 \%$ Concentration of New Product

$\mathrm{D}=0 \%$ Concentration of New Product (control)

$\mathrm{E}=$ Solvent Alone (70\% DMSO)

$\mathrm{F}=6 \% \mathrm{NaOCl}$

$\mathrm{M}-\mathrm{H}=$ Mueller Hinton Media (Planktonic)

POLX = Poloxamer Media (Biofilm)

\begin{tabular}{|l|r|r|}
\hline & \multicolumn{2}{|c|}{ (C. albicans) } \\
\hline & Muller - Hinton & Poloxamer \\
\hline A Avg & 22.8225 & 10.244167 \\
\hline Std Dev A & 1.270004474 & 1.4289313 \\
\hline B Avg & 19.11916667 & 9.9708333 \\
\hline Std Dev B & 5.53882335 & 1.2756992 \\
\hline C Avg & 16.20333333 & 8.7908333 \\
\hline Std Dev C & 0.865262265 & 0.9240864 \\
\hline D Avg & 0 & 0 \\
\hline Std Dev D & 0 & 0 \\
\hline E Avg & 0 & 7.7883333 \\
\hline Std Dev E & 0 & 0.5518484 \\
\hline F Avg & 68.00833333 & 76.285 \\
\hline Std Dev F & 6.065362039 & 6.7605821 \\
\hline
\end{tabular}

Table 2: ZOI results of C. albicans trials (AVG and STD DEV) 


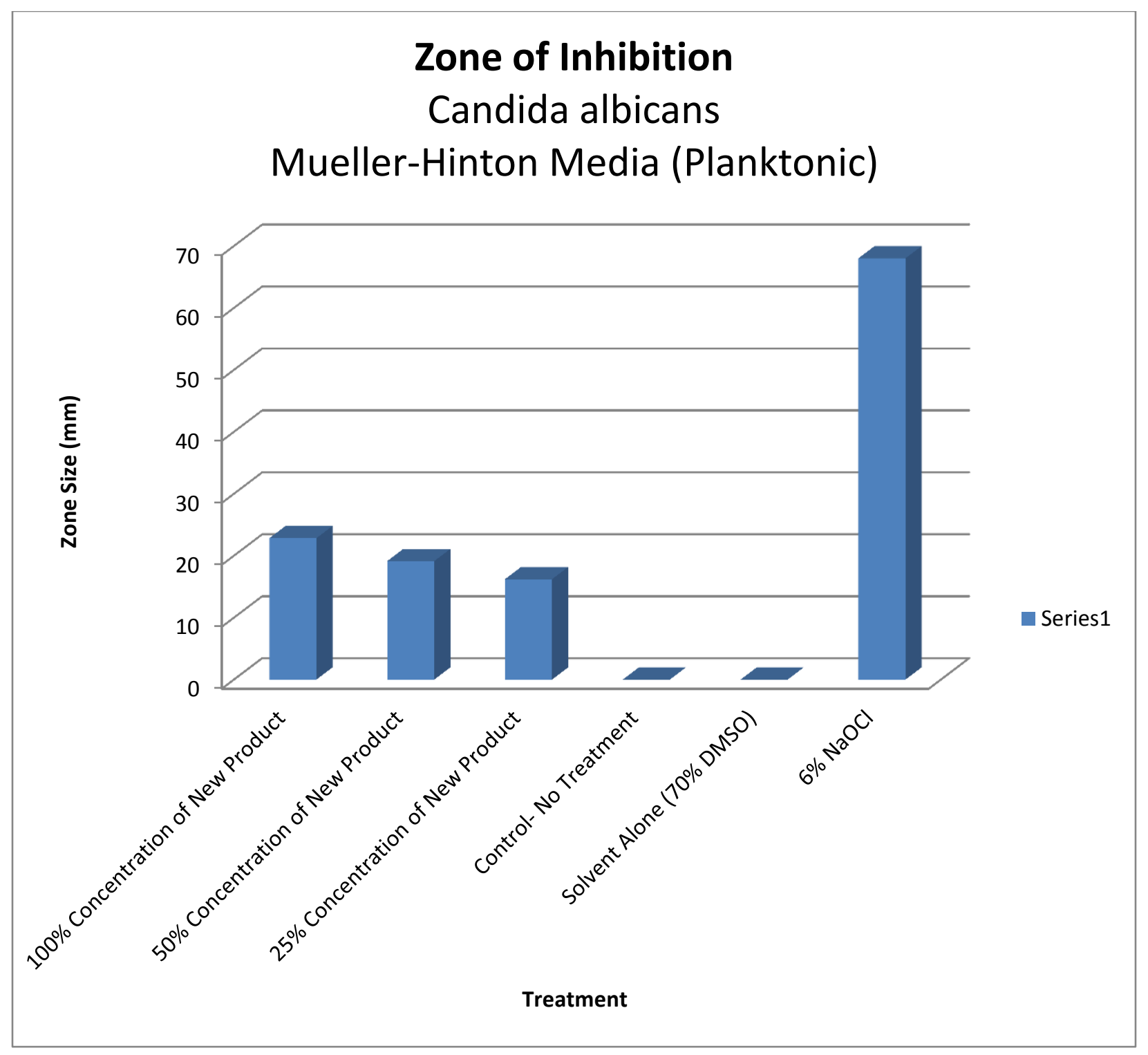

Figure 18: ZOI Results $C$. albicans (Average of trials n=12), Mueller-Hinton Media (Planktonic) 


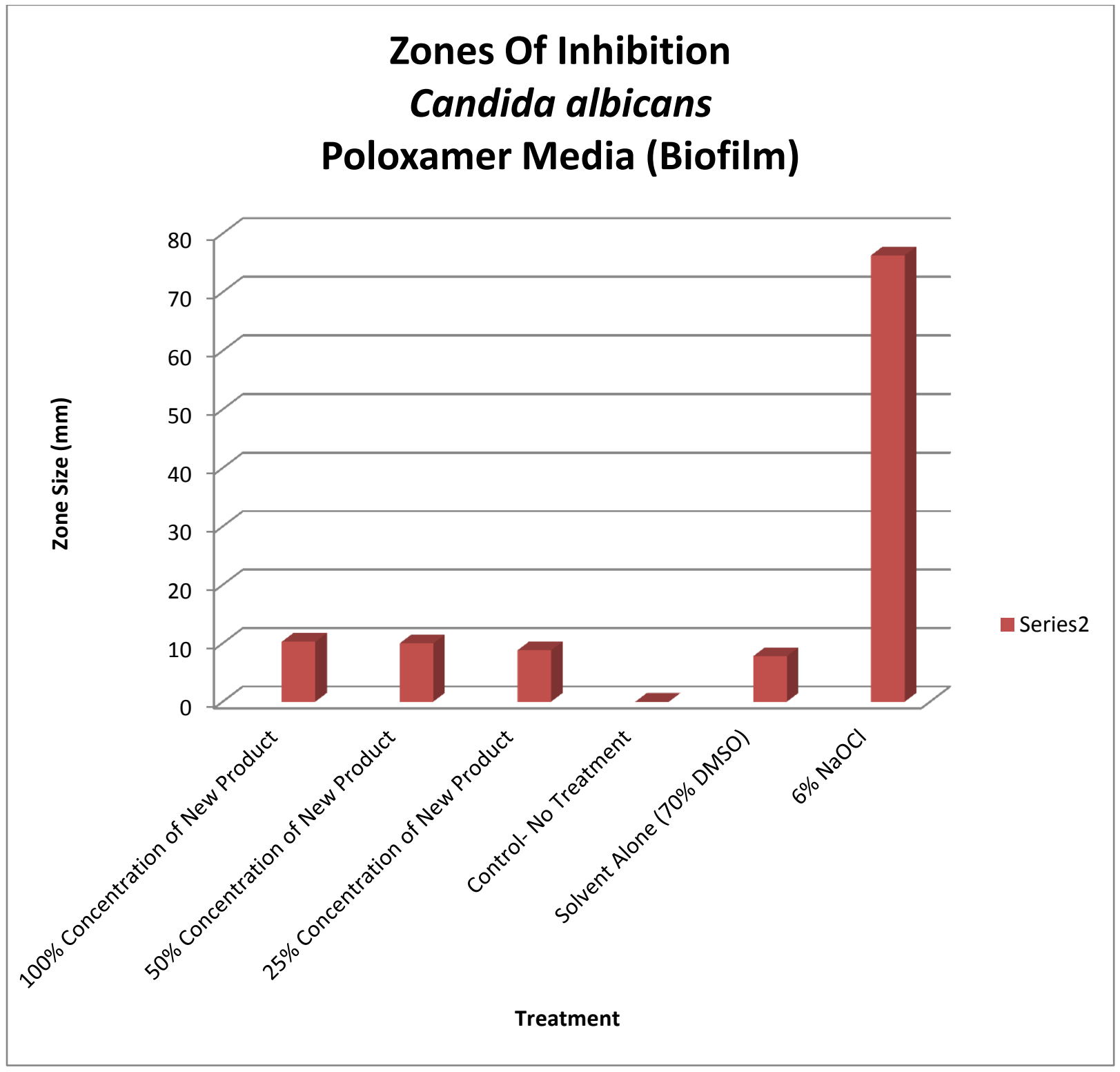

Figure 19: ZOI Results C. albicans (Average of trials n=12) Poloxamer Media (Biofilm)

The $6 \% \mathrm{NaOCl}$ was significantly more effective than the $100 \%, 50 \%$, and $25 \%$ concentrations of the novel irrigant as well as the $70 \%$ DMSO alone in the ZOI study using the Mueller-Hinton agar plates $(\mathrm{p}$-Value <.0001). The $100 \%$ concentration of the novel irrigant was significantly more effective than the solvent alone and the $25 \%$ concentration of the novel irrigant ( $\mathrm{p}$-Value $<.0001$ ) as well as $50 \%$ concentration (p-Value 0.0010$)$. The $50 \%$ concentration of novel 
irrigant was more effective than the solvent alone (p-Value <.0001) and 25\% concentration (pValue 0.0160 ). The $25 \%$ concentration was significantly more effective than the solvent alone (p-Value <.0001).

CFU: The CFU assay showed that there was no significant difference in the anti-microbial ability of $6 \% \mathrm{NaOCl}$ when compared to $100 \%$ concentration of the novel irrigant.

\begin{tabular}{|c|c|c|c|c|c|c|c|c|c|c|c|c|c|c|c|c|c|c|}
\hline Dilution & $10^{-2}$ & & & & & & $10^{-4}$ & & & & & & $10^{-6}$ & & & & & \\
\hline Trial & 1 & 2 & 3 & 4 & 5 & 6 & 1 & 2 & 3 & 4 & 5 & 6 & 1 & 2 & 3 & 4 & 5 & 6 \\
\hline A & 93 & 71 & 56 & 102 & 68 & 87 & 2 & 0 & 0 & 3 & 0 & 0 & 0 & 0 & 0 & 0 & 0 & 0 \\
\hline B & 183 & 135 & 219 & 237 & 196 & 272 & 4 & 3 & 5 & 7 & 2 & 6 & 0 & 0 & 0 & 1 & 0 & 0 \\
\hline C & 140 & 193 & 89 & 173 & 87 & 67 & 3 & 5 & 2 & 4 & 3 & 3 & 0 & 1 & 0 & 1 & 1 & 1 \\
\hline $\mathrm{D}$ & 500 & 500 & 500 & 500 & 500 & 500 & 37 & 42 & 66 & 49 & 56 & 29 & 1 & 3 & 4 & 1 & 3 & 1 \\
\hline$E$ & 6 & 11 & 8 & 5 & 13 & 1 & 2 & 3 & 1 & 0 & 1 & 0 & 0 & 1 & 0 & 0 & 0 & 0 \\
\hline $\mathrm{F}$ & 0 & 0 & 0 & 0 & 0 & 0 & 0 & 0 & 0 & 0 & 0 & 0 & 0 & 0 & 0 & 0 & 0 & 0 \\
\hline
\end{tabular}

Table 3: CFU Assay, $C$. albicans Results of each trial $(n=6)$, number of colonies present at given dilutions.

$$
\begin{aligned}
& A=100 \% \text { Concentration of New Product } \\
& B=50 \% \text { Concentration of New Product } \\
& C=25 \% \text { Concentration of New Product } \\
& D=0 \% \text { Concentration of New Product } \\
& E=\text { Solvent Alone }(70 \% \text { DMSO) } \\
& F=6 \% \mathrm{NaOCl}
\end{aligned}
$$

500 signifies that the colonies were too numerous to count and was used for statistical purposes 


\begin{tabular}{|c|c|c|c|c|}
\hline Dilution & AVG & $10^{-2}$ & $10^{-4}$ & $10^{-6}$ \\
\hline $\begin{array}{l}A=100 \% \text { Concentration of } \\
\text { New Product }\end{array}$ & $8.33 * 10^{3}$ & 79.5 & 0.833333 & 0 \\
\hline $\begin{array}{l}B=50 \% \text { Concentration of } \\
\text { New Product }\end{array}$ & $4.5 * 10^{4}$ & 207 & 4.5 & 0.166667 \\
\hline $\begin{array}{l}C=25 \% \text { Concentration of } \\
\text { New Product }\end{array}$ & $3.3^{*} 10^{4}$ & 124.8333 & 3.333333 & 0.666667 \\
\hline $\begin{array}{l}D=0 \% \text { Concentration of } \\
\text { New Product }\end{array}$ & $4.65 * 10^{5}$ & 500 & 46.5 & 2.166667 \\
\hline $\begin{array}{l}\text { E = Solvent Alone }(70 \% \\
\text { DMSO) }\end{array}$ & $1.16 * 10^{4}$ & 7.333333 & 1.166667 & 0.166667 \\
\hline $\mathrm{F}=6 \% \mathrm{NaOCl}$ & 0 & 0 & 0 & 0 \\
\hline
\end{tabular}

Table 4: Average of CFU Assay Results C. albicans 


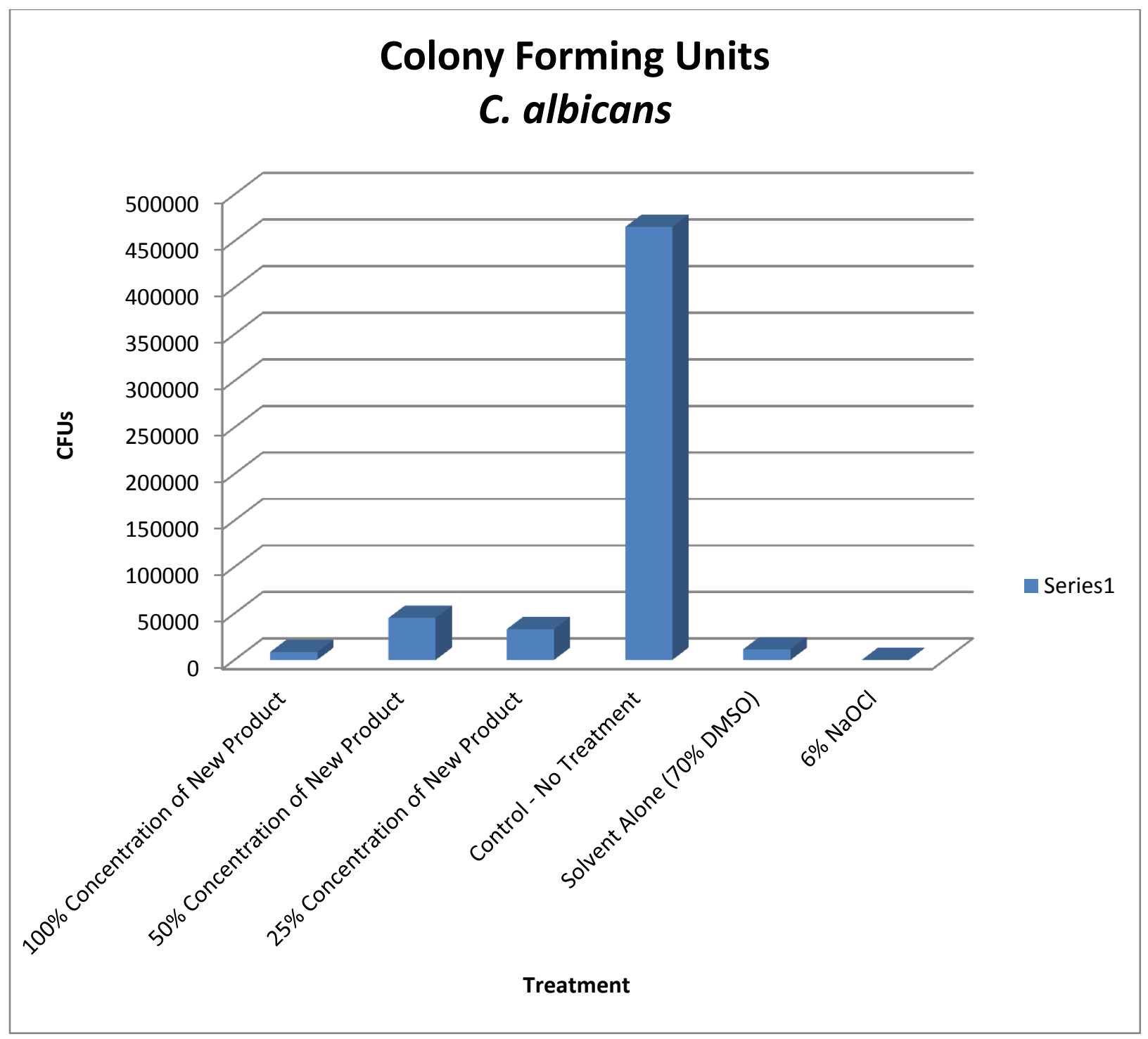

Figure 20: Graph of CFU Assay C. albicans Results

Optical Density Absorbance: The absorbance assay showed that the $100 \%$ concentration of the novel irrigant was more effective than $6 \% \mathrm{NaOCl}$ and all other concentrations of the novel irrigant at biofilm removal. The solvent alone showed similar results. The positive control did not respond as expected, this could be due to the fact that untreated biofilm is easily removed from the plastic pegs by the glacial acetic acid. A lower absorbance value was indicative of greater solution anti-microbial activity. 


\begin{tabular}{|l|r|}
\hline Optical Density Absorbance Data recorded at 562nm \\
\hline$A=100 \%$ Concentration of New Product & C. albicans \\
\hline$B=50 \%$ Concentration of New Product & 0.786 \\
\hline$C=25 \%$ Concentration of New Product & 0.83 \\
\hline$D=0 \%$ Concentration of New Product & 0.818 \\
\hline$E=$ Solvent Alone (70\% DMSO) & 0.765 \\
\hline F $=6 \% \mathrm{NaOCl}$ & 0.787 \\
\hline
\end{tabular}

Table 5: Results of Absorbance Assay, C. albicans

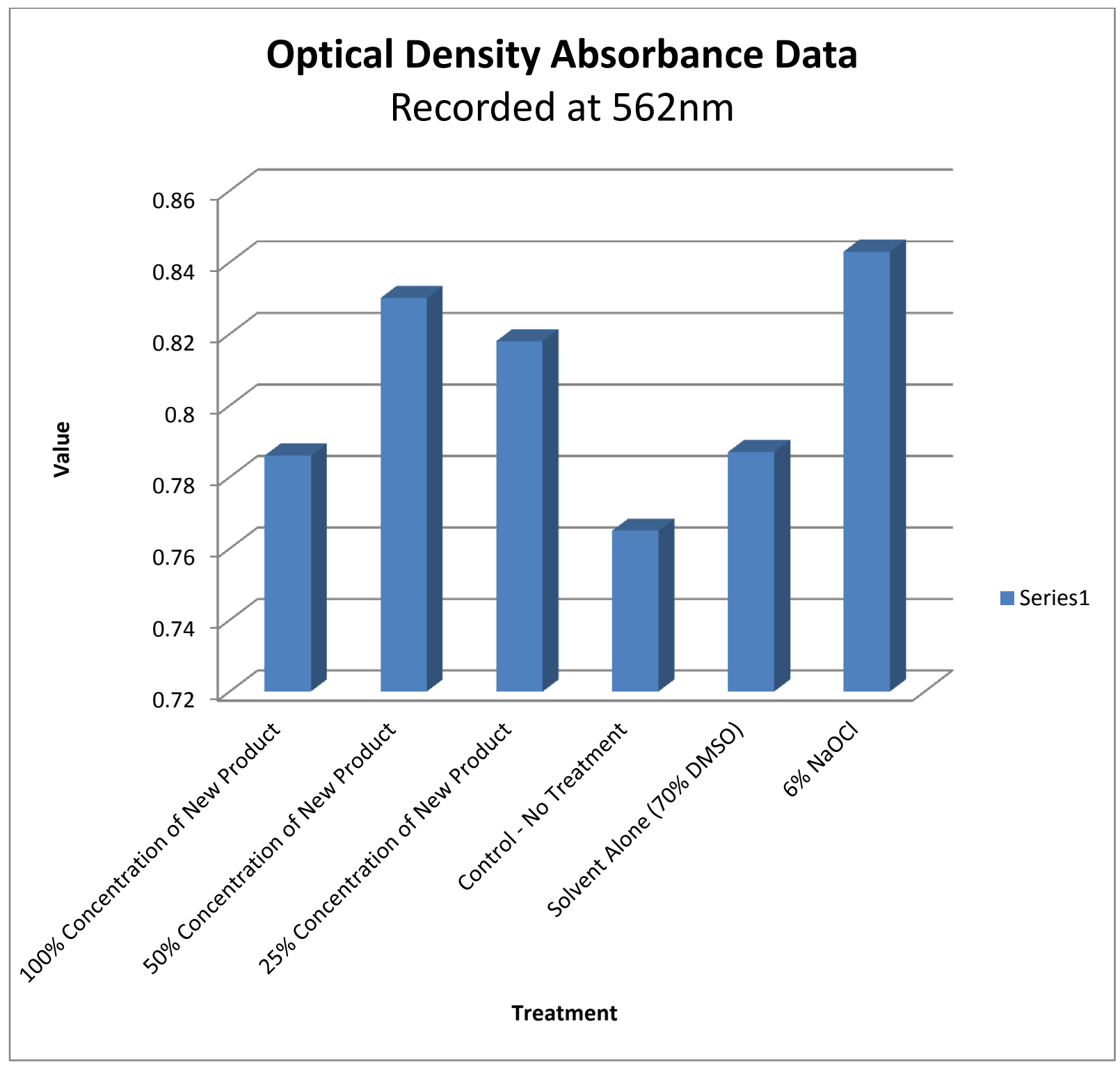

Figure 21: Graph showing results of Optical Density Absorbance Assay, C. albicans 
SEM Photography: The SEM assay confirmed the presence of biofilm on the pegs of our Calgary Biofilm Device. Different stages of biofilm growth were observed ranging from budding yeast cells, to pseudo-hyphae, and the more pathogenic hyphae phase. This assay clearly demonstrated the bi-phasic nature of this eukaryotic organism, C. albicans.

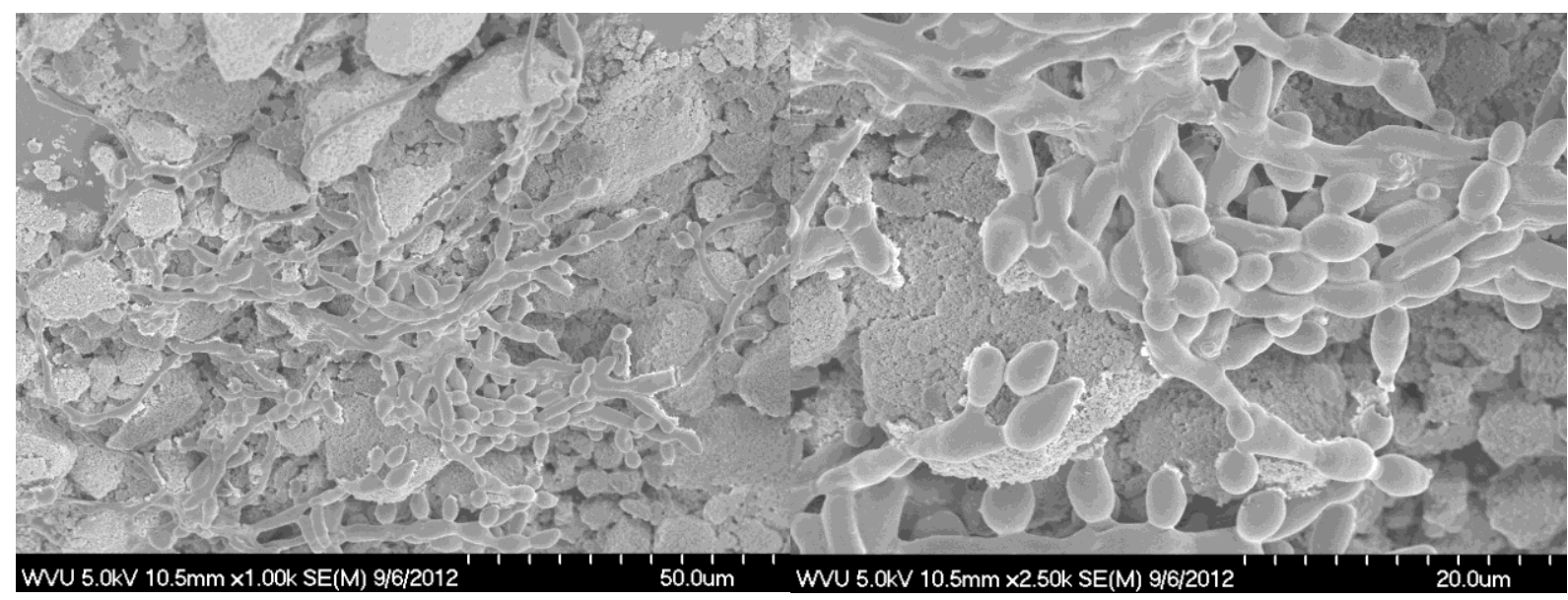

Figure 22: Bi-phasic budding yeast (Stage III), hyphae and pseudo-hyphae (Stage I)

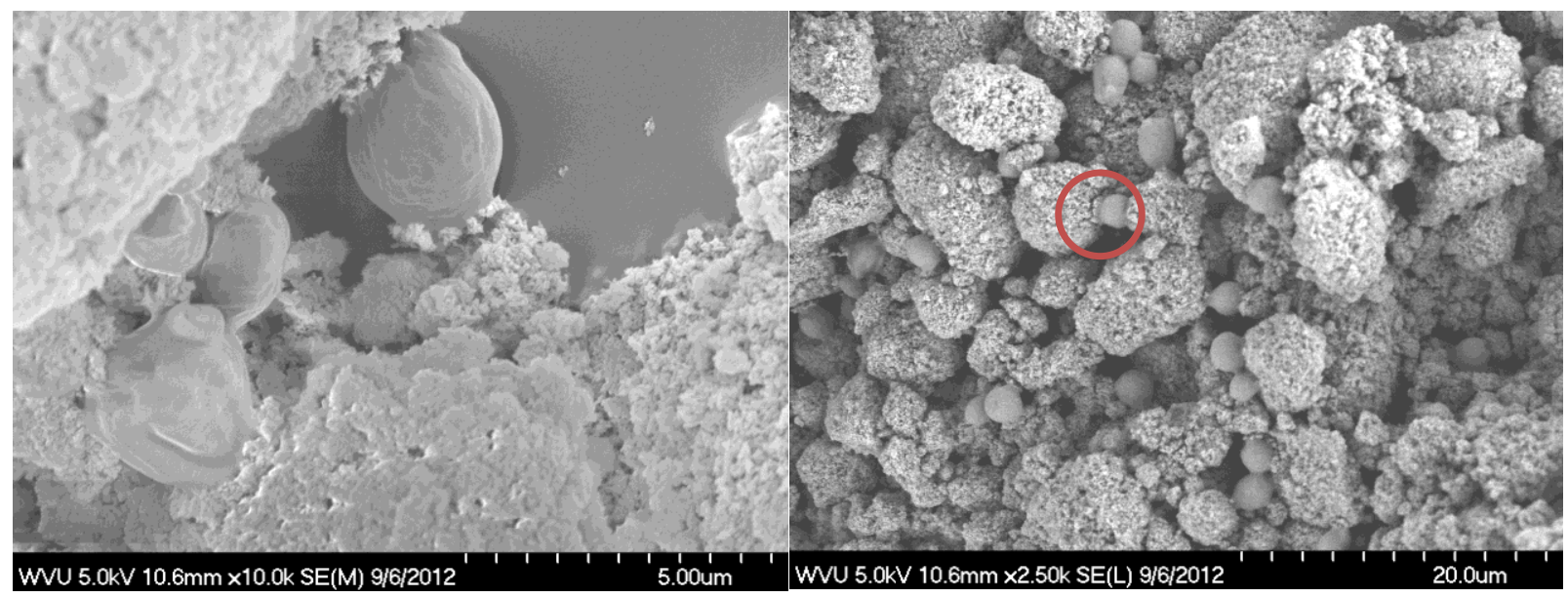

Figure 23: Isolated single yeast cells 


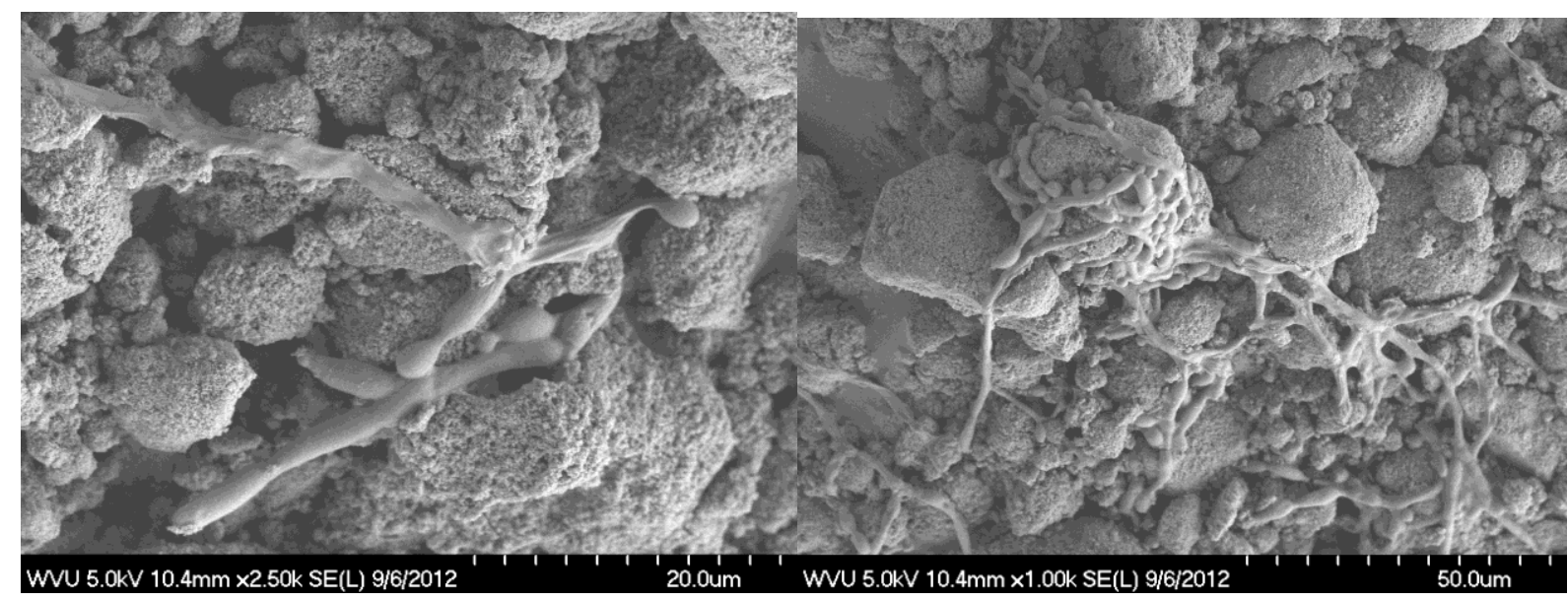

Figure 24: Pseudo hyphae, penetrating hyphae, example of bi-phasic eukaryote

Coverage Area Assay: The results of the biofilm coverage assay showed that $100 \%$ and $25 \%$ concentration of the novel irrigant were twice as effective at removing biofilm from the pegs of the Calgary Biofilm Device when compared to $\mathrm{NaOCl}$. The $100 \%$ concentration of the novel irrigant was significantly better than $\mathrm{NaOCl}$ (p-Value 0.0059 ). 25\% concentration was also significantly better than $\mathrm{NaOCl}$ (p-Value 0.0085). There was no significant difference in the amount of biofilm coverage remaining when comparing the three concentrations of the novel irrigant to each other as well as the solvent (70\% DMSO) alone. The corresponding images on the following pages are in order from left to right, the original crystal violet stained image (as viewed under the microscope) that has been cropped for consistency in all samples, an 8-bit converted black and white image, the image with the threshold value adjusted to be inclusive of the area of biofilm coverage, and computer analysis of area measurement. 


\section{Area of Candida albicans Biofilm Coverage On Peg of Calgary Biofilm Device}

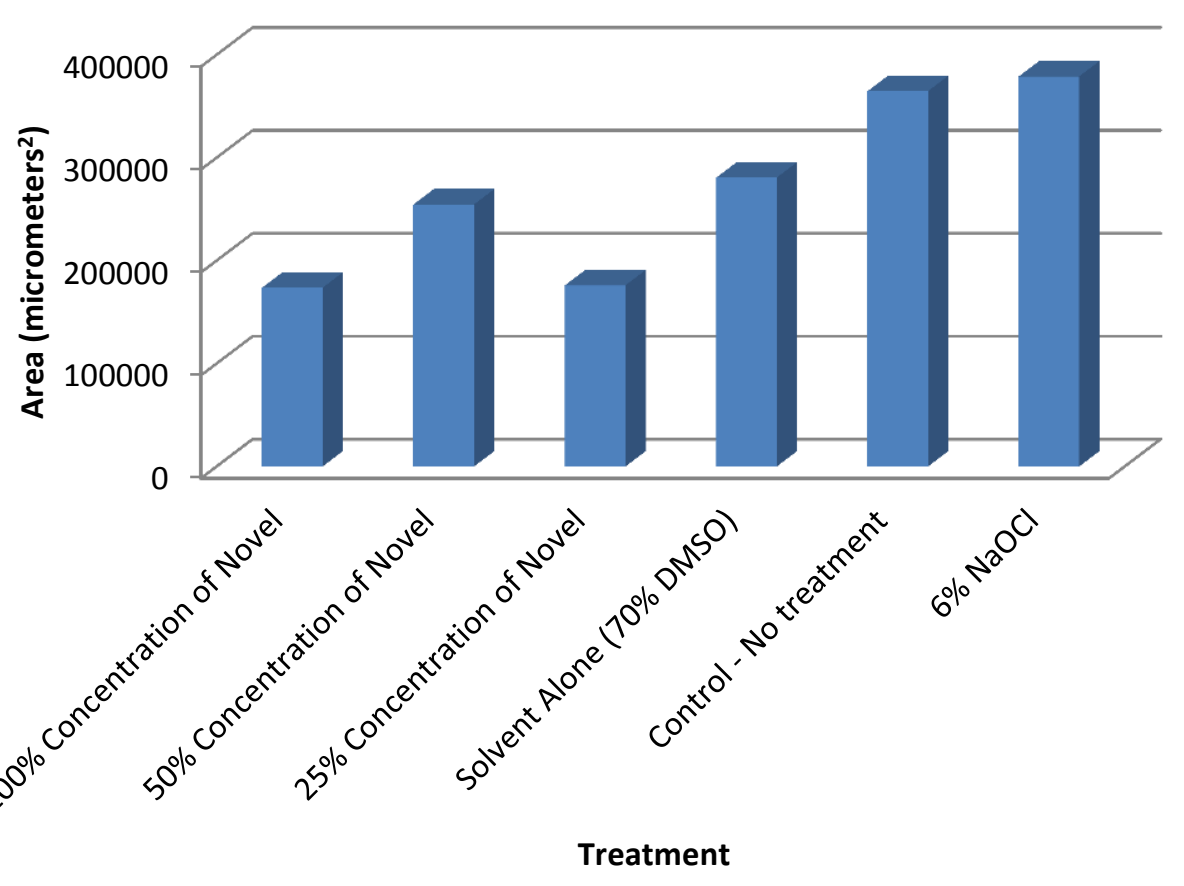

Figure 25: Graph of Biofilm Coverage Area Assay, C. albicans 

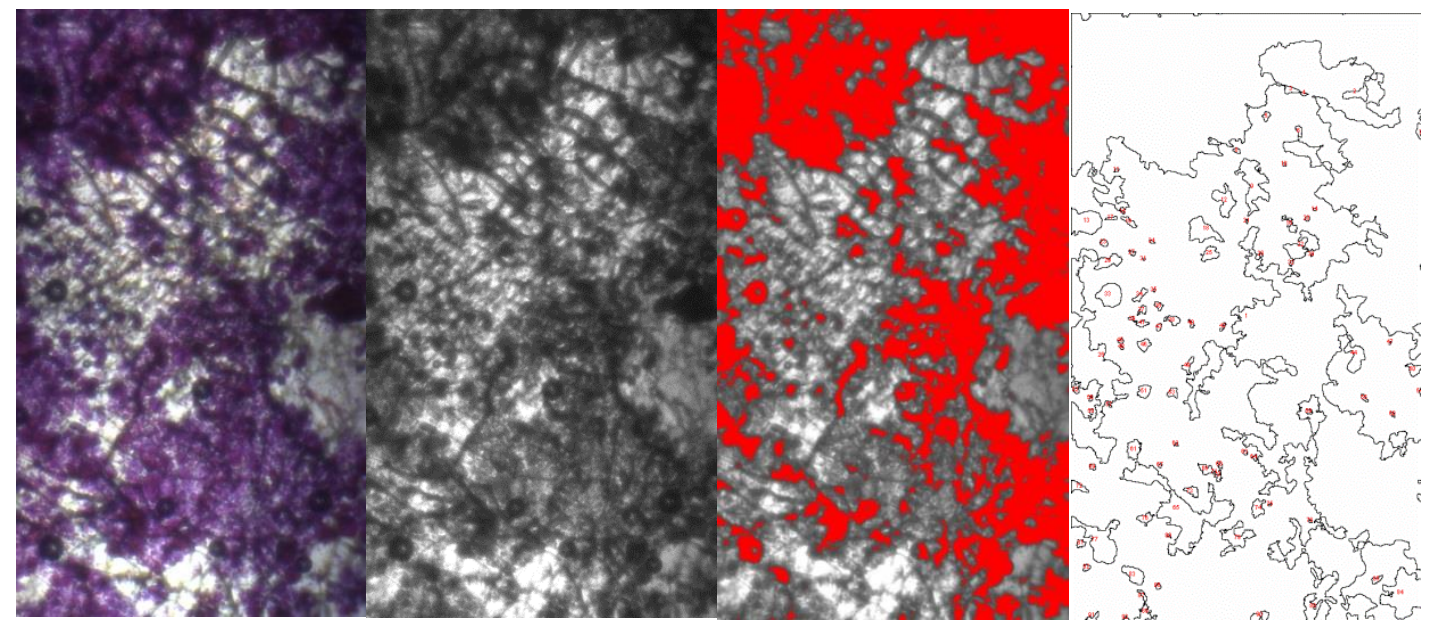

Figure 26: 100\% Concentration of Novel Irrigant: The following represents, in order from left to right, original image obtained from the Zeiss Microscope at 5X, 8-bit Black and White image, Image adjusted with threshold value, and computer analysis of coverage area

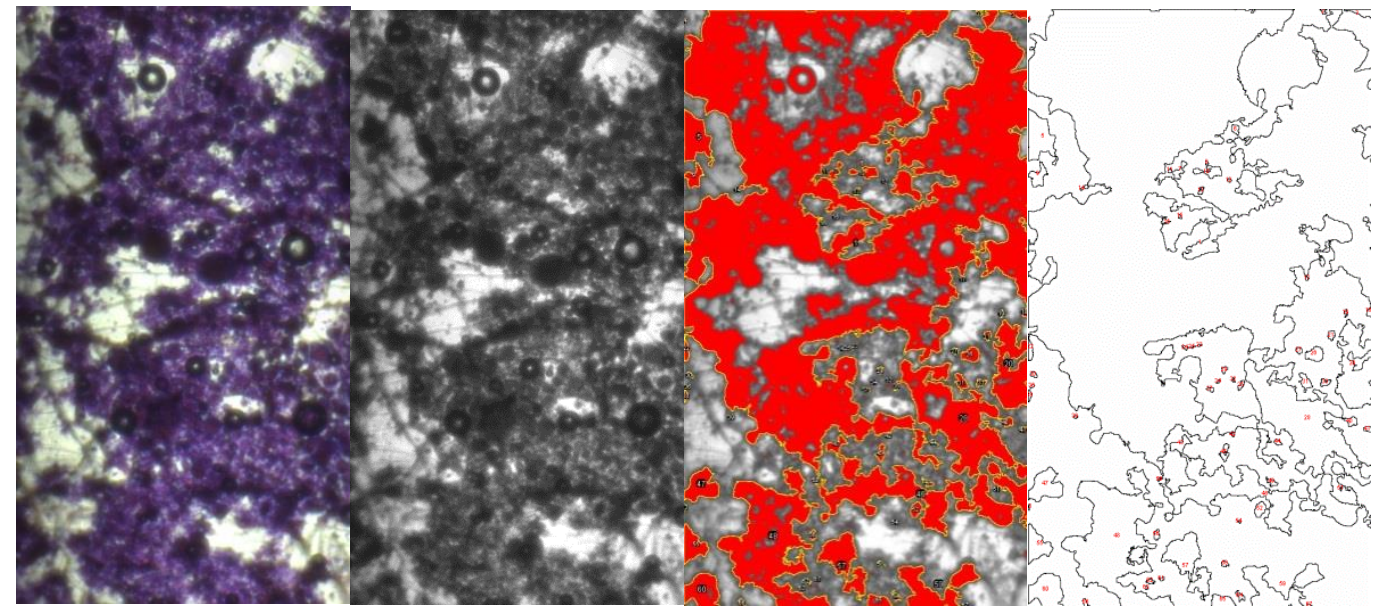

Figure 27: 50\% Concentration of Novel Irrigant 

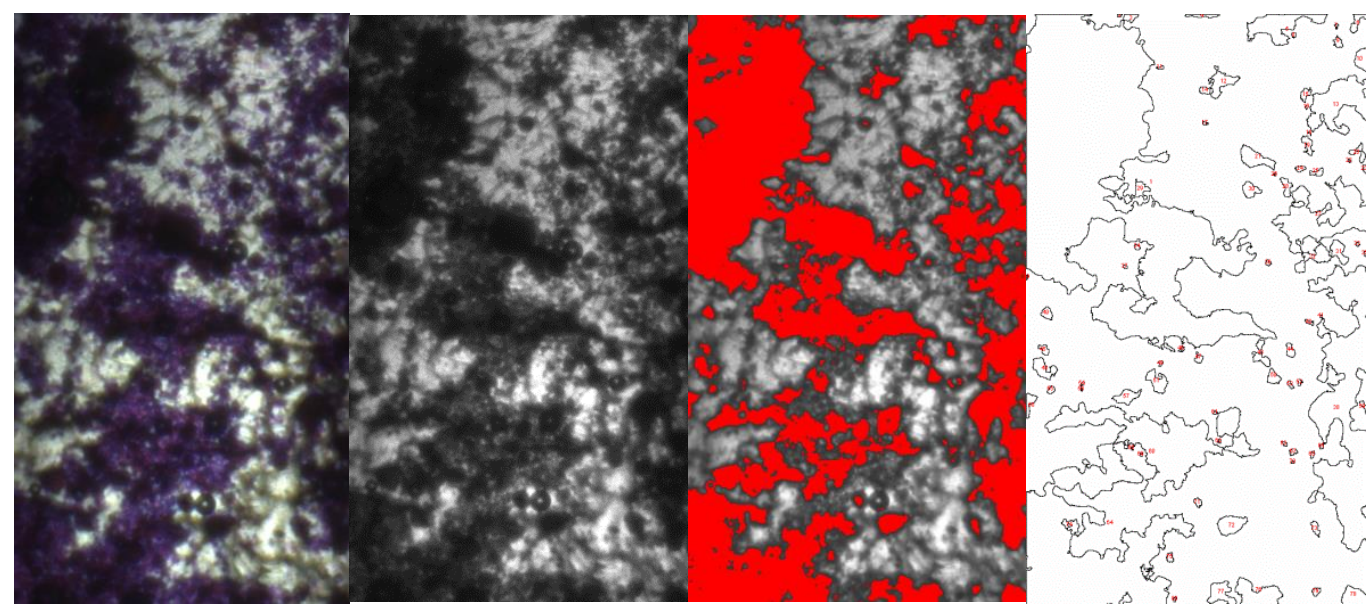

Figure 28: 25\% Concentration of Novel Irrigant

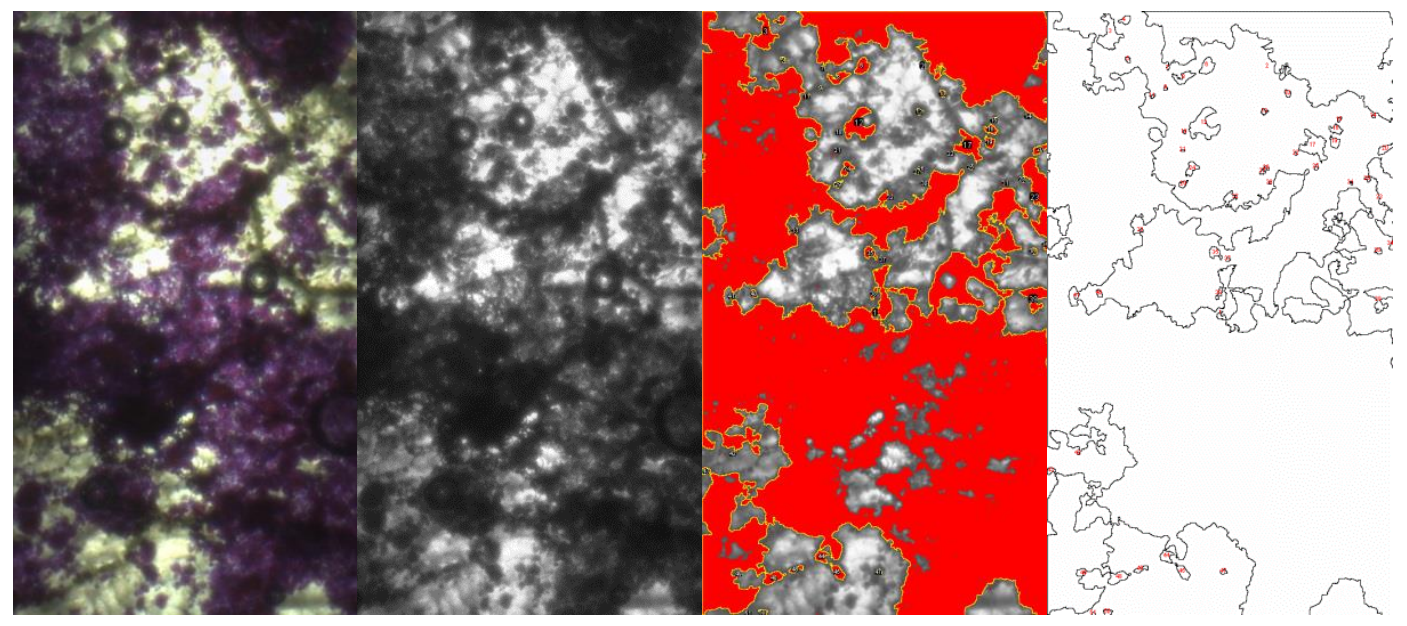

Figure 29: 70\% DMSO (Solvent Alone) 

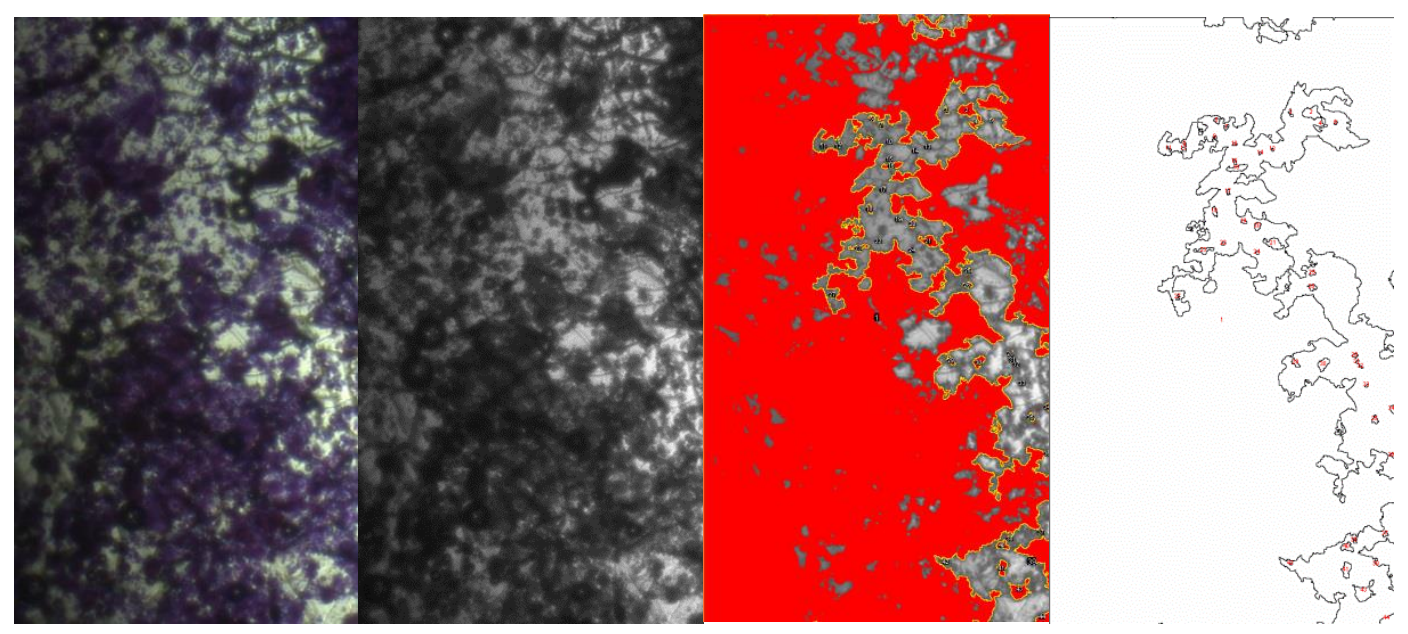

Figure 30: No Treatment (Positive Control)

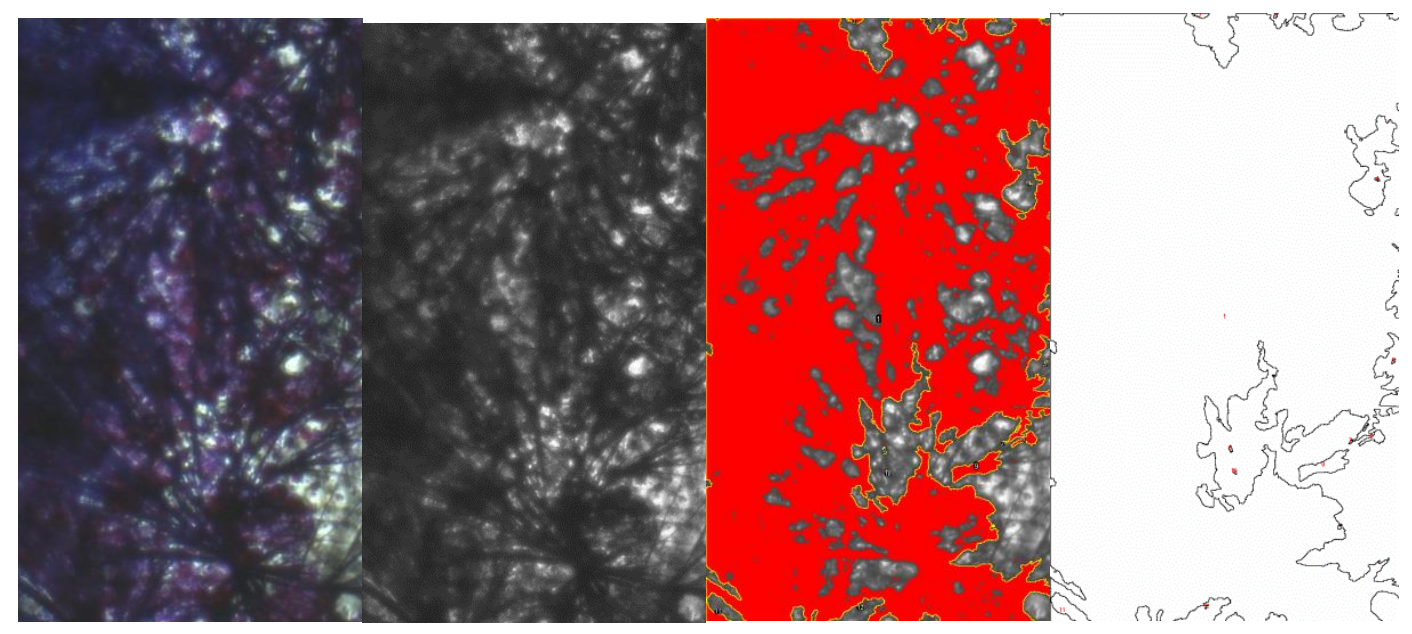

Figure 31: 6\% NaOCl 
Penetration Study: The results of the penetration study showed that the mean penetration (in micrometers) of each tested combination into dentin tubules of extracted human teeth were as follows:

\begin{tabular}{|c|c|c|c|c|c|c|c|c|c|}
\hline $100 \%$ & EDTA/ & $25 \%$ & $70 \%$ & $50 \%$ & ED & $17 \%$ & EDTA/ & $6 \%$ & No \\
\hline Novel & DMSO & Novel & DMSO & Novel & Novel & EDTA & $\mathrm{NaOCl}$ & $\mathrm{NaOCl}$ & Treat \\
\hline 601.52 & 362.26 & 311.05 & 308.33 & 276.59 & 257.03 & 140.30 & 129.44 & 77.27 & 7.55 \\
\hline
\end{tabular}

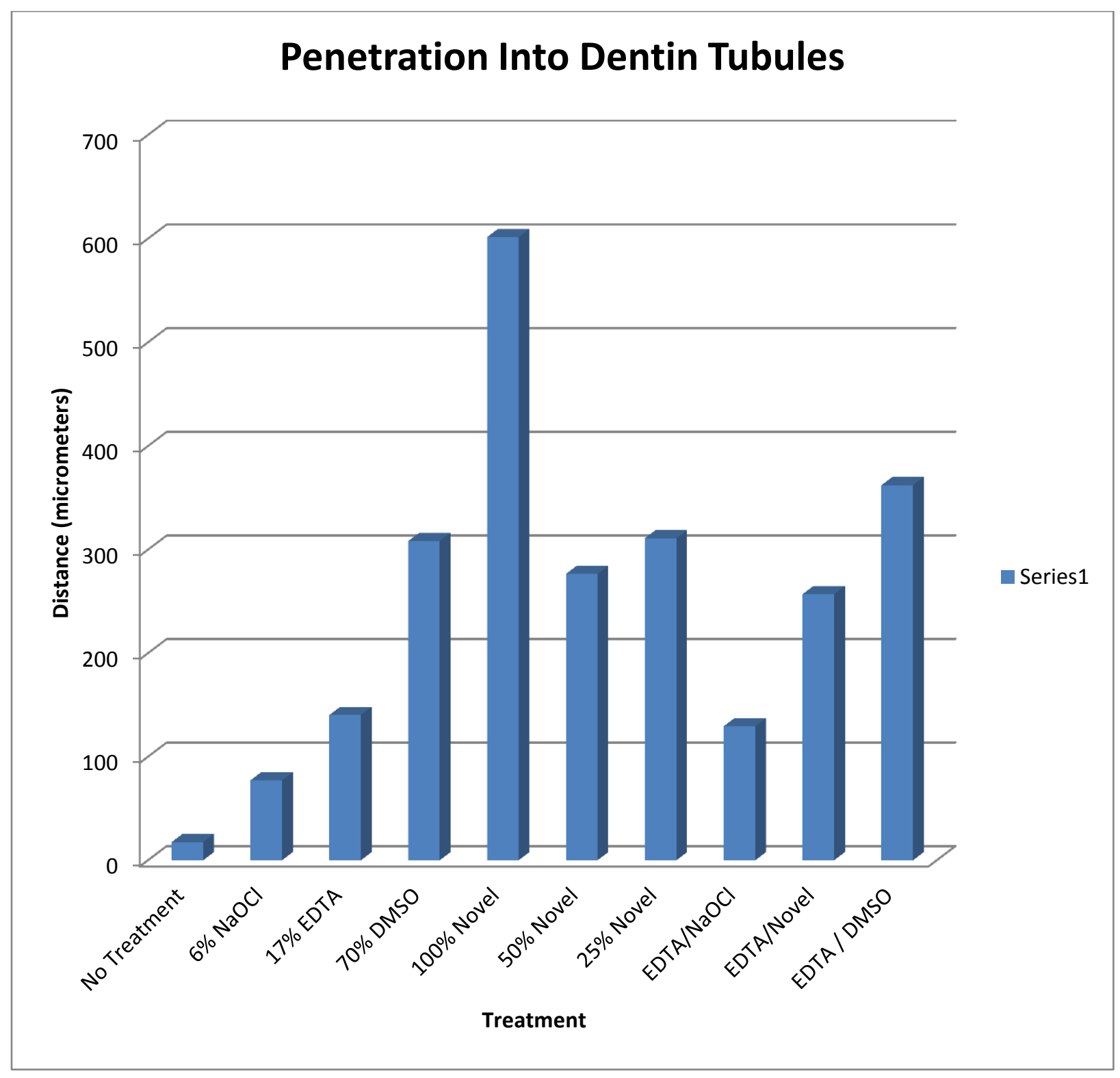

Figure 32: Graph of Penetration into Dentin Tubules (micrometers) 
The $100 \%$ concentration of the novel irrigant penetrated significantly further into the dentin tubules of extracted human teeth when compared to the no treatment group (p-value $<0.0001$ ), $6 \% \mathrm{NaOCl}$ (p-value <0.0001), combination of 17\% EDTA and 6\% $\mathrm{NaOCl}$ (p-value <0.0001), and $17 \%$ EDTA alone (p-value <0.0001). 


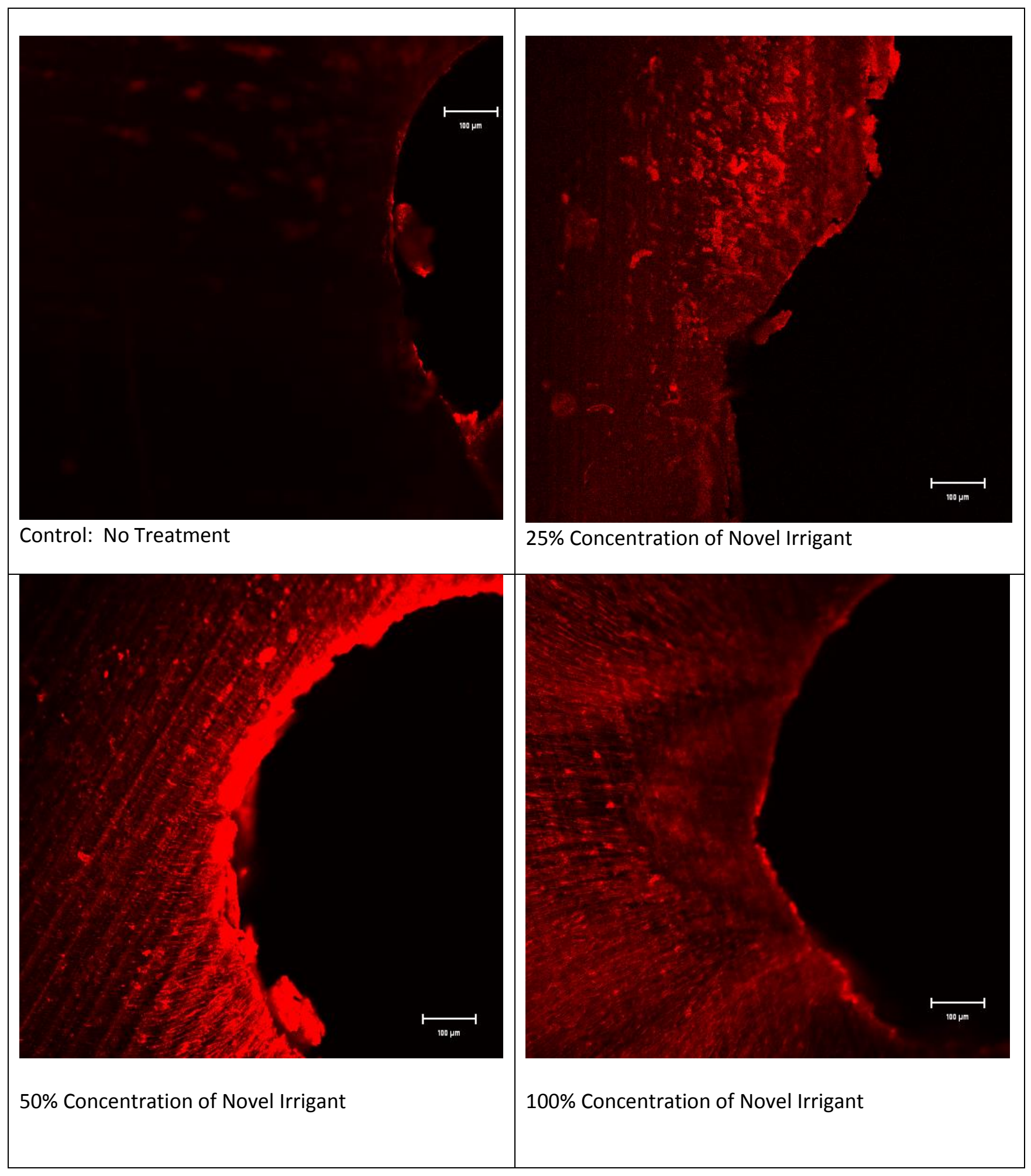

Figure 33: Comparison of Control and all concentrations of Novel Irrigant Tested 


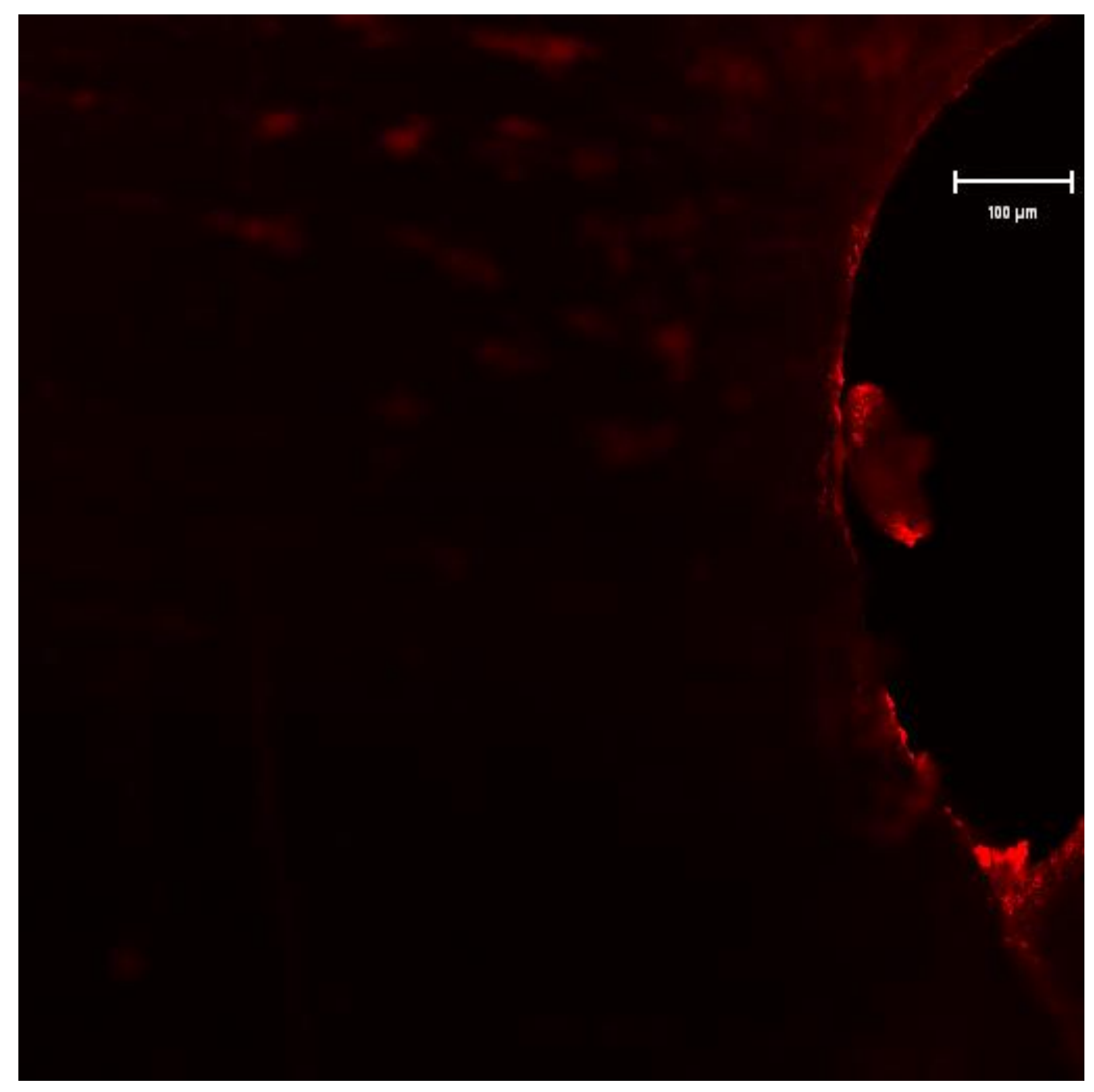

Figure 34: Confocal Laser Microscopy 10X No treatment 


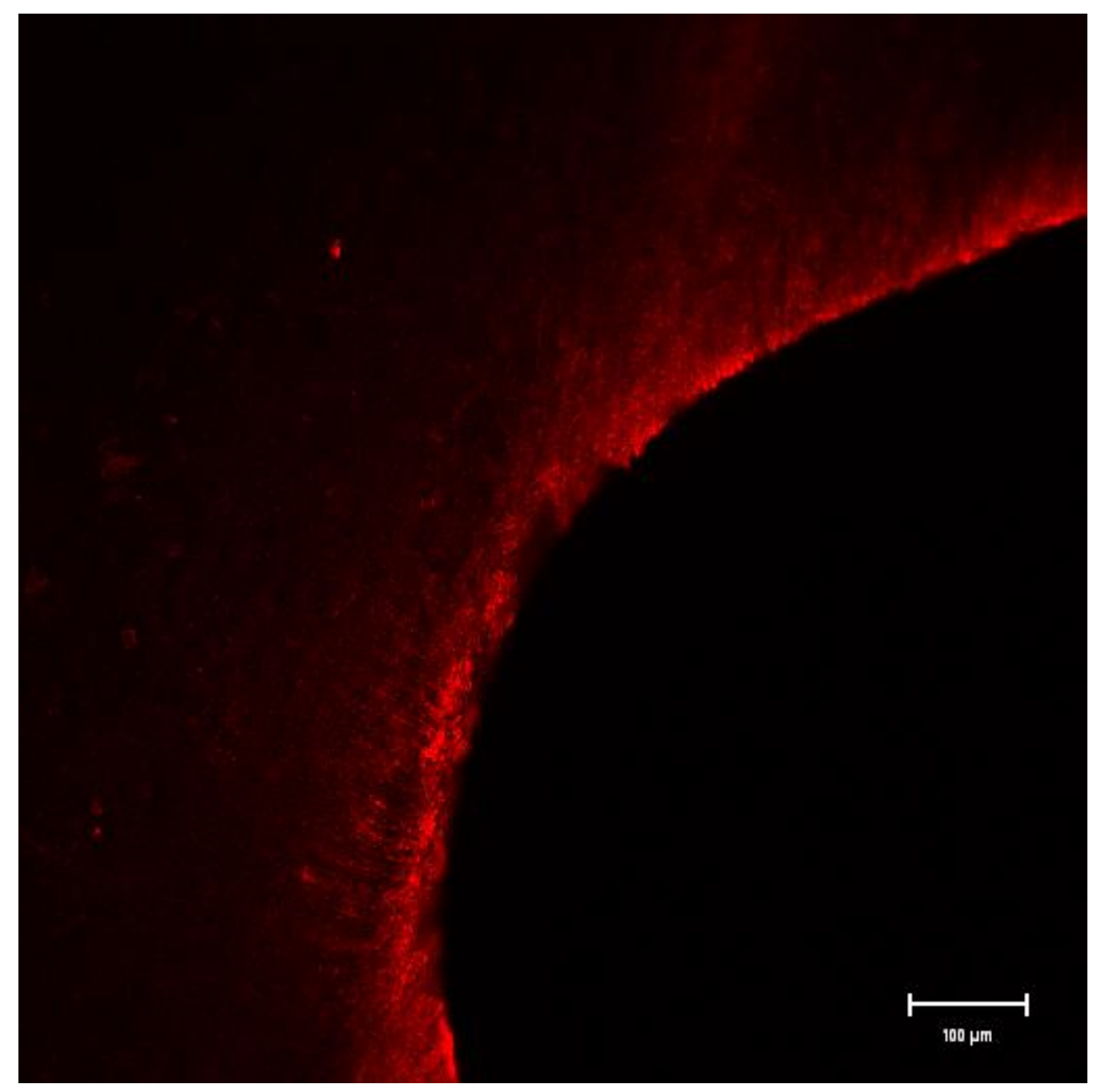

Figure 35: Confocal Laser Microscopy 10X $6 \%$ NaOCl Treatment 


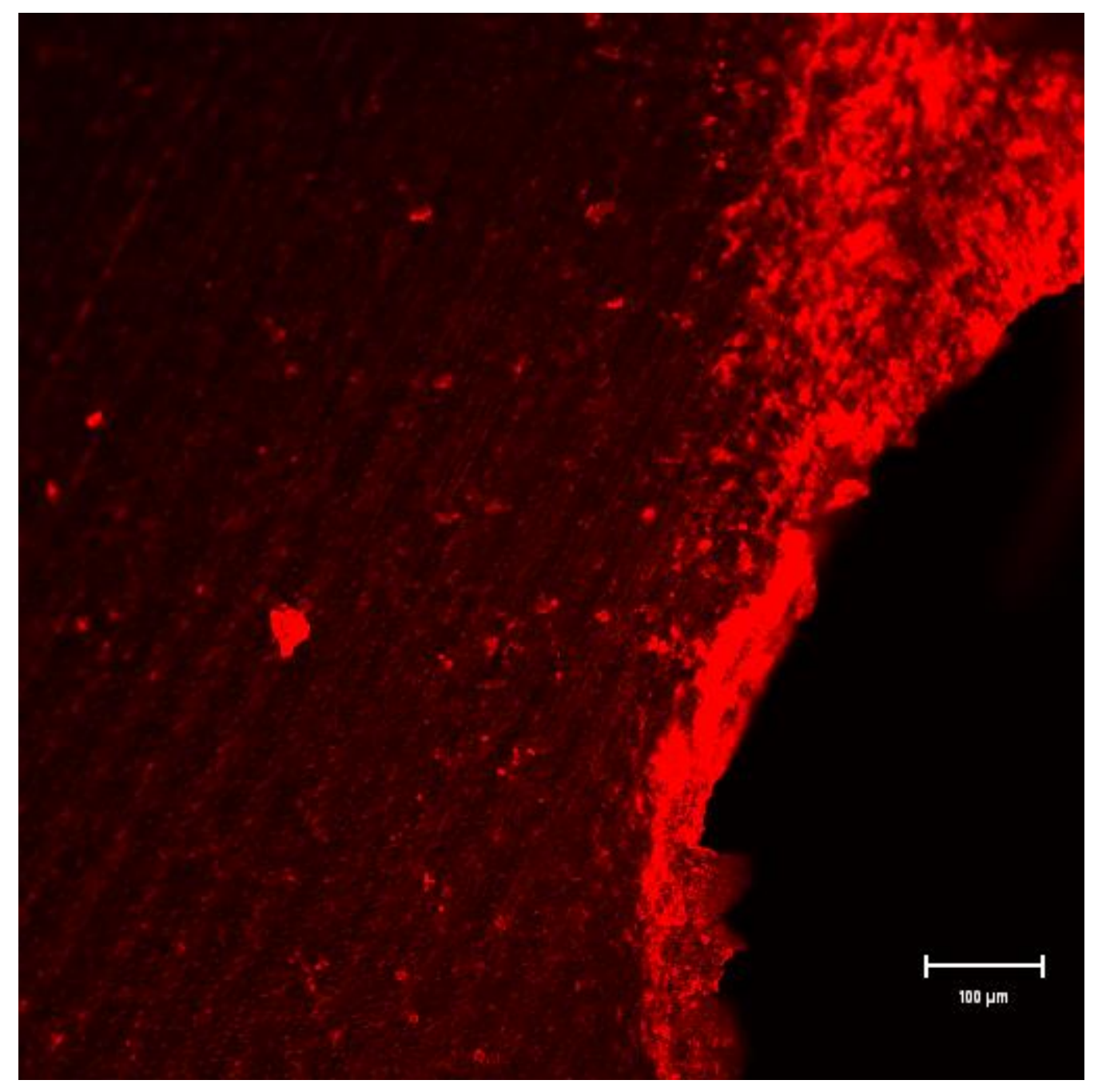

Figure 36: Confocal Laser Microscopy 17\% EDTA Treatment 


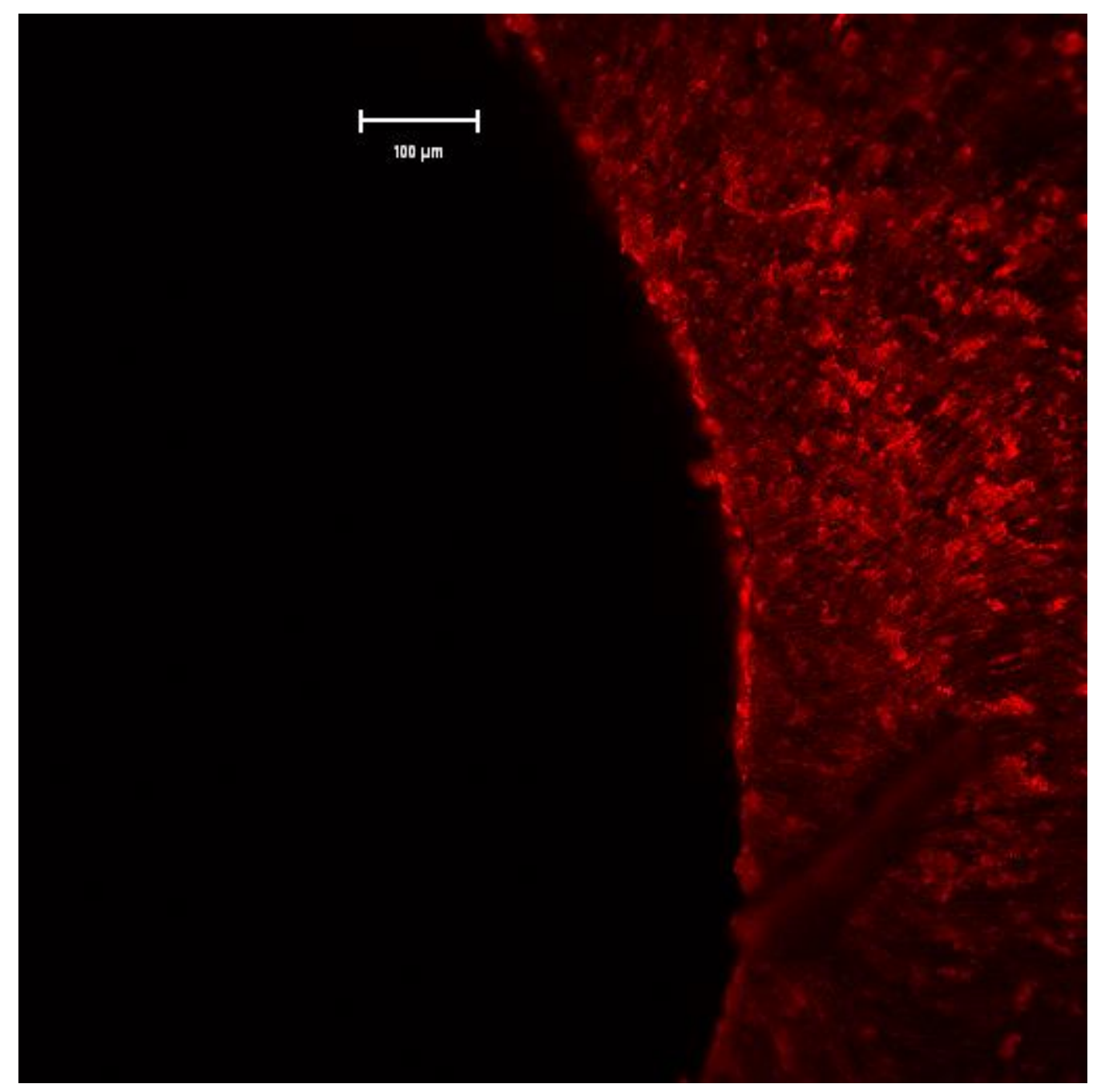

Figure 37: Confocal Laser Microscopy 10X 70\% DMSO Treatment 


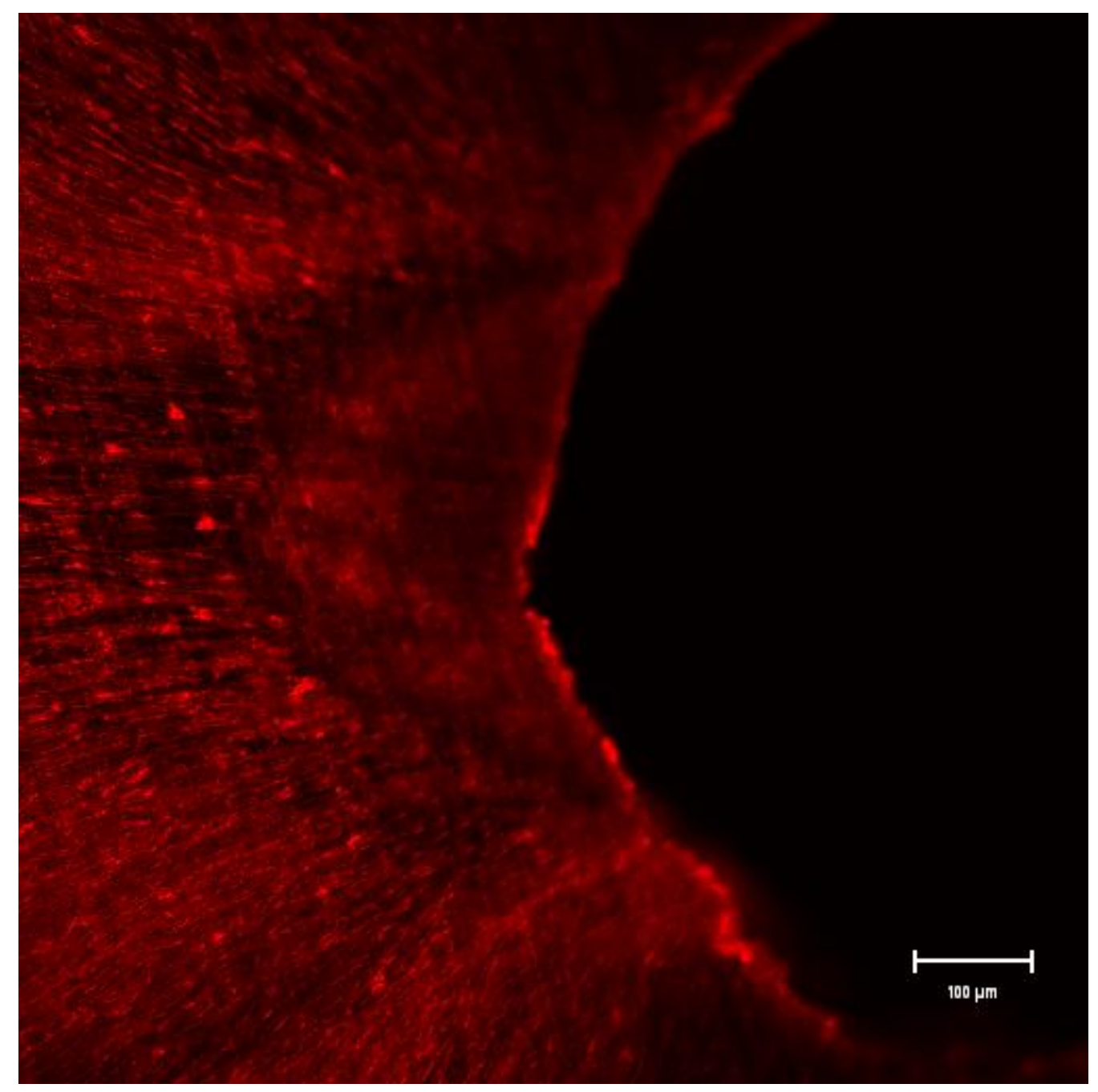

Figure 38: Confocal Laser Microscopy 10X 100\% Concentration of Novel Irrigant 


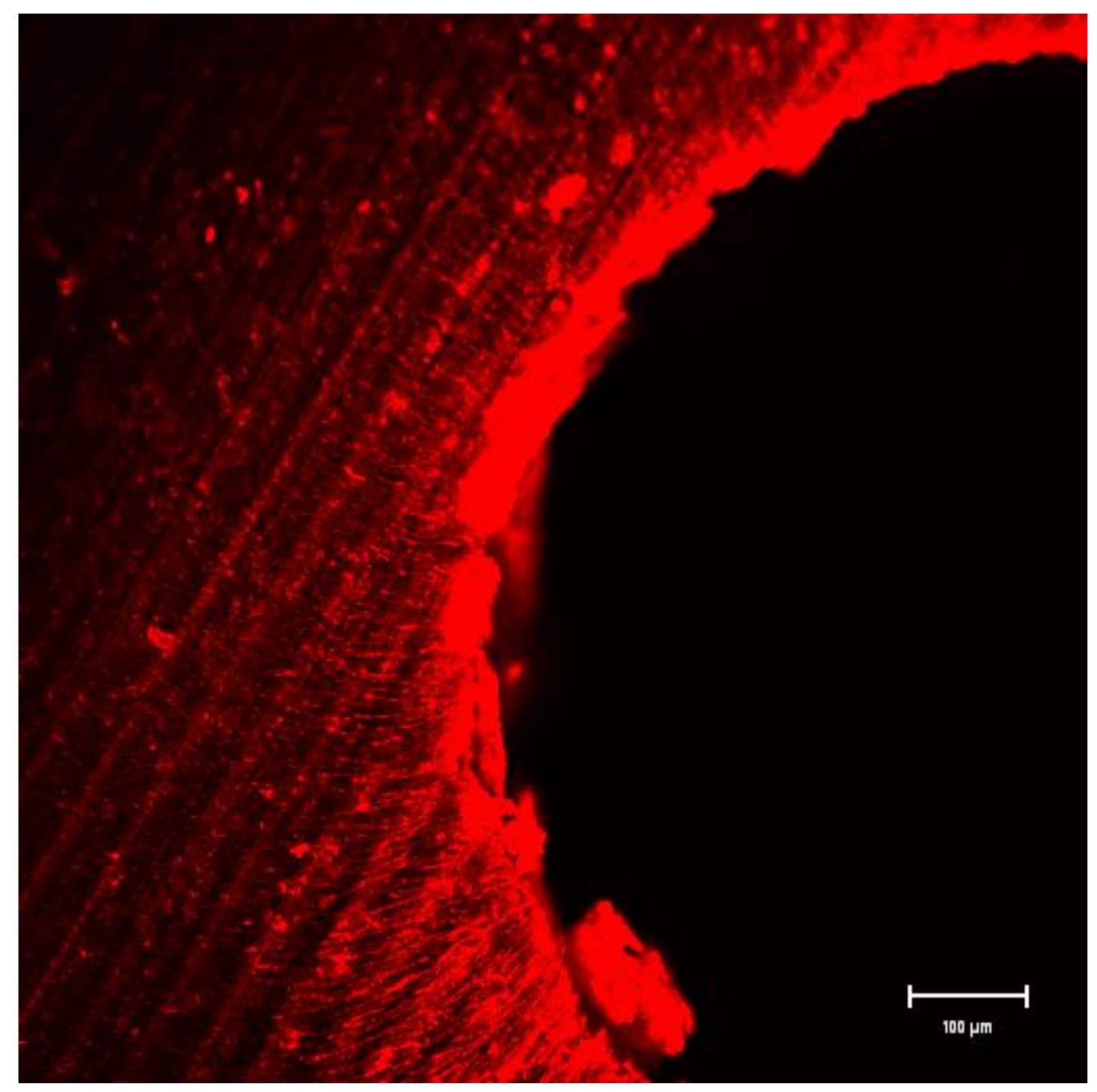

Figure 39: Confocal Laser Microscopy 10X $50 \%$ Concentration of Novel Irrigant 


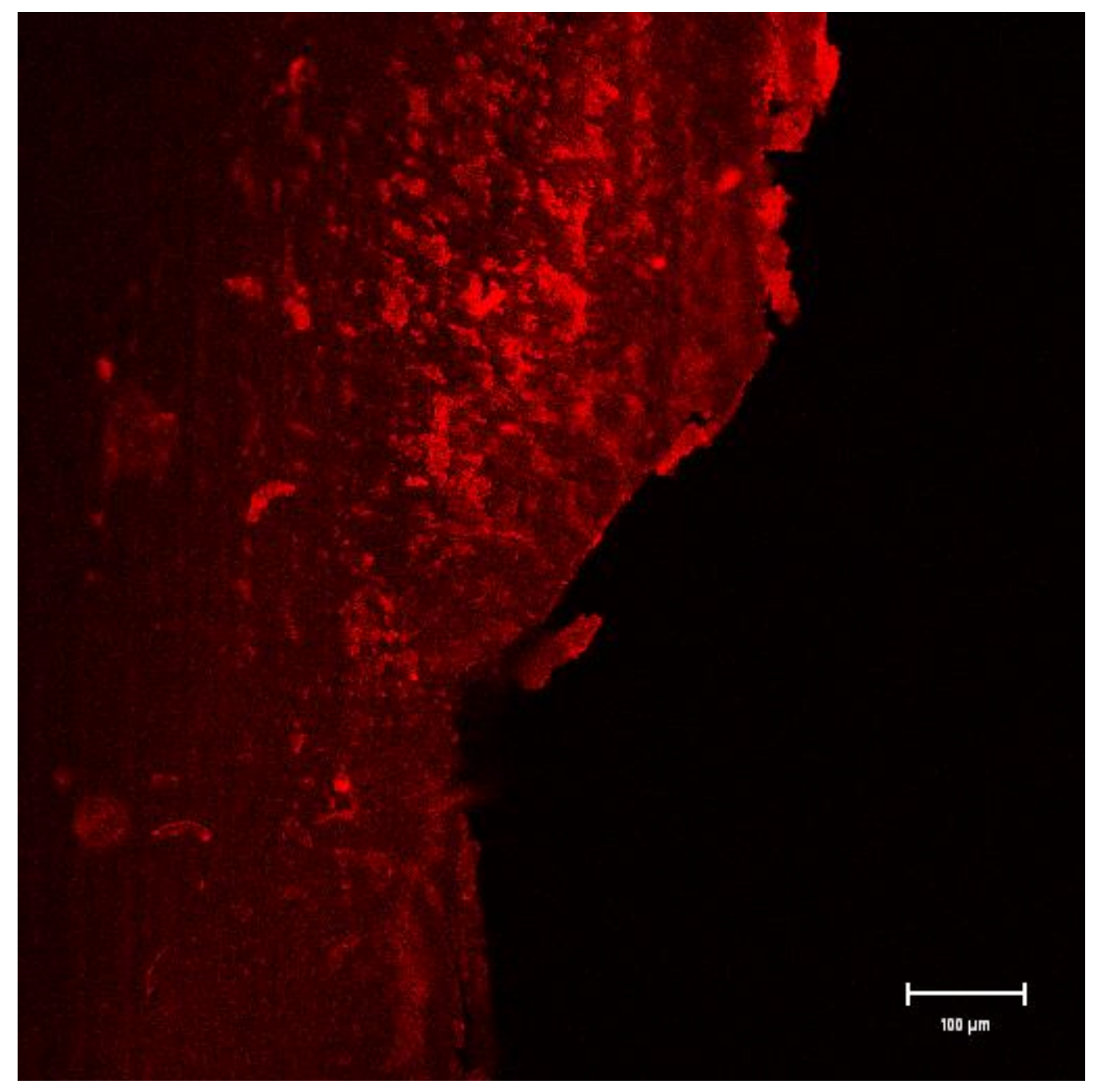

Figure 40: Confocal Laser Microscopy 25\% Concentration of Novel Irrigant 


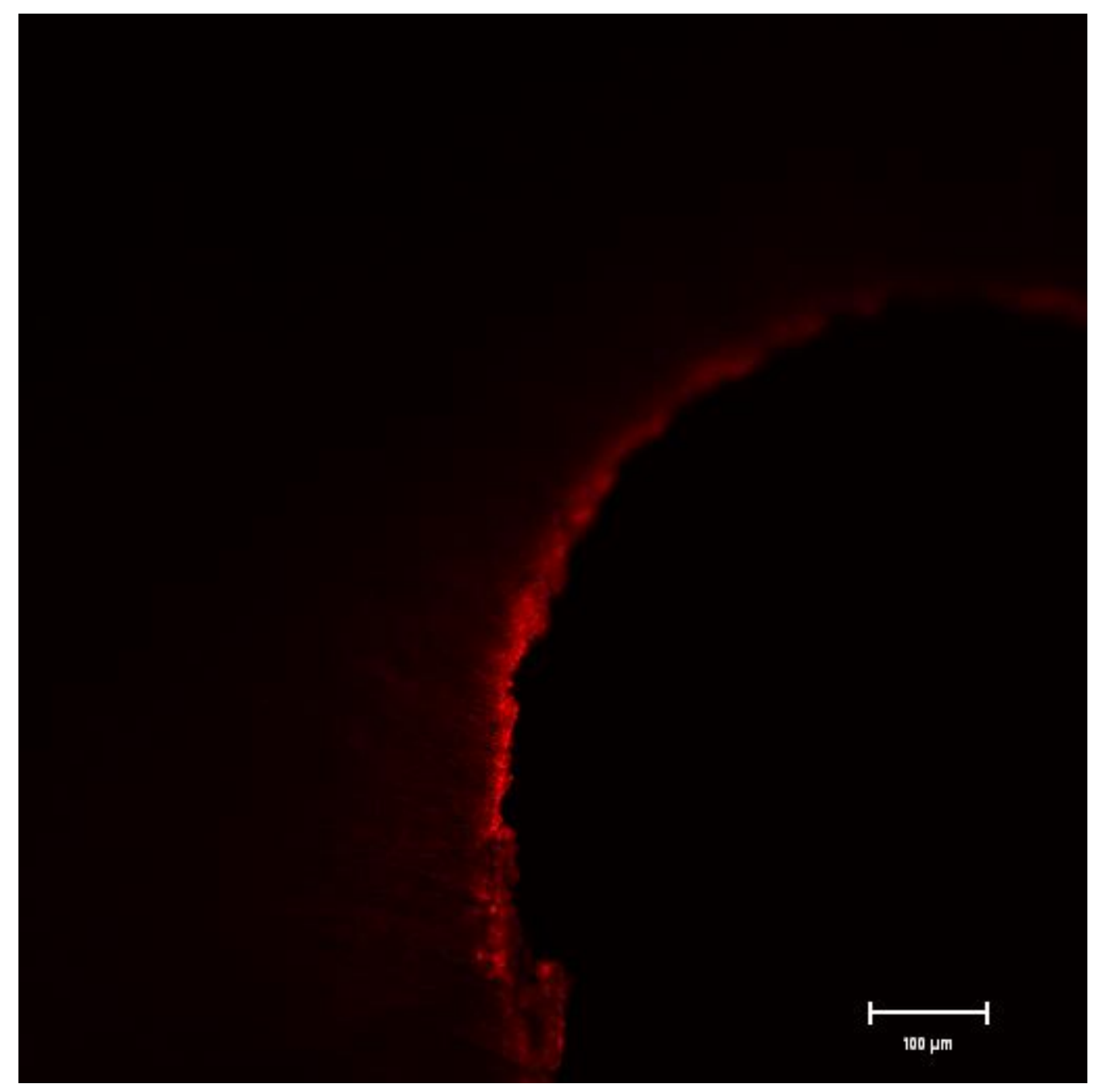

Figure 41: Confocal Laser Microscopy 10X Treatment with 17\% EDTA and $6 \% \mathrm{NaOCl}$ 


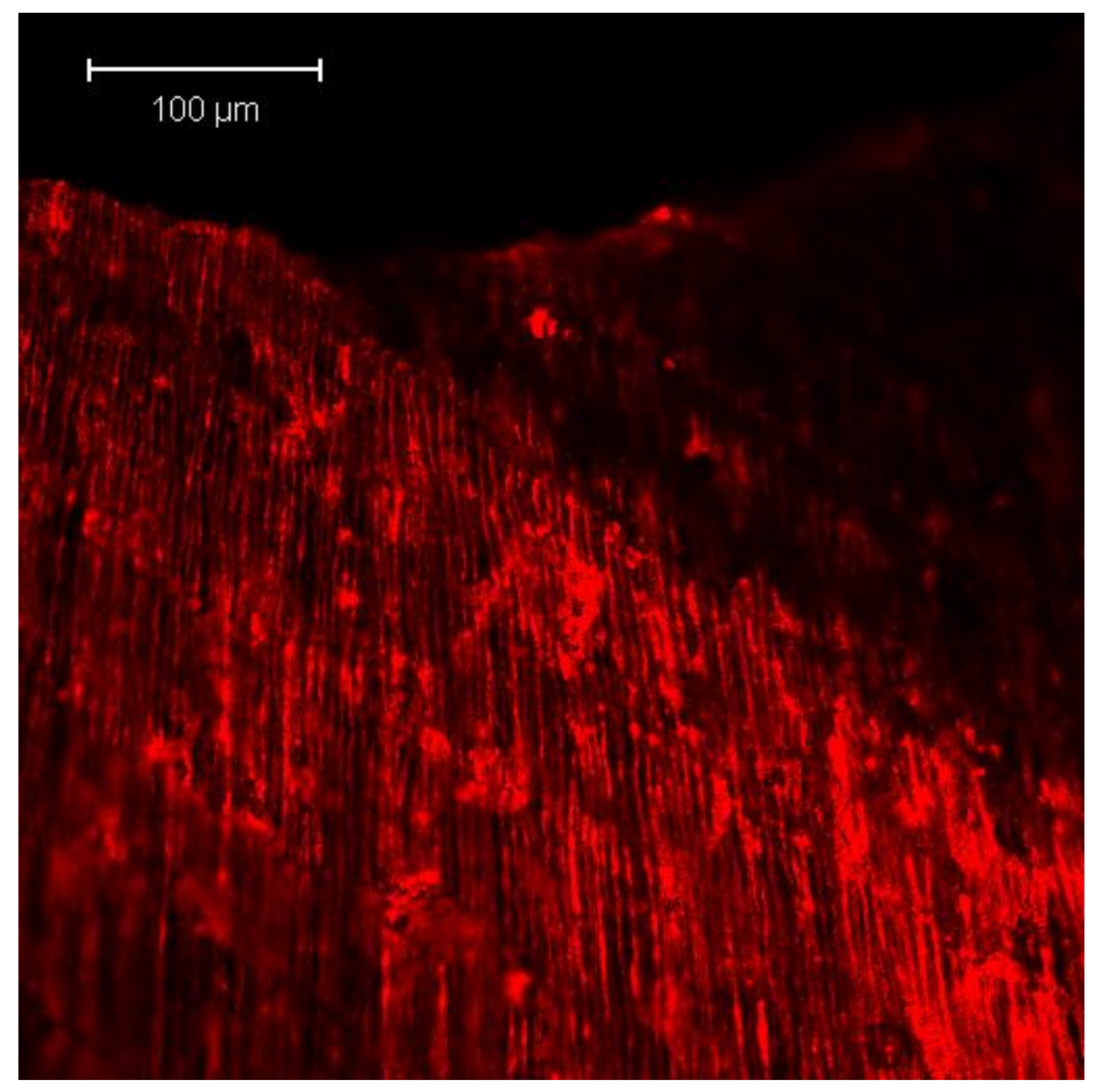

Figure 42: Confocal Laser Microscopy 20X 100\% Concentration Novel Irrigant 


\section{$\underline{\text { Discussion }}$}

As with any in vitro or bench top study, differences in results may be attributed to variations in specimens, testing procedures, instrumentation/experimentation techniques and interpretation of data. One advantage of in vitro testing is that it provides a reasonable method for technique examination and observation without the many restrictions found in a clinical setting. Conversely, it is difficult, if not impossible, for in vitro studies to reproduce clinical conditions. Conclusive evidence regarding efficacy should be drawn from many studies conducted by independent investigators looking at similar technique aspects, animal trials, and from history of clinical use.

The present study was designed to formulate and evaluate the ability of a novel irrigant in different concentrations $(25,50$, and $100 \%)$ to have anti-microbial activity against a recalcitrant C. albicans biofilm as well as observe penetration of the irrigant into the dentin tubules of root canals prepared in an identical manner. Comparable levels of disinfection were found between the novel irrigant and full strength $(6 \%) \mathrm{NaOCl}$. Superior penetration into dentin tubules was found with $100 \%$ concentration of the novel irrigant when compared to $\mathrm{NaOCl}$ and $17 \%$ EDTA or some combination of the two. All of the positive controls demonstrated microbial growth and did not show penetration into the dentin tubules supporting the experimental design.

Prepared root canals by conventional standards are chemically disinfected using some form of irrigation. The ability to chemically disinfect areas of root canals that are inaccessible to instrumentation has been considered to be essential for clinical success. Irrigation materials can reach fins, apical deltas, and lateral canals, thus improving the outcome of non-surgical root canal therapy. Unfortunately, all irrigants suffer physical short-comings such as inability to 
penetrate deep into the dentin tubules and address remaining microorganisms that these areas harbor. These undesirable characteristics are incompatible with long-term endodontic success, especially when dealing with extraradicular biofilms. The objective of irrigation is to minimize the amount of bio load (microorganisms) present in the canal system while leaving the remaining dentin occupying the root canal unharmed.

Full strength $\mathrm{NaOCl}$ was used in this study as the control irrigant because of its known clinical success and history of use.

Recently, the materials such as $\mathrm{MTAD}^{\circledR}$ and $\mathrm{QMIX}^{\circledR}$ have attempted to replace $\mathrm{NaOCl}$ and the potential dangers associated with its use. At best, these new materials can be used as adjuncts with some degree of clinical success. Use of other less harmful irrigation materials can potentially decrease the chance of a sodium hypochlorite accident. However, no other endodontic irrigant seems to possess the ability to dissolve tissue like that of $\mathrm{NaOCl}$.

Some studies have concluded that irrigants such as $\mathrm{QMIX}^{\circledR}$ when used according to manufacturer's recommendations have the ability to better disinfect root canal systems while removing the smear layer when compared to $\mathrm{NaOCl}$ and EDTA or some combination of the two.

The experimental groups studied containing DMSO were the only groups that demonstrated statistically significant ability to remove biofilm from pegs of the Calgary Biofilm Device. In addition, the $100 \%$ concentration of novel irrigant was statistically significant in its ability to penetrate into the dentin tubules of a prepared root canal.

After NMR analysis of the newly formulated mixture there appears to be no reaction between any of the ingredients, Clindamycin, Nystatin, and Dimethyl sulfoxide. The NMR spectroscopy study confirms the stability of the mixture. The concern always exists that this 
mixture may potentially have interactions with other commonly utilized endodontic irrigants, but this question requires further testing in a laboratory setting. There is also always the possibility that certain patients may have or develop allergies to certain drugs. Clindamycin does not appear to be the allergen that other commonly used antibiotics (penicillin based drugs) seem to be; however, there is always the risk of developing Pseudomembranous colitis with the use of antibiotics. It is assumed that the dose of Clindamycin in this particular formulation is relatively low compared to an oral regimen of the drug and will not leave the root canal system. Nystatin is a commonly used antifungal agent, and hence the reason it was chosen for this formulation. It too can potentially be an allergen for some patients, though this is seen as an extremely rare occurrence. Dimethyl sulfoxide has currently only gained FDA approval in the treatment of bladder inflammation or interstitial cystitis. There is concern over whether or not DMSO could further denature collagen perhaps causing damage to the tooth structure. DMSO absorbed systemically is primarily excreted in the urine and the only listed side effect is a garlic-like odor on the breath. Again the rather miniscule amount of DMSO that the patient would be exposed to is quite small in this application and no adverse effects are anticipated. Further testing is required to verify this hypothesis. Derivatives of DMSO could possibly be substituted as a more biocompatible solvent.

The ZOI study demonstrated that all concentrations of the novel irrigant resulted in disinfection activity against E. coli, S. aureus, and C. albicans, as did full strength $\mathrm{NaOCl}$. The novel irrigant did not show activity against $P$. aeruginosa or Lactobacillus. This was true for both the planktonic simulation with Mueller-Hinton agar and the biofilm phenotype simulation with Poloxamer plates. Full strength $\mathrm{NaOCl}$ was significantly more effective than the novel irrigant in the ZOI study. DMSO alone had activity against the biofilm phenotype of both E. coli 
and $C$. albicans. While $\mathrm{NaOCl}$ did show some activity against P. aeruginosa and Lactobacillus after 24 hours, when viewed at 48 hours, it was apparent that colonies had re-grown inside the original zone of inhibition. Because $C$. albicans was the organism chosen for this study, further trials were repeated yielding similar results in both the planktonic and biofilm phenotypes. Because of these results and the unknown variable of whether or not the novel irrigant will possess the ability to dissolve tissue, it may be that the novel irrigant will not replace the use of $\mathrm{NaOCl}$; rather it could be used as an adjunct to endodontic irrigation.

Pegs from the Calgary Biofilm Device were used to complete three different assays as well as obtain SEM images to verify biofilm formation. Six independent trials of performing colony forming unit dilutions were conducted using $C$. albicans as the test organism. Biofilm remaining after treatment was removed via sonication, serial dilutions were performed with physiologic saline, plated on $\mathrm{M}-\mathrm{H}$, and results were quantified using an aCOLyte colony counter. A colony forming unit is used to determine the number of viable bacterial cells in a sample per mL. A lower CFU is indicative of greater solution activity. The results suggest similar antimicrobial activity as compared to full strength $\mathrm{NaOCl}$. Although the $\mathrm{NaOCl}$ showed no growth, this was not significantly different to the different concentrations of the novel irrigant when compared with the positive control value.

The crystal violet assay involved staining the biofilm covered plastic pegs and viewing under a Zeiss tissue microscope. Representative photographs were taken with a Nikon digital capture device. These photos were then cropped at a consistent orientation and size and converted to scale as an 8-bit gray image. Computer software was able to allow the observer to select the darker areas on the image which corresponded to remaining biofilm on the pegs. The computer software was able to map out the dark areas that were selected and obtain an average 
area of coverage. The larger the dark area, corresponded with the more remaining biofilm, and therefore the less effective treatment solution. The novel irrigant did appear to have a significantly better ability to remove biofilm from the Calgary Biofilm Device compared to full strength $\mathrm{NaOCl}$. The process of selecting the dark areas was a bit subjective; however, identical sample sizes were taken from each peg at the same location and consistent threshold values were used.

The absorbance assay was conducted after the remaining biofilm (having been treated with a specific treatment) was stained with crystal violet, washed with deionized water and removed from the peg into glacial acetic acid. The absorbance of the glacial acetic acid was read at a fixed wavelength of $562 \mathrm{~nm}$. A lower absorbance value was indicative of greater solution antimicrobial activity (Trotonda 2008). These results also suggest that the novel irrigant possesses better anti-biofilm activity compared to $\mathrm{NaOCl}$.

The positive control C. albicans peg was viewed under SEM and representative photographs were taken to ensure biofilm formation. Quantitative analysis to determine the amount of actual biofilm coverage was unable to be computed due to variability and orientation of the pegs.

The penetration study showed that the $100 \%$ concentration of the novel irrigant was statistically more significant in its ability to penetrate the dentin tubules of extracted human teeth when compared with current irrigation protocols. This characteristic sets the novel irrigant apart from other endodontic irrigation materials and is quite unique. 


\section{Chapter 5}

\section{Conclusion}

The present study indicated that a novel irrigant composed of Clindamycin, Nystatin, and $70 \%$ DMSO has equal or better ability to disinfect a recalcitrant C. albicans biofilm phenotype when compared to $6 \% \mathrm{NaOCl}$ as observed through the $\mathrm{CFU}$, absorbance, and biofilm coverage area assays performed using the Calgary Biofilm Device. 100\% Concentration of the novel irrigant was statistically significant in its ability to penetrate into the dentin tubules of a prepared root canal in an extracted human tooth when compared to $6 \% \mathrm{NaOCl}$ and 17\% EDTA. Although the clinician should examine many studies and rely on clinically proven methods before choosing one technique or material over another, it is logical to place value in further research and evaluation of a technique or material which has been shown to provide disinfection and penetration in-vitro. Further studies are necessary to evaluate the in-vivo success of cases which have been irrigated in this manner. It must be remembered that there are numerous other factors that contribute to endodontic success. Ray and Trope concluded that the quality of the coronal seal is equally important to the successful outcome of endodontic therapy as is the quality of the apical seal (Ray 1995). Other authors agree in the importance of appropriate obturation, apical seal, and restoration in addition to an irrigation protocol that is effective.

All groups tested had similar disinfecting abilities, with the exception being $6 \% \mathrm{NaOCl}$ in the ZOI studies which demonstrated that it may have superior ability to disinfect selected pathogens on agar plates. This in vitro study supports the need to continue research and development on a novel irrigant that not only has the ability to effectively disinfect root canal systems, but also has the ability to penetrate into the dentin tubules and address a bio load that has previously been inaccessible by modern irrigation materials and protocols. 


\section{Works Cited}

Ari, Hale, Ali Erdemir, and Sema Belli. "Evaluation of the Effect of Endodontic Irrigation Solutions on the Microhardness and the Roughness of Root Canal Dentin." Journal of endodontics 30.11 (2004): 792-5.

Baker, N. A., et al. "Scanning Electron Microscopic Study of the Efficacy of various Irrigating Solutions." Journal of endodontics 1.4 (1975): 127-35.

Beighton D., et al. "The growth of bacteria and the production of exoglycosidic enzymes in the dental plaque of macaque monkeys." Arch Oral Biol (1986): 31: 829-835.

Baumgartner JC. "A Scanning Electron Microscopic Evaluation of Four Root Canal Irrigation Regimens." Journal of endodontics 13.4 (1987): 147.

Baumgartner, J. C., and P. R. Cuenin. "Efficacy of several Concentrations of Sodium Hypochlorite for Root Canal Irrigation." Journal of endodontics 18.12 (1992): 605-12.

Baumgartner, J.C., Watts, C.M., Xia, T., "Occurrence of Candida albicans in Infections of Endodontic Origin." Journal of Endodontics 26.12 (2000): 695-97.

Beltz, Richard E., Mahmoud Torabinejad, and Manucher Pouresmail. "Quantitative Analysis of the Solubilizing Action of MTAD, Sodium Hypochlorite, and EDTA on Bovine Pulp and Dentin." Journal of endodontics 29.5 (2003): 334-7.

Bruheim, P., Borgos, S.E.F., Tsan, P., Sletta, H., Ellingsen, T.E., Lancelin, J.-M., and Zotchev, S.B. "Chemical Diversity of Polyene Macrolides Produced by Streptomyces Noursei ATCC 11455 and Recombinant Strain ERD44 with Genetically Altered Polyketide Synthase NysC", Antimicrob. Agents Chemother. (2004) 48:4120-4129.

Byström A. "Bacteriologic Evaluation of the Effect of 0.5 Percent Sodium Hypochlorite in Endodontic Therapy." Oral surgery, oral medicine, oral pathology 55.3 (1983): 307.

Bystrom A., Sundqvist G."Bacteriologic Evaluation of the Efficacy of Mechanical Root Canal Instrumentation in Endodontic Therapy." Scandinavian journal of dental research 89.4 (1981): 321 .

Bystrom A. "Healing of Periapical Lesions of Pulpless Teeth After Endodontic Treatment with Controlled Asepsis." Endodontics \& dental traumatology 3.2 (1987): 58.

Costerton, J.W. et al. "Microbial biofilms." Annual Review of Microbiology, vol. 49, (1995) pp. 711-745.

Cymbler DM. "Sodium Hypochlorite Injection into Periapical Tissues." Dental update 21.8 (1994): 345. 
Dai, Lin, et al. "The Effect of QMix, an Experimental Antibacterial Root Canal Irrigant, on Removal of Canal Wall Smear Layer and Debris." Journal of endodontics 37.1 (2011): 804.

Dakin, H. D. "The Antiseptic Action of Hypochlorites: The Ancient History of the "New Antiseptic"." The British Medical Journal 2.2866 (1915): pp. 809-810.

Dakin, H.D. "On the use of Certain Antiseptic Substances in the Treatment of Infected Wounds." The British Medical Journal 2.2852 (1915): pp. 318-320.

David, NA. "The Pharmacology of Dimethyl Sulfoxide 6544.” Annu. Rev. Pharmacol. 1972. (12): 353-374.

De-Deus G, Reis C, Fidel S, Fidel R, Paciornik S. "Dentin demineralization when subjected to BioPure MTAD: a longitudinal and quantitative assessment." J Endod. 33.11 (2007): 1364-8.

Denton W, "Chlorhexidine In: Sterilisation and Preservation" 5th Edition, Block SS, eds. Lippincott Williams \& Williams, Philadelphia, 2001.

Donlan, R.M. "Biofilms: microbial life on surfaces," Emerging Infectious Disease, vol. 8 no. 9, pp. 881-890, 2002.

Dunavant, Thomas R., et al. "Comparative Evaluation of Endodontic Irrigants Against Enterococcus Faecalis Biofilms." Journal of endodontics 32.6 (2006): 527-31.

Dutner, Joseph, Pete Mines, and Alfred Anderson. "Irrigation Trends among American Association of Endodontists Members: A Web-Based Survey." Journal of endodontics 38.1 (2012): 37-40.

Formanek, K., Kovac, W. In DMSO Symposium, Vienna, ed. G. Laudahn, 18. Berlin: Saladruck. 1966.

Friedman S., "Treatment Outcome in Endodontics. The Toronto Study: Phase I." Journal of endodontics 29 (12) 2003: 787.

Gernhardt, C. R., et al. "Toxicity of Concentrated Sodium Hypochlorite used as an Endodontic Irrigant." International endodontic journal 37.4 (2004): 272-80.

Giardino, Luciano, et al. "Comparative Evaluation of Antimicrobial Efficacy of Sodium Hypochlorite, MTAD, and Tetraclean Against Enterococcus Faecalis Biofilm." Journal of endodontics 33.7 (2007): 852-5.

Gillchriest, W.C., Nelson, P.L. "Protein synthesis in bacterial and mammalian cells.” Biophys. J. 1969. 9:A-133. 
Haapasalo M. "Irrigation in Endodontics." The Dental clinics of North America 54.2 (2010): 291.

Hand, R. E., M. L. Smith, and J. W. Harrison. "Analysis of the Effect of Dilution on the Necrotic Tissue Dissolution Property of Sodium Hypochlorite." Journal of endodontics 4.2 (1978): 60-4.

Hasselgren G. "Effects of Calcium Hydroxide and Sodium Hypochlorite on the Dissolution of Necrotic Porcine Muscle Tissue." Journal of endodontics 14.3 (1988): 125.

Herschler, RJ, Jacob, SW. "DMSO-A new drug from lignin." TAPPI (Tech. Assoc. Pulp Paper Inc.) 1965. 48:43A-46A.

Hucker, HB. et al., "Studies on the absorption, excretion and metabolism of DMSO in man." $J$. Pharmacol. Exp. Ther. 1967. 155:309-17.

Ibragimova, V. KH., Alieva, I. N., Aliev, D. I. "New Approach to Use of Polyene Antibiotics." Radiation Safety Problems in the Caspian Region. 2004: 121-128.

Jacob, SW., Bischel, M., Herschler, RJ. "DMSO: A new concept in Pharmacotherapy." Curr. Ther. Res. 1964. (6): 134-35.

Jacob, S.W., "Dimethyl sulfoxide, its basic pharmacology and usefulness in the therapy of headache." Headache. 1965. 5:78-81.

Jacob, SW, Wood, DC. "Notes on DMSO symposium Vienna, Austria." Curr. Ther. Res. 1967. (9): 229-33.

Jacob, S.W., Wood, D.C. "Dimethyl sulfoxide (DMSO). Toxicology, pharmacology, and clinical experience." Am. J. Surg. 1967. 114:414-26.

Jacob, S.W., "Pharmacology of DMSO." In Dimethyl Sulfoxide I, Basic Concepts, ed. S.W. Jacob, E.E. Rosenbaum, D.C. Wood, Chap. 2. 99-112. New York: Marcel Dekker, Inc. 1971.

Johal, Stephen, J. C. Baumgartner, and J. G. Marshall. "Comparison of the Antimicrobial Efficacy of $1.3 \% \mathrm{NaOCl} / \mathrm{BioPure} \mathrm{MTAD}$ to $5.25 \% \mathrm{NaOCl} / 15 \%$ EDTA for Root Canal Irrigation." Journal of endodontics 33.1 (2007): 48-51.

KAKEHASHI S. "THE EFFECTS OF SURGICAL EXPOSURES OF DENTAL PULPS IN GERM-FREE AND CONVENTIONAL LABORATORY RATS." Oral surgery, oral medicine, oral pathology 20 (1965): 340.

Kamiya, S., Wakao, T., Nichioka, K. "Studies on improvement of eye drops." Japan. J. Clin. Ophthalmol. 1966. 20:143. 
Kho, Patricia, and J. C. Baumgartner. "A Comparison of the Antimicrobial Efficacy of $\mathrm{NaOCl} /$ Biopure MTAD Versus NaOCl/EDTA Against Enterococcus Faecalis." Journal of endodontics 32.7 (2006): 652-5.

Kligman, AM. "Topical Pharmacology and Toxicology of Dimethyl Sulfoxide-Part I." J. Am. Med. Assoc. 1965. 193:796-804.

Kligman, AM. "Topical Pharmacology and Toxicology of Dimethyl Sulfoxide-Part II." J. Am. Med. Assoc. 1965. 193:923-928.

Koskinen, K. P., H. Stenvall, and V. J. Uitto. "Dissolution of Bovine Pulp Tissue by Endodontic Solutions." Scandinavian Journal Of Dental Research 88.5 (1980): 406-11.

Kumar, Brajesh, S. K. Jain, and S. K. Prajapati. "Effect of Penetration Enhancer DMSO on inVitro Skin Permeation of Acyclovir Transdermal Microemulsion Formulation." International Journal of Drug Delivery (2011): 83-94.

Ma, Jingzhi, et al. "A New Noninvasive Model to Study the Effectiveness of Dentin Disinfection by using Confocal Laser Scanning Microscopy." Journal of endodontics 37.10 (2011): $1380-5$.

Mayer, F.L., et al. “Candida albicans pathogenicity mechanism.” Virulence (4)2: 119-128. 2013.

McDermot, H.L., Murray, G.W., Heggie, R.M. "Penetration of Guinea Pig and Rabbit Skin by Dimethyl Sulfoxide Solutions of a Quaternary Oxime." Can. J. Phsiol. Pharmacol. 1965. (43): 845-48.

Mohammadi, Z., and P. V. Abbott. "The Properties and Applications of Chlorhexidine in Endodontics." International endodontic journal 42.4 (2009): 288-302.

Moorer, W. R., and P. R. Wesselink. "Factors Promoting the Tissue Dissolving Capability of Sodium Hypochlorite." International endodontic journal 15.4 (1982): 187-96.

Ordinola-Zapata, R., et al. "Antimicrobial Effect of Endodontic Solutions used as Final Irrigants on a Dentine Biofilm Model." International endodontic journal 45.2 (2012): 162-8.

Palazzi, F., et al. "Comparison of the Surface Tension of 5.25\% Sodium Hypochlorite Solution with Three New Sodium Hypochlorite-Based Endodontic Irrigants." International endodontic journal 45.2 (2012): 129-35.

Pfaller, M.A., et al. "National surveillance of nosocomial bloodstreatm infection due to species of Candida other than Candida albicans: frequency of occurrence and antifungal susceptibility in the SCOPE program." Diagn. Microbiol. Infect. Dis. 1998. 30:121-29.

Qian, Wei, Ya Shen, and Markus Haapasalo. "Quantitative Analysis of the Effect of Irrigant Solution Sequences on Dentin Erosion." Journal of endodontics 37.10 (2011): 1437-41. 
Ramage G., et al. "Our current understanding of fungal biofilms." Critical Reviews in Microbiology. 35 (4). 2009: 340.

Ramage G., et al. "Fungal Biofilm Resistance." International Journal of Microbiology, Volume 2012.

Ramirez, E., Luza, S. "Dimethyl sulfoxide in the treatment of mental patients." Ann. N.Y. Acad. Sci. 1967. 141:655-69.

Rasimick, Brian J., et al. "Interaction between Chlorhexidine Digluconate and EDTA." Journal of endodontics 34.12 (2008): 1521-3.

Ray, Ha, Trope, M. Pericapical status of endodontically treated teeth in relation to the technical quality of the root filling and the coronal restoration. Int Endo J. 28:12-18, 1995.

Ring, Karla C., et al. "The Comparison of the Effect of Endodontic Irrigation on Cell Adherence to Root Canal Dentin." Journal of endodontics 34.12 (2008): 1474-9.

Rosenfeld EF. "Vital Pulp Tissue Response to Sodium Hypochlorite." Journal of endodontics 4.5 (1978): 140.

Ruff, Melissa L., Scott B. McClanahan, and Britta S. Babel. "In Vitro Antifungal Efficacy of Four Irrigants as a Final Rinse." Journal of endodontics 32.4 (2006): 331-3.

Rosenbaum, W.M., Rosenbaum, E.E., Jacob, S.W. "THE USE OF DIMETHYLSULFOXIDE (DMSO) FOR THE TREATMENT OF INTRACTABLE PAIN IN SURGICAL PATIENTS." Surgery 1965. 58:258-66.

Sabala, C. L., and S. E. Powell. "Sodium Hypochlorite Injection into Periapical Tissues." Journal of endodontics 15.10 (1989): 490-2.

Saytzeff, A. "On the Influence of Nitric Acid on Methyl Sulfide and Ethyl Sulfide." Ann. Chem. (144). 1867: 148-56.

Senia, E. S., F. J. Marshall, and S. Rosen. "The Solvent Action of Sodium Hypochlorite on Pulp Tissue of Extracted Teeth." Oral surgery, oral medicine, and oral pathology 31.1 (1971): 96-103.

Shih M, Marshall FJ, Rosen S. "The Bactericidal efficiency of sodium hypochlorite as an endodontic irrigant.” Oral Surg Oral Med Oral Pathol. 29.4 (1970): 613-9.

Singla, Meenu G., Ashima Garg, and Sumit Gupta. "MTAD in Endodontics: An Update Review." Oral surgery, oral medicine, oral pathology, oral radiology, and endodontics 112.3 (2011): e70-6. 
SJÖGREN, U., et al. "Influence of Infection at the Time of Root Filling on the Outcome of Endodontic Treatment of Teeth with Apical Periodontitis." International endodontic journal 30.5 (1997): 297-306.

Sjogren, U., et al. "Factors Affecting the Long-Term Results of Endodontic Treatment." Journal of endodontics 16.10 (1990): 498-504.

Smith, ER., Hadidian, Z., Mason, MM. "The single--and repeated--dose toxicity of dimethyl sulfoxide." Ann. N.Y. Acad. Sci. 1967. 141:96-109.

Spangberg, L., B. Engström, and K. Langeland. "Biologic Effects of Dental Materials. 3. Toxicity and Antimicrobial Effect of Endodontic Antiseptics in Vitro." Oral surgery, oral medicine, and oral pathology 36.6 (1973): 856-71.

Stojicic, S., et al. "Antibacterial and Smear Layer Removal Ability of a Novel Irrigant, QMiX." International endodontic journal 45.4 (2012): 363-71.

Svensater G., Bergenholtz G. "Biofilms in Endodontic Infections.” Endodontic Topics 9 (2004): 27-36.

Swartz, D. B., A. E. Skidmore, and J. A. Griffin J. "Twenty Years of Endodontic Success and Failure." Journal of endodontics 9.5 (1983): 198-202.

Szmant, HH. "Chemistry of DMSO.” In Dimethyl Sulfoxide I, Basic Concepts, ed. S.W. Jacob, E.E. Rosenbaum, D.C. Wood, Chap. 1, 1-94. New York: Marcel Dekker, Inc. 1971.

Torabinejad, Mahmoud, et al. "The Antimicrobial Effect of MTAD: An in Vitro Investigation." Journal of endodontics 29.6 (2003): 400-3.

Trotonda, M.P., et al. "MgrA Represses Biofilm Formation in Staphylococcus aureus." Infection and Immunity, Dec. 2008. P. 5645-54.

Tsuchiya, T., Iriyama, S., Umezawa, “DMSO” S. Bull. Chem. Soc. Japan 1964. 31:286-87.

Verdier, L., Bertho, G., Gharbi-Benarous, J., Girault, and Jean-Pierre, "Lincomycin and Clindamycin Conformations. A Fragment Shared by Macrolides, Ketolides and Lincosamides Determined from TRNOE Ribosome-Bound Conformations" Bioorg. Med. Chem. (2000) 8:1225-1243.

Vieira, Adalberto R., et al. "Dentinal Tubule Infection as the Cause of Recurrent Disease and Late Endodontic Treatment Failure: A Case Report." Journal of endodontics 38.2 (2012): 250-4.

Walker, A. “A Definite and Dependable Therapy for Pulpless Teeth.” J. Amer. Dent. Ass. (23) 1936: 1418. 
Zhang, Wu, Mahmoud Torabinejad, and Yiming Li. "Evaluation of Cytotoxicity of MTAD using the MTT-Tetrazolium Method." Journal of endodontics 29.10 (2003): 654-7. 


\section{Appendix 1: Statistics}

Rsquare

0.988755

Adj Rsquare

0.987714

Root Mean Square Error

2.110992

Mean of Response

18.42983

Observations (or Sum Wgts)

60

Table 6: One-way Analysis of Data (ANOVA, Summary of Fit) ZOI Study C. albicans, Mueller - Hinton (Planktonic)

$\begin{array}{lrrrrr}\text { Source } & \text { DF } & \text { Sum of Squares } & \text { Mean Square } & \text { F Ratio } & \text { Prob > F } \\ \text { Treat } & 5 & 21158.760 & 4231.75 & 949.6140 \\ \text { Error } & 54 & 240.639 & 4.46 & \\ \text { C. Total } & 59 & 21399.399 & & \end{array}$

Table 7: ANOVA, ZOI C. albicans, Mueller-Hinton (Planktonic)

$\begin{array}{lrrrrr}\text { Level } & \text { Number } & \text { Mean } & \text { Std Error } & \text { Lower 95\% } & \text { Upper 95\% } \\ \text { A } & 12 & 22.8225 & 0.60939 & 21.60 & 24.044 \\ \text { B } & 12 & 19.1192 & 0.60939 & 17.90 & 20.341 \\ \text { C } & 12 & 16.2033 & 0.60939 & 14.98 & 17.425 \\ \text { D } & 12 & 0.0000 & 0.60939 & -1.22 & 1.222 \\ \text { E } & 6 & 0.0000 & 0.86181 & -1.73 & 1.728 \\ \text { F } & 6 & 68.0083 & 0.86181 & 66.28 & 69.736\end{array}$

Table 8: Means of One-way ANOVA, ZOI, C. albicans, Mueller-Hinton (Planktonic)

$A=100 \%$ Concentration of Novel Irrigant $B=50 \%$ Concentration of Novel Irrigant $\mathrm{C}=\mathbf{2 5 \%}$ Concentration of Novel Irrigant $\mathrm{D}=$ No Treatment (Positive Control)

$\mathrm{E}=70 \%$ DMSO (Solvent Only)

$\mathrm{F}=6 \% \mathrm{NaOCl}$

Std Error uses a pooled estimate of error variance

Confidence Quantile

$\begin{array}{rr}\mathbf{q}^{*} & \text { Alpha } \\ 2.95448 & 0.05\end{array}$

Table 9: Means Comparisons for all pairs using Tukey-Kramer HSD, ZOI C. albicans, M-H (Planktonic)

$\begin{array}{lrrrrrr}\text { Abs(Dif)-HSD } & \text { F } & \text { A } & \text { B } & \text { C } & \text { D } & \text { E } \\ \text { F } & -3.601 & 42.067 & 45.771 & 48.687 & 64.890 & 64.407 \\ \text { A } & 42.067 & -2.546 & 1.157 & 4.073 & 20.276 & 19.704 \\ \text { B } & 45.771 & 1.157 & -2.546 & 0.370 & 16.573 & 16.001 \\ \text { C } & 48.687 & 4.073 & 0.370 & -2.546 & 13.657 & 13.085 \\ \text { D } & 64.890 & 20.276 & 16.573 & 13.657 & -2.546 & -3.118 \\ \text { E } & 64.407 & 19.704 & 16.001 & 13.085 & -3.118 & -3.601\end{array}$

Table 10: LSD Threshold Matrix, ZOI C. albicans, M-H

Positive values show pairs of means that are significantly different. 


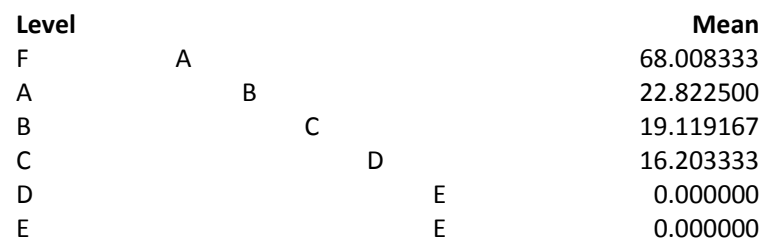

Table 11: Connecting Letters Report, ZOI C. albicans, M-H

Levels not connected by same letter are significantly different.

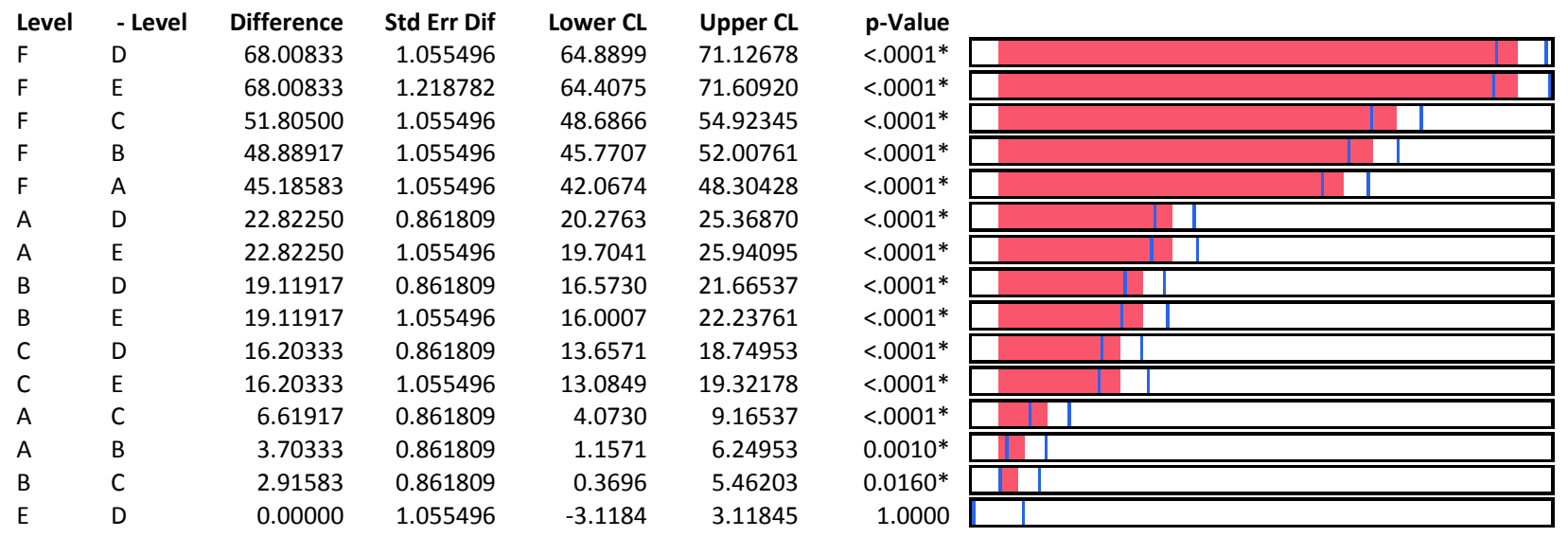

Table 12: Ordered Differences Report, ZOI C. albicans, M-H

Rsquare

Adj Rsquare

0.98957

Root Mean Squ

0.988604

Square Error

2.276308

Mean of Response

14.2085

Table 13: One-way Analysis of Data (Summary of Fit) ZOI C. albicans Poloxamer (Biofilm)

$\begin{array}{lrrrrr}\text { Source } & \text { DF } & \text { Sum of Squares } & \text { Mean Square } & \text { F Ratio } & \text { Prob > F } \\ \text { Treat } & 5 & 26547.138 & 5309.43 & 1024.674 & <.0001^{*} \\ \text { Error } & 54 & 279.805 & 5.18 & & \\ \text { C. Total } & 59 & 26826.944 & & & \end{array}$

Table 14: Analysis of Variance, ZOI C. albicans (Biofilm)

$\begin{array}{lrrrrr}\text { Level } & \text { Number } & \text { Mean } & \text { Std Error } & \text { Lower 95\% } & \text { Upper 95\% } \\ \text { A } & 12 & 10.2442 & 0.65711 & 8.93 & 11.562 \\ \text { B } & 12 & 9.9708 & 0.65711 & 8.65 & 11.288 \\ \text { C } & 12 & 8.7908 & 0.65711 & 7.47 & 10.108 \\ \text { D } & 12 & 0.0000 & 0.65711 & -1.32 & 1.317 \\ \text { E } & 6 & 7.7883 & 0.92930 & 5.93 & 9.651 \\ \text { F } & 6 & 76.2850 & 0.92930 & 74.42 & 78.148\end{array}$

Table 15: Means of One-way ANOVA, ZOI C. albicans (Biofilm)

Std Error uses a pooled estimate of error variance 
Confidence Quantile

$\begin{array}{rr}\mathbf{q}^{*} & \text { Alpha } \\ 2.95448 & 0.05\end{array}$

Table 16: Means Comparisons for all pairs using Tukey-Kramer HSD, ZOI C. albicans (Biofilm)

\begin{tabular}{|c|c|c|c|c|c|c|}
\hline Abs(Dif)-HSD & $\mathbf{F}$ & A & B & C & $\mathbf{E}$ & D \\
\hline $\mathrm{F}$ & -3.883 & 62.678 & 62.952 & 64.132 & 64.614 & 72.922 \\
\hline A & 62.678 & -2.746 & -2.472 & -1.292 & -0.907 & 7.499 \\
\hline B & 62.952 & -2.472 & -2.746 & -1.566 & -1.180 & 7.225 \\
\hline C & 64.132 & -1.292 & -1.566 & -2.746 & -2.360 & 6.045 \\
\hline$E$ & 64.614 & -0.907 & -1.180 & -2.360 & -3.883 & 4.426 \\
\hline D & 72.922 & 7.499 & 7.225 & 6.045 & 4.426 & -2.746 \\
\hline
\end{tabular}

\section{Table 17: LSD Threshold Matrix, ZOI C. albicans (Biofilm)}

Positive values show pairs of means that are significantly different.

$\begin{array}{lrrr}\text { Level } & & & \text { Mean } \\ \text { F } & \text { A } & & 76.285000 \\ \text { A } & & \text { B } & 10.244167 \\ \text { B } & & \text { B } & 9.970833 \\ \text { C } & \text { B } & 8.790833 \\ \text { E } & \text { B } & 7.788333 \\ \text { D } & & & 0.000000\end{array}$

Table 18: Connecting Letters Report, ZOI C. albicans (Biofilm)

Levels not connected by same letter are significantly different.

\begin{tabular}{|c|c|c|c|c|c|c|c|}
\hline Level & - Level & Difference & Std Err Dif & Lower CL & Upper CL & p-Value & \\
\hline $\mathrm{F}$ & D & 76.28500 & 1.138154 & 72.9223 & 79.64766 & $<.0001^{*}$ & - \\
\hline $\mathrm{F}$ & $\mathrm{E}$ & 68.49667 & 1.314227 & 64.6138 & 72.37953 & $<.0001^{*}$ & \\
\hline $\mathrm{F}$ & C & 67.49417 & 1.138154 & 64.1315 & 70.85682 & $<.0001^{*}$ & $=$ \\
\hline $\mathrm{F}$ & B & 66.31417 & 1.138154 & 62.9515 & 69.67682 & $<.0001^{*}$ & 工 \\
\hline $\mathrm{F}$ & A & 66.04083 & 1.138154 & 62.6782 & 69.40349 & $<.0001^{*}$ & $=$ \\
\hline A & D & 10.24417 & 0.929299 & 7.4986 & 12.98976 & $<.0001^{*}$ & $\overline{11}$ \\
\hline B & D & 9.97083 & 0.929299 & 7.2252 & 12.71643 & $<.0001^{*}$ & \\
\hline C & D & 8.79083 & 0.929299 & 6.0452 & 11.53643 & $<.0001^{*}$ & \\
\hline$E$ & $D$ & 7.78833 & 1.138154 & 4.4257 & 11.15099 & $<.0001^{*}$ & T \\
\hline A & $\mathrm{E}$ & 2.45583 & 1.138154 & -0.9068 & 5.81849 & 0.2744 & \\
\hline B & $\mathrm{E}$ & 2.18250 & 1.138154 & -1.1802 & 5.54516 & 0.4029 & \\
\hline A & C & 1.45333 & 0.929299 & -1.2923 & 4.19893 & 0.6253 & एس \\
\hline B & C & 1.18000 & 0.929299 & -1.5656 & 3.92560 & 0.7999 & एس \\
\hline C & $\mathrm{E}$ & 1.00250 & 1.138154 & -2.3602 & 4.36516 & 0.9495 & $\square$ \\
\hline A & B & 0.27333 & 0.929299 & -2.4723 & 3.01893 & 0.9997 & 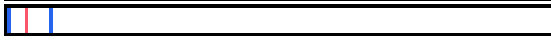 \\
\hline
\end{tabular}

Table 19: Ordered Differences Report, ZOI C. albicans (Biofilm)

$\begin{array}{lr}\text { Rsquare } & 0.641112 \\ \text { Adj Rsquare } & 0.581297 \\ \text { Root Mean Square Error } & 0.628048 \\ \text { Mean of Response } & 0.527778 \\ \text { Observations (or Sum Wgts) } & 36\end{array}$

Table 20: One-way ANOVA Analysis of CFU (Summary of Fit) C. albicans, Dilution=10 ${ }^{-6}$ 


$\begin{array}{lrrrrr}\text { Source } & \text { DF } & \text { Sum of Squares } & \text { Mean Square } & \text { F Ratio } & \text { Prob > F } \\ \text { Trial: } & 5 & 21.138889 & 4.22778 & 10.7183 & <.0001^{*} \\ \text { Error } & 30 & 11.833333 & 0.39444 & & \\ \text { C. Total } & 35 & 32.972222 & & & \end{array}$

Table 21: Analysis of Variance, $C$. albicans, CFU Dilution $=10^{-6}$

$\begin{array}{lrrrrr}\text { Level } & \text { Number } & \text { Mean } & \text { Std Error } & \text { Lower 95\% } & \text { Upper 95\% } \\ \text { A } & 6 & 0.00000 & 0.25640 & -0.524 & 0.5236 \\ \text { B } & 6 & 0.16667 & 0.25640 & -0.357 & 0.6903 \\ \text { C } & 6 & 0.66667 & 0.25640 & 0.143 & 1.1903 \\ \text { D } & 6 & 2.16667 & 0.25640 & 1.643 & 2.6903 \\ \text { E } & 6 & 0.16667 & 0.25640 & -0.357 & 0.6903 \\ \text { F } & 6 & 0.00000 & 0.25640 & -0.524 & 0.5236\end{array}$

Table 22: Means for One-way ANOVA, $C$. albicans, CFU Dilution=10 ${ }^{-6}$

Std Error uses a pooled estimate of error variance

$\begin{array}{lrrrrr}\text { Level } & \text { Count } & \text { Score Sum } & \text { Expected Score } & \text { Score Mean } & \text { (Mean-Mean0)/Std0 } \\ \text { A } & 6 & 75.000 & 111.000 & 12.5000 & -1.816 \\ \text { B } & 6 & 91.500 & 111.000 & 15.2500 & -0.972 \\ \text { C } & 6 & 141.000 & 111.000 & 23.5000 & 1.509 \\ \text { D } & 6 & 192.000 & 111.000 & 32.0000 & 4.118 \\ \text { E } & 6 & 91.500 & 111.000 & 15.2500 & -0.972 \\ \text { F } & 6 & 75.000 & 111.000 & 12.5000 & -1.816\end{array}$

Table 23: Wilcoxon / Kruskal-Wallis Tests (Rank Sums), C. albicans, CFU Dilution=10-6

$\begin{array}{rrr}\text { ChiSquare } & \text { DF } & \text { Prob }>\text { ChiSq } \\ 23.5852 & 5 & 0.0003^{*}\end{array}$

Table 24: 1-way Test, ChiSquare Approximation, $C$. albicans, CFU Dilution=10 ${ }^{-6}$

Confidence Quantile

$\begin{array}{rr}\mathbf{q}^{*} & \text { Alpha } \\ 3.04160 & 0.05\end{array}$

Table 25: Means Comparisons for all pairs using Tukey-Kramer HSD, C. albicans, CFU Dilution $=10^{-6}$

D

$\begin{array}{lr}\text { Abs(Dif)-HSD } & \\ \text { D } & -1.1029 \\ \text { C } & 0.3971 \\ \text { B } & 0.8971 \\ \text { E } & 0.8971 \\ \text { A } & 1.0638 \\ \text { F } & 1.0638\end{array}$

C

$$
\begin{array}{r}
0.3971 \\
-1.1029 \\
-0.6029 \\
-0.6029 \\
-0.4362 \\
-0.4362
\end{array}
$$

B

$$
\begin{array}{r}
0.8971 \\
-0.6029 \\
-1.1029 \\
-1.1029 \\
-0.9362 \\
-0.9362
\end{array}
$$

E

0.8971

$-0.6029$

$-1.1029$

$-1.1029$

$-0.9362$

$-0.9362$

Table 26: LSD Threshold Matrix, $C$. albicans, CFU Dilution $=10^{-6}$

Positive values show pairs of means that are significantly different. 


\begin{tabular}{|c|c|c|}
\hline Level & & Mean \\
\hline D & A & 2.1666667 \\
\hline C & B & 0.6666667 \\
\hline B & B & 0.1666667 \\
\hline$E$ & B & 0.1666667 \\
\hline A & B & 0.0000000 \\
\hline $\mathrm{F}$ & B & 0.0000000 \\
\hline
\end{tabular}

Table 27: Connecting Letters Report, $C$. albicans, CFU Dilution=10 ${ }^{-6}$

Levels not connected by same letter are significantly different.

$\begin{array}{llrrrr}\text { Level } & \text { - Level } & \text { Difference } & \text { Std Err Dif } & \text { Lower CL } & \text { Upper CL } \\ \text { D } & \text { A } & 2.166667 & 0.3626038 & 1.06377 & 3.269561 \\ \text { D } & \text { F } & 2.166667 & 0.3626038 & 1.06377 & 3.269561 \\ \text { D } & \text { B } & 2.000000 & 0.3626038 & 0.89711 & 3.102895 \\ \text { D } & \text { E } & 2.000000 & 0.3626038 & 0.89711 & 3.102895 \\ \text { D } & \text { C } & 1.500000 & 0.3626038 & 0.39711 & 2.602895 \\ \text { C } & \text { A } & 0.666667 & 0.3626038 & -0.43623 & 1.769561 \\ \text { C } & \text { F } & 0.666667 & 0.3626038 & -0.43623 & 1.769561 \\ \text { C } & \text { B } & 0.500000 & 0.3626038 & -0.60289 & 1.602895 \\ \text { C } & \text { E } & 0.500000 & 0.3626038 & -0.60289 & 1.602895 \\ \text { B } & \text { A } & 0.166667 & 0.3626038 & -0.93623 & 1.269561 \\ \text { E } & \text { A } & 0.166667 & 0.3626038 & -0.93623 & 1.269561 \\ \text { B } & \text { F } & 0.166667 & 0.3626038 & -0.93623 & 1.269561 \\ \text { E } & \text { F } & 0.166667 & 0.3626038 & -0.93623 & 1.269561 \\ \text { E } & \text { B } & 0.000000 & 0.3626038 & -1.10289 & 1.102895 \\ \text { F } & \text { A } & 0.000000 & 0.3626038 & -1.10289 & 1.102895\end{array}$

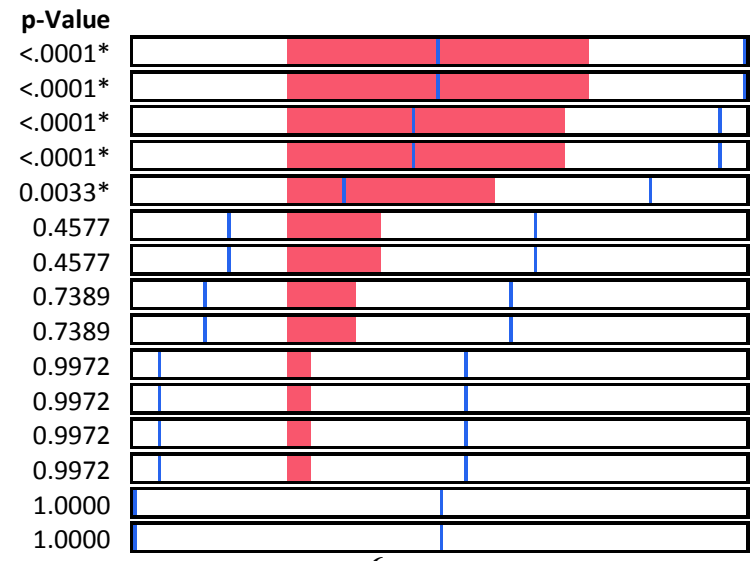

Table 28: Ordered Differences Report, $C$. albicans, CFU Dilution $=10^{-6}$

Rsquare

0.91475

Adj Rsquare

0.900542

Root Mean Square Error

5.573748

Mean of Response

9.388889

Observations (or Sum Wgts)

36

Table 29: One-way ANOVA Analysis of CFU (Summary of Fit) C. albicans, CFU Dilution $=10^{-4}$

$\begin{array}{lrrrrr}\text { Source } & \text { DF } & \text { Sum of Squares } & \text { Mean Square } & \text { F Ratio } & \text { Prob > F } \\ \text { Trial: } & 5 & 10000.556 & 2000.11 & 64.3813 & <.0001^{*} \\ \text { Error } & 30 & 932.000 & 31.07 & & \\ \text { C. Total } & 35 & 10932.556 & & & \end{array}$

Table 30: Analysis of Variance, $C$. albicans, CFU Dilution=10 ${ }^{-4}$

$\begin{array}{lrrrrr}\text { Level } & \text { Number } & \text { Mean } & \text { Std Error } & \text { Lower 95\% } & \text { Upper 95\% } \\ \text { A } & 6 & 0.8333 & 2.2755 & -3.81 & 5.480 \\ \text { B } & 6 & 4.5000 & 2.2755 & -0.15 & 9.147 \\ \text { C } & 6 & 3.3333 & 2.2755 & -1.31 & 7.980 \\ \text { D } & 6 & 46.5000 & 2.2755 & 41.85 & 51.147 \\ \text { E } & 6 & 1.1667 & 2.2755 & -3.48 & 5.814 \\ \text { F } & 6 & 0.0000 & 2.2755 & -4.65 & 4.647\end{array}$

Table 31: Means for One-way ANOVA, $C$. albicans, CFU Dilution $=10^{-4}$

Std Error uses a pooled estimate of error variance 


$\begin{array}{lrrrrr}\text { Level } & \text { Count } & \text { Score Sum } & \text { Expected Score } & \text { Score Mean } & \text { (Mean-Mean0)/Std0 } \\ \text { A } & 6 & 64.000 & 111.000 & 10.6667 & -2.018 \\ \text { B } & 6 & 150.000 & 111.000 & 25.0000 & 1.671 \\ \text { C } & 6 & 134.000 & 111.000 & 22.3333 & 0.976 \\ \text { D } & 6 & 201.000 & 111.000 & 33.5000 & 3.883 \\ \text { E } & 6 & 78.000 & 111.000 & 13.0000 & -1.410 \\ \text { F } & 6 & 39.000 & 111.000 & 6.5000 & -3.102 \\ \text { Table 32: Wilcoxon / Kruskal-Wallis Tests (Rank Sums), C. albicans, CFU Dilution=10 }\end{array}$

$\begin{array}{rrr}\text { ChiSquare } & \text { DF } & \text { Prob>ChiSq } \\ 29.2326 & 5 & <.0001^{*}\end{array}$

Table 33: 1-way Test, ChiSquare Approximation, $C$. albicans, CFU Dilution=10 ${ }^{-4}$

$\begin{array}{llrr}\text { Level } & & & \text { Mean } \\ \text { D } & \text { A } & & 46.500000 \\ \text { B } & & \text { B } & 4.500000 \\ \text { C } & & \text { B } & 3.333333 \\ \text { E } & & \text { B } & 1.166667 \\ \text { A } & & \text { B } & 0.833333 \\ \text { F } & & \text { B } & 0.000000\end{array}$

Table 34: Connecting Letters Report, $C$. albicans, CFU Dilution=10 ${ }^{-4}$

Levels not connected by same letter are significantly different.

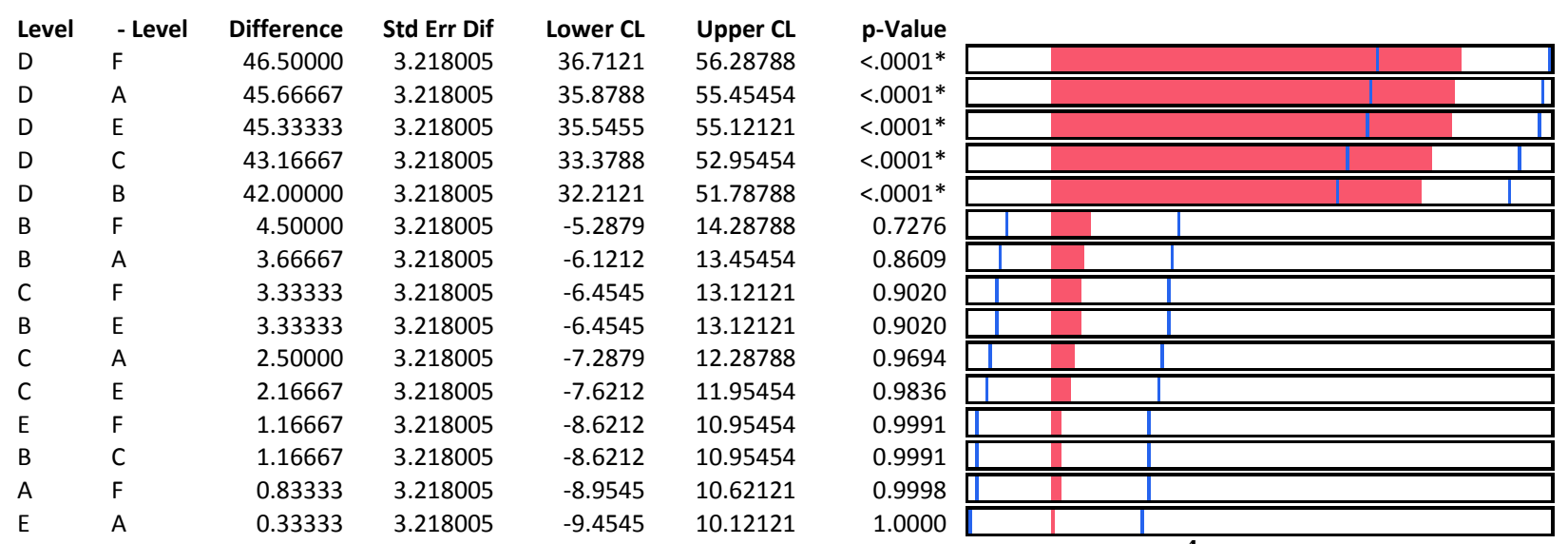

Table 35: Ordered Differences Report, $C$. albicans, CFU Dilution $=10^{-4}$

Rsquare

Adj Rsquare

0.971673

Root Mean Square Error

29.44015

Mean of Response

153.1111

Observations (or Sum Wgts)

36

Table 36: One-way ANOVA Analysis of CFU (Summary of Fit) C. albicans, CFU Dilution $=10^{-2}$

$\begin{array}{lrrrrr}\text { Source } & \text { DF } & \text { Sum of Squares } & \text { Mean Square } & \text { F Ratio } & \text { Prob > F } \\ \text { Trial: } & 5 & 1044889.9 & 208978 & 241.1130 & <.0001^{*} \\ \text { Error } & 30 & 26001.7 & 867 & & \\ \text { C. Total } & 35 & 1070891.6 & & \end{array}$

Table 37: Analysis of Variance, $C$. albicans, CFU Dilution=10 


$\begin{array}{lrrrrr}\text { Level } & \text { Number } & \text { Mean } & \text { Std Error } & \text { Lower 95\% } & \text { Upper 95\% } \\ \text { A } & 6 & 79.500 & 12.019 & 55.0 & 104.05 \\ \text { B } & 6 & 207.000 & 12.019 & 182.5 & 231.55 \\ \text { C } & 6 & 124.833 & 12.019 & 100.3 & 149.38 \\ \text { D } & 6 & 500.000 & 12.019 & 475.5 & 524.55 \\ \text { E } & 6 & 7.333 & 12.019 & -17.2 & 31.88 \\ \text { F } & 6 & 0.000 & 12.019 & -24.5 & 24.55\end{array}$

Table 38: Means for One-way ANOVA, $C$. albicans, CFU Dilution=10-2

Std Error uses a pooled estimate of error variance

$\begin{array}{lrrrrr}\text { Level } & \text { Count } & \text { Score Sum } & \text { Expected Score } & \text { Score Mean } & \text { (Mean-Mean0)/Std0 } \\ \text { A } & 6 & 102.500 & 111.000 & 17.0833 & -0.341 \\ \text { B } & 6 & 161.000 & 111.000 & 26.8333 & 2.111 \\ \text { C } & 6 & 123.500 & 111.000 & 20.5833 & 0.512 \\ \text { D } & 6 & 201.000 & 111.000 & 33.5000 & 3.817 \\ \text { E } & 6 & 57.000 & 111.000 & 9.5000 & -2.281 \\ \text { F } & 6 & 21.000 & 111.000 & 3.5000 & -3.817\end{array}$

Table 39: Wilcoxon / Kruskal-Wallis Tests (Rank Sums), C. albicans, CFU Dilution=10 ${ }^{-2}$

$\begin{array}{rrr}\text { ChiSquare } & \text { DF } & \text { Prob }>\text { ChiSq } \\ 33.1020 & 5 & <.0001^{*}\end{array}$

Table 40: 1-way Test, ChiSquare Approximation, C. albicans, CFU Dilution=10 ${ }^{-2}$

Confidence Quantile

$\begin{array}{rr}\mathbf{q}^{*} & \text { Alpha } \\ 3.04160 & 0.05\end{array}$

Table 41: Means Comparisons for all pairs using Tukey-Kramer HSD, C. albicans, CFU Dilution $=10^{-2}$

\begin{tabular}{|c|c|c|c|c|c|c|}
\hline Abs(Dif)-HSD & D & B & C & A & E & $\mathbf{F}$ \\
\hline D & -51.70 & 241.30 & 323.47 & 368.80 & 440.97 & 448.30 \\
\hline B & 241.30 & -51.70 & 30.47 & 75.80 & 147.97 & 155.30 \\
\hline C & 323.47 & 30.47 & -51.70 & -6.37 & 65.80 & 73.13 \\
\hline A & 368.80 & 75.80 & -6.37 & -51.70 & 20.47 & 27.80 \\
\hline E & 440.97 & 147.97 & 65.80 & 20.47 & -51.70 & -44.37 \\
\hline $\mathrm{F}$ & 448.30 & 155.30 & 73.13 & 27.80 & -44.37 & -51.70 \\
\hline
\end{tabular}

Table 42: LSD Threshold Matrix, C. albicans, CFU Dilution=10 ${ }^{-2}$ Positive values show pairs of means that are significantly different.

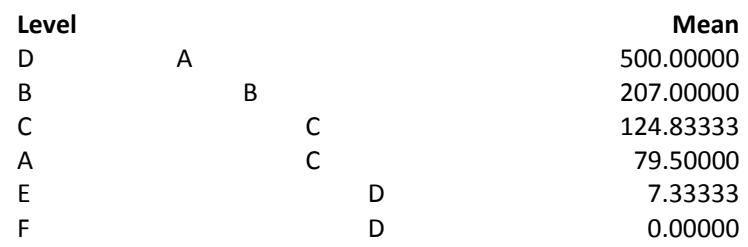

Table 43: Connecting Letters Report, $C$. albicans, CFU Dilution $=10^{-2}$

Levels not connected by same letter are significantly different. 


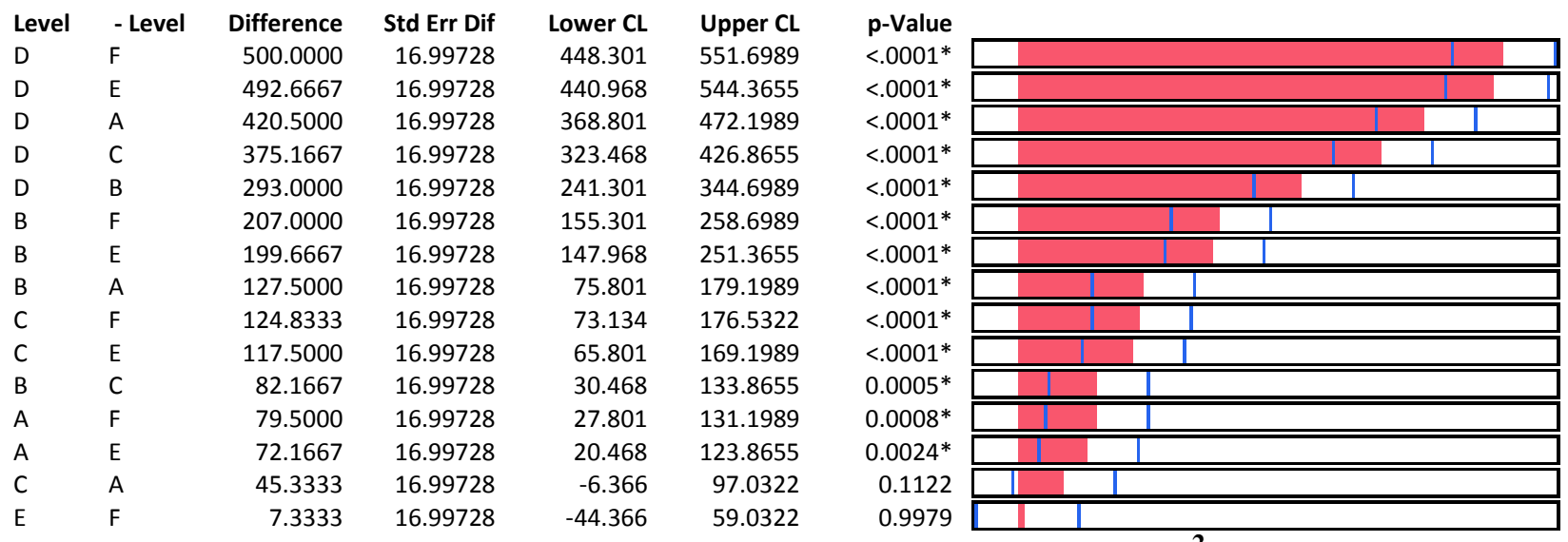

Table 44: Ordered Differences Report, $C$. albicans, CFU Dilution $=10^{-2}$

$\begin{array}{lrrrrr}\text { Source } & \text { DF } & \text { Sum of Squares } & \text { Mean Square } & \text { F Ratio } & \text { Prob > F } \\ \text { RawIntDen 3 } & 4 & 1.0059 \mathrm{e}+10 & 2.5147 \mathrm{e}+9 & 3.1006 & 0.0159^{*} \\ \text { Error } & 309 & 2.5061 \mathrm{e}+11 & 811029508 & & \\ \text { C. Total } & 313 & 2.6067 \mathrm{e}+11 & & & \end{array}$

Table 45: One-way Analysis of Variance of Area of Biofilm Coverage on Pegs of Calgary Biofim Device (C. albicans)

$\begin{array}{lrrrrr}\text { Level } & \text { Number } & \text { Mean } & \text { Std Error } & \text { Lower 95\% } & \text { Upper 95\% } \\ \text { 100\% Novel Irrigant } & 103 & 1686.0 & 2806.1 & -3835 & 7207 \\ 25 \% \text { concentration Novel } & 80 & 2200.3 & 3184.0 & -4065 & 8465 \\ 50 \% \text { concentration Novel } & 68 & 3744.0 & 3453.5 & -3051 & 10539 \\ \text { DMSO } & 51 & 5504.0 & 3987.8 & -2343 & 13351 \\ \mathrm{NaOCl} & 12 & 31580.7 & 8221.1 & 15404 & 47757\end{array}$

Table 46: Means for One-way ANOVA, Area of Biofilm Coverage

Std Error uses a pooled estimate of error variance

Confidence Quantile

$$
\begin{array}{rr}
\mathbf{q}^{*} & \text { Alpha } \\
2.74396 & 0.05
\end{array}
$$

Table 47: Means Comparisons for all pairs using Tukey-Kramer HSD, Area of Biofilm Coverage

Level

$\mathrm{NaOCl}$

DMSO

$50 \%$ concentration Novel $5 \mathrm{X}$

$25 \%$ concentration Novel $5 X$

$100 \%$ Novel Irrigant $5 x$

$\begin{array}{rrr} & \text { Mean } \\ \text { A } & & 31580.742 \\ \text { B } & 5504.037 \\ \text { B } & 3744.000 \\ \text { B } & 2200.306 \\ \text { B } & 1686.001\end{array}$

Table 48: Connecting Letters Report, Area of Biofilm Coverage

Levels not connected by same letter are significantly different. 


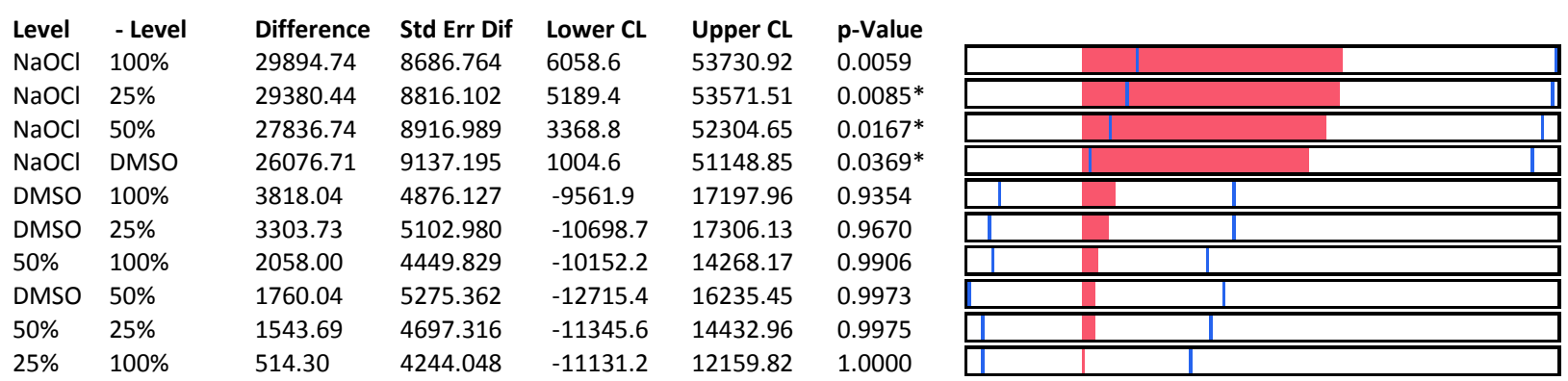

Table 49: Ordered Differences Report, Area of Biofilm Coverage

*Percentages reflect \% of Novel concentration

Analysis of Variance

$\begin{array}{lrrrrr}\text { Source } & \text { DF } & \text { Sum of Squares } & \text { Mean Square } & \text { F Ratio } & \text { Prob > F } \\ \text { Treatment } & 9 & 763373.08 & 84819.2 & 19.1326 & <.0001^{*} \\ \text { Error } & 20 & 88664.51 & 4433.2 & & \\ \text { C. Total } & 29 & 852037.59 & & & \end{array}$

Table 50: One-way Analysis of Variance of Penetration into Dentin Tubules of prepared root canals (micrometers)

\begin{tabular}{|c|c|c|c|c|c|}
\hline Level & Number & Mean & Std Error & Lower 95\% & Upper 95\% \\
\hline $100 \%$ Novel & 3 & 601.520 & 38.441 & 521.3 & 681.71 \\
\hline $17 \%$ EDTA & 3 & 140.304 & 38.441 & 60.1 & 220.49 \\
\hline $25 \%$ Novel & 3 & 311.053 & 38.441 & 230.9 & 391.24 \\
\hline $50 \%$ Novel & 3 & 276.588 & 38.441 & 196.4 & 356.78 \\
\hline $6 \% \mathrm{NaOCl}$ & 3 & 77.274 & 38.441 & -2.9 & 157.46 \\
\hline 70\% DMSO & 3 & 308.330 & 38.441 & 228.1 & 388.52 \\
\hline EDTA / DMSO & 3 & 362.259 & 38.441 & 282.1 & 442.45 \\
\hline EDTA/NaOCl & 3 & 129.436 & 38.441 & 49.2 & 209.62 \\
\hline EDTA/Novel & 3 & 257.027 & 38.441 & 176.8 & 337.21 \\
\hline No Treatment & 3 & 17.547 & 38.441 & -62.6 & 97.73 \\
\hline
\end{tabular}

Table 51: Means for One-way ANOVA, Penetration Study

Std Error uses a pooled estimate of error variance

Confidence Quantile

$$
\begin{array}{rr}
\mathbf{q}^{*} & \text { Alpha } \\
3.54111 & 0.05
\end{array}
$$

Table 52: Means Comparisons for all pairs using Tukey-Kramer HSD, Penetration Study

\begin{tabular}{|c|c|c|c|c|c|c|}
\hline Level & & & & & & $\begin{array}{l}\text { Mean Penetration } \\
\text { (micrometers) }\end{array}$ \\
\hline $100 \%$ Novel & A & & & & & 601.52033 \\
\hline EDTA / DMSO & & B & & & & 362.25867 \\
\hline $25 \%$ Novel & & B & C & & & 311.05267 \\
\hline 70\% DMSO & & B & C & & & 308.33000 \\
\hline $50 \%$ Novel & & B & C & & & 276.58767 \\
\hline EDTA/Novel & & B & C & D & & 257.02733 \\
\hline $17 \%$ EDTA & & & $\mathrm{C}$ & D & $\mathrm{E}$ & 140.30367 \\
\hline $\mathrm{EDTA} / \mathrm{NaOCl}$ & & & C & $\mathrm{D}$ & $E$ & 129.43567 \\
\hline $6 \% \mathrm{NaOCl}$ & & & & $\mathrm{D}$ & $E$ & 77.27400 \\
\hline No Treatment & & & & & $E$ & 17.54667 \\
\hline
\end{tabular}

Table 53: Connecting Letters Report, Penetration Study Levels not connected by same letter are significantly different. 


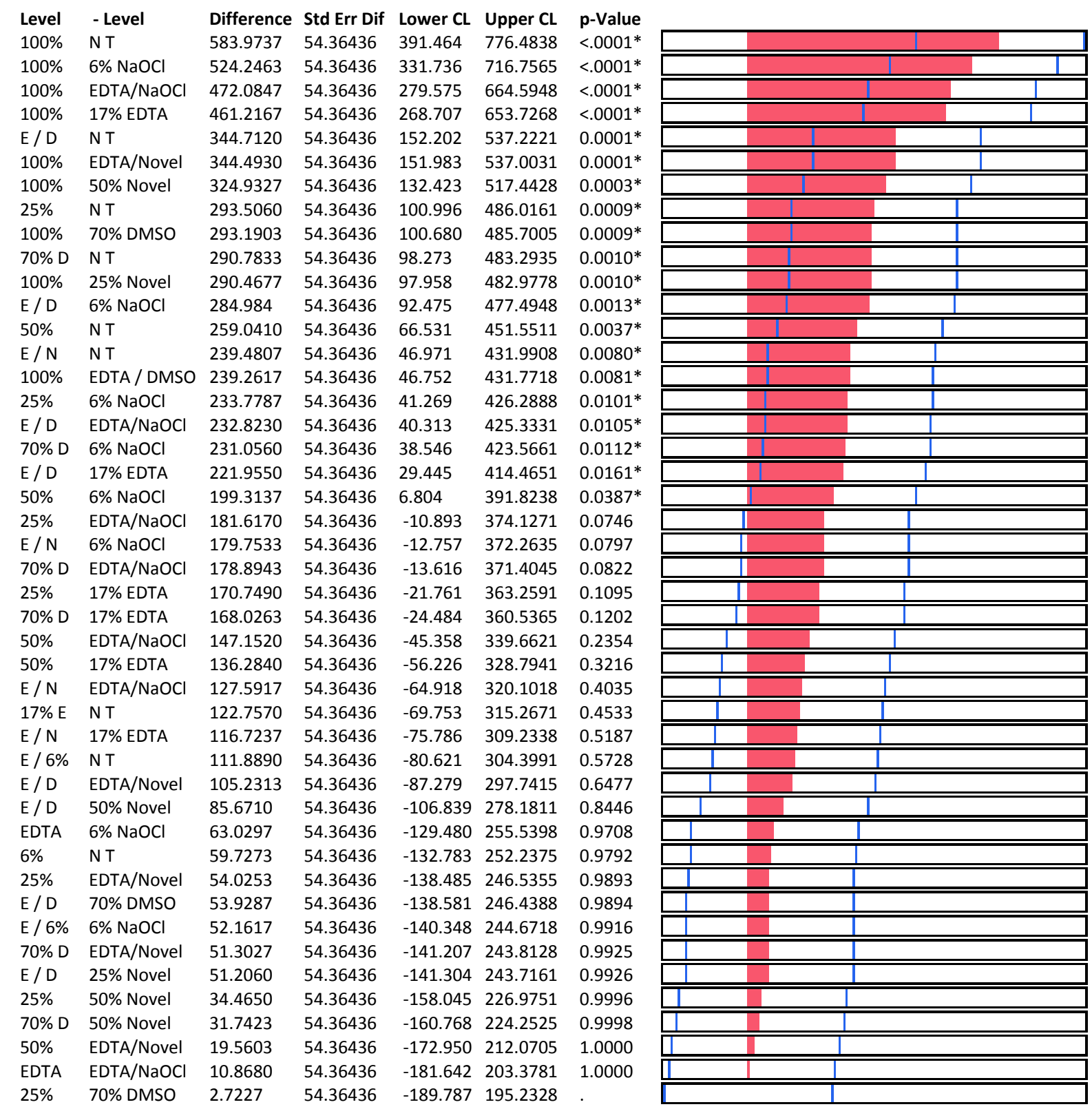

Table 54: Ordered Differences Report, Penetration Study

Percentages $(100,50,25)$ reflect concentration of Novel Irrigant

NT $=$ No Treatment (Positive Control)

$E / D=17 \%$ EDTA followed by $70 \%$ DMSO

$\mathrm{E} / \mathrm{N}=17 \%$ EDTA followed by $100 \%$ Novel

$\mathrm{E} / 6 \%=17 \%$ EDTA followed by $6 \% \mathrm{NaOCl}$

$6 \%=6 \% \mathrm{NaOCl}$

$70 \% \mathrm{D}=70 \% \mathrm{DMSO}$ 